This document was prepared in conjunction with work accomplished under Contract No. DE-AC09-96SR18500 with the U. S. Department of Energy.

\title{
DISCLAIMER
}

This report was prepared as an account of work sponsored by an agency of the United States Government. Neither the United States Government nor any agency thereof, nor any of their employees, nor any of their contractors, subcontractors or their employees, makes any warranty, express or implied, or assumes any legal liability or responsibility for the accuracy, completeness, or any third party's use or the results of such use of any information, apparatus, product, or process disclosed, or represents that its use would not infringe privately owned rights. Reference herein to any specific commercial product, process, or service by trade name, trademark, manufacturer, or otherwise, does not necessarily constitute or imply its endorsement, recommendation, or favoring by the United States Government or any agency thereof or its contractors or subcontractors. The views and opinions of authors expressed herein do not necessarily state or reflect those of the United States Government or any agency thereof. 


\section{INVESTIGATION OF SLUDGE BATCH 3 (MACROBATCH 4) GLASS SAMPLE ANOMALOUS BEHAVIOR}

C. J. Bannochie

N. E. Bibler

D. K. Peeler

June 2005 


\title{
DISCLAIMER
}

This report was prepared by Westinghouse Savannah River Company (WSRC) for the United States Department of Energy under Contract No. DE-AC09-96SR18500 and is an account of work performed under that contract. Neither the United States Department of Energy, nor WSRC, nor any of their employees makes any warranty, expressed or implied, or assumes any legal liability or responsibility for the accuracy, completeness, or usefulness, of any information, apparatus, or product or process disclosed herein or represents that its use will not infringe privately owned rights. Reference herein to any specific commercial product, process, or service by trademark, name, and manufacturer or otherwise does not necessarily constitute or imply endorsement, recommendation, or favoring of same by WSRC or by the United States Government or any agency thereof. The views and opinions of the authors expressed herein do not necessarily state or reflect those of the United States Government or any agency thereof.

\author{
Printed in the United States of America \\ Prepared For \\ U.S. Department of Energy
}


Key Words: DWPF, Sludge Batch 3, Glass, Silicone, Coal

Retention: PERMANENT

\section{INVESTIGATION OF SLUDGE BATCH 3 (MACROBATCH 4) GLASS SAMPLE ANOMALOUS BEHAVIOR}

C. J. Bannochie

N. E. Bibler

D. K. Peeler

June 2005

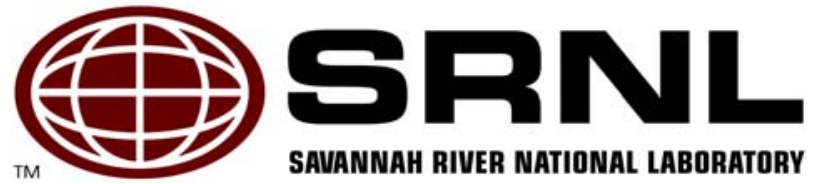


WSRC-TR-2005-00240

Revision 0

\section{REVIEWS AND APPROVALS}

\section{AUTHORS:}

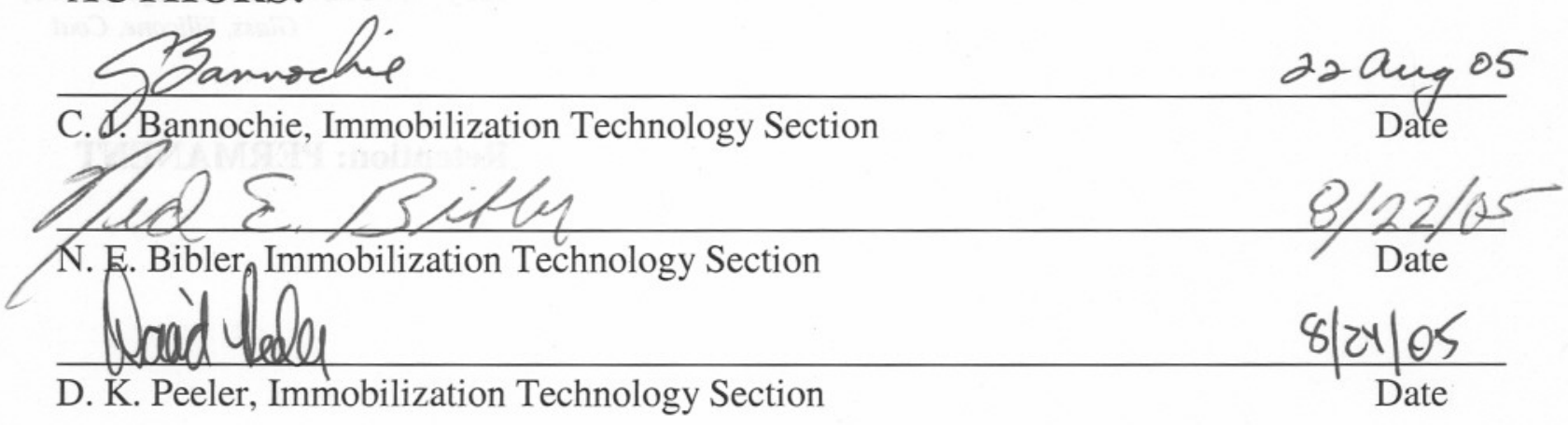

\section{TECHNICAL REVHEWER:}

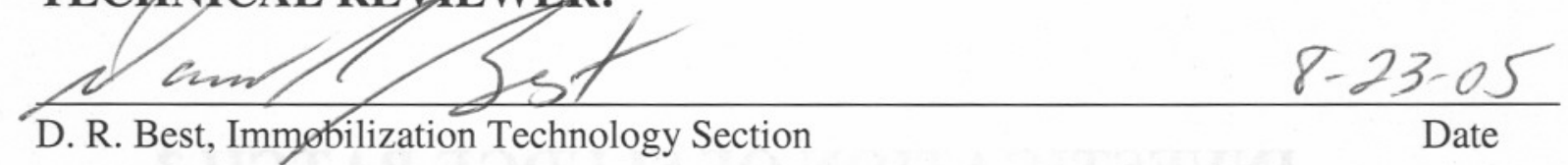

\section{APPROVERS:}

\section{Ew thoekshet}

E. W. Holtzscheiter, Manager, Immobilization Technology Section

S. L. Marra, Manager, Glass Formulation \& Process Development

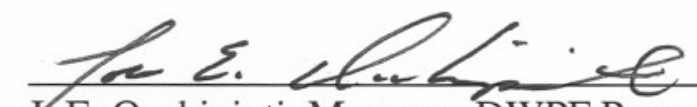

J. E. Occhipinti, Manager, DWPF Process Engineering

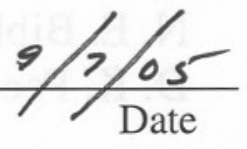




\section{EXECUTIVE SUMMARY}

Two Defense Waste Processing Facility (DWPF) glass samples from Sludge Batch 3 (SB3) (Macrobatch 4) were received by the Savannah River National Laboratory (SRNL) on February 23, 2005. One sample, S02244, was designated for the Product Consistency Test (PCT) and elemental and radionuclide analyses. The second sample, S02247, was designated for archival storage. The samples were pulled from the melter pour stream during the feeding of Melter Feed Tank (MFT) Batch 308 and therefore roughly correspond to feed from Slurry Mix Evaporator (SME) Batches 306 $-308$.

During the course of preparing sample S02244 for PCT and other analyses two observations were made which were characterized as "unusual" or anomalous behavior relative to historical observations of glasses prepared for the PCT. These observations ultimately led to a series of scoping tests in order to determine more about the nature of the behavior and possible mechanisms. The first observation was the behavior of the ground glass fraction $(-100+200$ mesh $)$ for PCT analysis when contacted with deionized water during the washing phase of the PCT procedure. The behavior was analogous to that of an organic compound in the presence of water: clumping, floating on the water surface, and crawling up the beaker walls. In other words, the glass sample did not "wet" normally, displaying a hydrophobic behavior in water. This had never been seen before in 18 years SRNL PCT tests on either radioactive or non-radioactive glasses. Typical glass behavior is largely to settle to the bottom of the water filled beaker, though there may be suspended fines which result in some cloudiness to the wash water. The typical appearance is analogous to wetting sand.

The second observation was the presence of faint black rings at the initial and final solution levels in the Teflon vessels used for the mixed acid digestion of S02244 glass conducted for compositional analysis. The digestion is composed of two stages, and at both the intermediate and the final content levels in the digestion vessel the rings were present. The rings had not been seen previously during glass digestions and were not present in the Analytical Reference Glass (ARG) standard samples digested, in separate vessels, along with the DWPF glass.

What follows in this report are the results and analyses from various scoping experiments done in order to explain the anomalous behavior observed with DWPF glass S02244, along with a comparison with tests on sample S02247 where the anomalous wetting behavior was not observed.

The following conclusions have been drawn from our examination of DWPF pour stream glass samples S02244 and S02247 through a series of experiments with both the radioactive glasses and a non-radioactive simulant to explain the anomalous behavior observed with glass sample S02244 when the ground glass was exposed to water:

1. Glass S02244 was contaminated with a silicone-based lubricant or grease which resulted in the following observations and data:

a. The glass had a hydrophobic behavior in water.

b. The contaminant is not removed in water, ethanol or $n$-hexane.

c. Methylene chloride partially dissolves the contaminant.

d. The Fourier transform infrared (FT-IR) spectrum of the contaminant corresponds to a silicone (-Si-O-Si-) containing material.

2. No source for the contamination could be found in the SRNL Shielded Cells glass handling operations. 
3. Glass S02244 contains a very high-temperature burning, carbon-based material which resulted in the following observations and data:

a. The ground glass has secondary particles in the scanning electron microscopy (SEM) images which give x-ray fluorescence (XRF) spectra that are largely carbonbased and which are distinctly different from the glass particles.

b. The thermal gravimetric analysis with mass spectroscopy (TGA-MS) data for the glass show the loss of $\mathrm{CO}_{2}, \mathrm{NO}_{2}$, and $\mathrm{SO}_{2}$ at temperatures similar to that observed for anthracite coal.

c. The glass density is slightly lower (7\%) than observed for the second glass sample S02247.

4. SME 308 simulant glass studies with a silicone stopcock grease and coal support the following observations:

a. The presence of grease on the glass significantly alters the behavior of ground glass in water giving it a hydrophobic nature.

b. The presence of coal does not change the wetting properties of ground glass in water.

5. Glass S02247 displayed neither the hydrophobic behavior in water, the secondary particles in SEM images, nor TGA-MS off-gas data for $\mathrm{CO}_{2}, \mathrm{NO}_{2}$, and $\mathrm{SO}_{2}$ at approximately $900{ }^{\circ} \mathrm{C}$.

With future DWPF pour stream glass samples SRNL recommends washing and drying the glass in methylene chloride prior to milling the samples for PCT, elemental and radiochemical analyses to help ensure the removal of any grease contamination. The methylene chloride should be a more effective solvent for grease prior to milling and distribution of the grease onto a large number of small particles. This is permitted by the PCT procedure which calls for washing of the bulk sample prior to grinding but does not specifically call out the solvent to be utilized for this washing. Additionally, the ground, washed, PCT glass fraction will be submitted for SEM imaging and XRF spectra to ensure the homogeneity of the sample used in the PCT. Other glass handling controls will continue to be implemented. 


\section{TABLE OF CONTENTS}

EXECUTIVE SUMMARY iii

LIST OF FIGURES vii

LIST OF TABLES viii

LIST OF ACRONYMS AND ABBREVIATIONS ix

1.0 INTRODUCTION AND BACKGROUND 1

2.0 EXPERIMENTAL 3

2.1 Glass Receipt and Preparation for S02244 and S02247 3

2.1.1 Glass Sample Fraction S02244-A 4

2.1.2 Glass Sample Fraction S02244-B 5

2.1.3 Glass Sample S02247 5

2.2 Glass Washing Behavior 5

2.2.1 $\mathrm{H}_{2} \mathrm{O}$ Washing 5

2.2.2 Ethanol Washing $\quad 6$

2.2.3 n-Hexane Washing 6

2.2.4 Methylene Chloride Washing $\quad 6$

2.3 Analytical Measurements 6

2.3.1 Inductively Couple Plasma - Atomic Emission Spectroscopy (ICP-AES) 6

2.3.2 Gas Chromatography - Mass Spectrometry (GC-MS) 7

2.3.3 Fourier Transform Infrared (FT-IR) Spectroscopy 7

2.3.4 Scanning Electron Microscopy (SEM) 7

2.3.5 Thermal Gravimetric Analysis with Mass Spectrometry (TGA-MS) 7

2.4 Glass Density Determinations 7

2.5 Non-Radioactive Simulant Studies $\quad 8$

$\begin{array}{ll}2.5 .1 \text { Glass-Only } & 10\end{array}$

2.5.2 Glass with Coal $\quad 10$

2.5.3 Glass with Grease Contamination 10

3.0 RESULTS AND DISCUSSION 13

3.1 Glass Receipt and Preparation for S02244 and S02247 13

3.1.1 Glass Sample Fraction S02244-A 13

3.1.2 Glass Sample Fraction S02244-B 14

3.1.3 Glass Sample S02247 14

3.2 Glass Washing Behavior $\quad 15$

3.2.1 $\mathrm{H}_{2} \mathrm{O}$ Washing $\quad 15$

3.2.2 Ethanol Washing 16

3.2.3 n-Hexane Washing 17

3.2.4 Methylene Chloride Washing 18

3.3 Analytical Measurements 18

3.3.1 Inductively Couple Plasma - Atomic Emission Spectroscopy (ICP-AES) 18

3.3.2 Gas Chromatography - Mass Spectrometry (GC-MS) 20

3.3.3 Fourier Transform Infrared (FT-IR) Spectroscopy 20

3.3.4 Scanning Electron Microscopy (SEM) 21

3.3.5 Thermal Gravimetric Analysis with Mass Spectrometry (TGA-MS) 32

3.4 Glass Density Determinations 35

3.5 Non-Radioactive Simulant Studies 35 
WSRC-TR-2005-00240

Revision 0

3.5.1 Glass-Only

35

3.5.2 Glass with Coal

36

3.5.3 Glass with Grease Contamination

36

3.6 Summary of Glass S02244 versus S02247

39

4.0 CONCLUSIONS

41

5.0 RECOMMENDATIONS/PATH FORWARD

43

6.0 REFERENCES

45

7.0 ACKNOWLEDGEMENTS

47 


\section{LIST OF FIGURES}

Figure 1-1. Behavior of DWPF Ground Pour Stream Glass Sample \#S02244 in the Presence of Water.

\section{1}

Figure 2-1. DWPF Pour Stream Glass Sample \#S02244 after Removal from the Primary Shipping Container...................................................................................... 3

Figure 2-2. Non-Radioactive SME 308 Glass as Fabricated ............................................ 9

Figure 2-3. Crushed Non-radioactive SME 308 Glass ................................................ 9

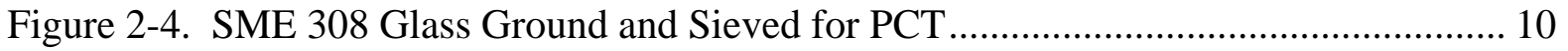

Figure 2-5. Silicone Lubricant: High Vacuum Grease ..................................................... 11

Figure 2-6. SME 308 Glass with "Dabs” of Silicone Grease Prior to Grinding................... 11

Figure 2-7. SME 308 with Silicone Grease after Grinding ............................................... 12

Figure 3-1. Tekmar Mill Lid Following Grinding of Sample S02244-A ............................ 13

Figure 3-2. Tekmar Mill Bowl Following Grinding of Sample S02244-A ......................... 14

Figure 3-3. DWPF Pour Stream Glass Sample S02244-C in Water................................... 15

Figure 3-4. DWPF Pour Stream Glass S02247-E in Water .............................................. 16

Figure 3-5. DWPF Pour Stream Glass Sample S02244-C in Ethanol ................................. 16

Figure 3-6. DWPF Pour Stream Glass Sample S02244-C in Water Following Ethanol

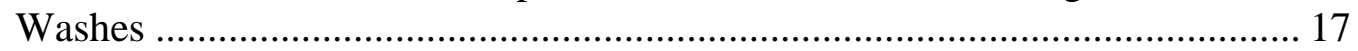

Figure 3-7. DWPF Pour Glass Sample S02244-F in Water Following $n$-Hexane Wash (Side

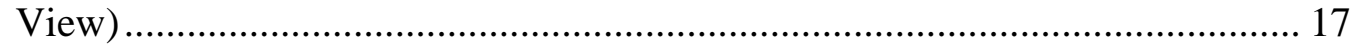

Figure 3-8. DPWF Pour Stream Glass Sample S02244-F in Water Following $n$-Hexane

Wash (Top View) ................................................................................ 18

Figure 3-9. Aluminum Dish Showing Dried Residues from Methylene Chloride Rinse of

DWPF Pour Stream Glass Sample S02244-F (Left) and Methylene Chloride

Blank (Right) ............................................................................................... 20

Figure 3-10. FT-IR Spectrum of Dissolved Compound from DWPF Pour Stream Glass

Sample S02244-F in Methylene Chloride ................................................... 21

Figure 3-11. FT-IR Spectrum of Methylene Chloride Blank ............................................ 21

Figure 3-12. SEM Image of DWPF Pour Stream Glass S02244-C (QBS Detector) at 50X . 22

Figure 3-13. SEM Image of DWPF Pour Stream Glass S02244-C (SE1 Detector) at 50X .. 22

Figure 3-14. SEM Image of DWPF Pour Stream Glass S02244-C (QBS Detector) at $150 X 23$

Figure 3-15. X-Ray Fluorescence Spectrum of Spot 1 in Figure 3-14 for DWPF Pour Stream

Glass Sample S02244-C.......................................................................... 24

Figure 3-16. X-Ray Fluorescence Spectrum of Spot 2 in Figure 3-14 for DWPF Pour Stream Glass Sample S02244-C............................................................................ 24

Figure 3-17. X-Ray Fluorescence Spectrum of Spot 3 in Figure 3-14 for DWPF Pour Stream Glass Sample S02244-C .............................................................................. 24

Figure 3-18. X-Ray Fluorescence Spectrum of Spot 4 in Figure 3-14 for DWPF Pour Stream Glass Sample S02244-C............................................................................. 25

Figure 3-19. X-Ray Fluorescence Spectrum of Spot 5 in Figure 3-14 for DWPF Pour Stream Glass Sample S02244-C............................................................................ 25

Figure 3-20. SEM Image of DWPF Pour Stream Glass S02244-G (QBS Detector) at 50X. 26

Figure 3-21. SEM Image of DWPF Pour Stream Glass S02244-G (QBS Detector) at 150X27 
Figure 3-22. X-Ray Fluorescence Spectrum of Spot 1 in Figure 3-21 at $25 \mathrm{keV}$ Beam Energy for DWPF Pour Stream Glass Sample S02244-G.

Figure 3-23. X-Ray Fluorescence Spectrum of Spot 5 in Figure 3-21 at $15 \mathrm{keV}$ Beam Energy for DWPF Pour Stream Glass Sample S02244-G.

Figure 3-24. X-Ray Fluorescence Spectrum of Spot 3 in Figure 3-21 at 25 keV Beam Energy for DWPF Pour Stream Glass Sample S02244-G.

Figure 3-25. X-Ray Fluorescence Spectrum of Spot 4 in Figure 3-21 at $15 \mathrm{keV}$ Beam Energy for DWPF Pour Stream Glass Sample S02244-G 28

Figure 3-26. SEM Image of DWPF Pour Stream Glass S02247-E (QBS Detector) at 50X . 29 Figure 3-27. SEM Image of DWPF Pour Stream Glass S02247-E (QBS Detector) at 110X 30 Figure 3-28. Characteristic X-Ray Fluorescence Spectrum for Spots 1-3 in Figure 3-27 for DWPF Pour Stream Glass Sample S02247-E

Figure 3-29. SEM Image of Anthracite Coal (QBS Detector) at 50X ................................. 31 Figure 3-30. X-Ray Fluorescence Spectrum of Anthracite Coal Particles in Figure 3-29 .... 31 Figure 3-31. TGA-MS Mass Loss vs. Time for DWPF Pour Stream Glass S02244-G ........ 32 Figure 3-32. TGA-MS Species vs. Time for DWPF Pour Stream Glass S02244-G ............. 32 Figure 3-33. TGA-MS Mass Loss vs. Time for DWPF Pour Stream Glass S02247-E ......... 33 Figure 3-34. TGA-MS Species vs. Time for DWPF Pour Stream Glass S02247-E.............. 34 Figure 3-35. TGA-MS Species vs. Time for Anthracite Coal ........................................... 34 Figure 3-36. SME 308 Glass: First Deionized Water Rinse ............................................. 35 Figure 3-37. SME 308 Glass Ground with Coal: First Deionized Water Rinse ................... 36 Figure 3-38. SME 308 Glass with Silicone Grease: First Deionized Water Rinse................ 37 Figure 3-39. SME 308 Glass with Silicone Grease (Test \#2): First Deionized Water Rinse 38 Figure 3-40. SME 308 Glass with Silicone Grease (Test \#3): First Water Rinse ................. 38 Figure 3-41. SME 308 Glass-Only Compared to Glass plus Silicone Lubricant during Deionized Water Rinse. 39

\section{LIST OF TABLES}

Table 2-1. Subsample Designators and Descriptions for DWPF Pour Stream Glass Samples 3

Table 2-2. SME 308 Glass Compositions.

Table 3-1. Elemental Composition of DWPF Pour Stream Glass S02244 (Std. Dev., \% RSD)

Table 3-2. Comparison of SME Batch 308 and Glass S02244 Compositions 19

Table 3-3. Density of DWPF Pour Stream Glass Samples, S02244 and S02247 (Std. Dev., $\%$ RSD) 


\section{LIST OF ACRONYMS AND ABBREVIATIONS}

\begin{tabular}{|c|c|}
\hline ADS & Analytical Development Section \\
\hline ARG & Analytical Reference Glass \\
\hline ARM-1 & Analytical Reference Material One \\
\hline ASTM & American Society for Testing Materials \\
\hline DWPF & Defense Waste Processing Facility \\
\hline EA & Environmental Assessment \\
\hline EDS & Electron Dispersive Spectroscopy \\
\hline FT-IR & Fourier Transform Infrared Spectroscopy \\
\hline g & gram \\
\hline GC-MS & Gas Chromatography - Mass Spectrometry \\
\hline ICP-AES & Inductively Coupled Plasma - Atomic Emission Spectroscopy \\
\hline MFT & Melter Feed Tank \\
\hline $\mathrm{mL}$ & milliliter \\
\hline ppm & parts per million \\
\hline QBSD & Quadrant Backscatter Detector \\
\hline PCCS & Product Composition Control System \\
\hline PCT & Product Consistency Test \\
\hline $\mathrm{S}$ & Surface \\
\hline SB2 & Sludge Batch 2 \\
\hline SB3 & Sludge Batch 3 \\
\hline SE1 & Secondary Electron Detector \\
\hline SEM & Scanning Electron Microscopy \\
\hline SME & Slurry Mix Evaporator Tank \\
\hline SRAT & Slurry Receipt and Adjustment Tank \\
\hline SRNL & Savannah River National Laboratory \\
\hline SVOC & Semivolatile Organic Compound \\
\hline TGA-MS & Thermal Gravimetric Analysis with Mass Spectrometry \\
\hline $\mathrm{V}$ & Volume \\
\hline $\mathrm{XRF}$ & X-Ray Fluorescence Spectroscopy \\
\hline
\end{tabular}


WSRC-TR-2005-00240

Revision 0

This page intentionally left blank. 


\subsection{INTRODUCTION AND BACKGROUND}

Two Defense Waste Processing Facility (DWPF) glass samples from Sludge Batch 3 (SB3) (Macrobatch 4) were received by the Savannah River National Laboratory (SRNL) on February 23, 2005. One sample, S02244, was designated for the Product Consistency Test (PCT) and elemental and radionuclide analyses. The second sample, S02247, was designated for archival storage. The samples were pulled from the melter pour stream during the feeding of Melter Feed Tank (MFT) Batch 308 and therefore roughly correspond to feed from Slurry Mix Evaporator (SME) Batches 306 - 308.

During the course of preparing sample S02244 for PCT and other analyses two observations were made which were characterized as "unusual" or anomalous behavior relative to historical observations of glasses prepared for the PCT. These observations ultimately led to a series of scoping tests in order to determine more about the nature of the behavior and possible mechanisms. The first observation was the behavior of the ground glass fraction $(-100+200$ mesh) for PCT analysis when contacted with deionized water during the washing phase of the PCT procedure ${ }^{1}$. The behavior was analogous to that of an organic compound in the presence of water: clumping, floating on the water surface, and crawling up the beaker walls - see Figure 1. In other words, the glass sample did not "wet" normally, displaying a hydrophobic behavior in water. This had never been seen before in 18 years of SRNL PCT tests on either radioactive or non-radioactive glasses. Typical glass behavior is largely to settle to the bottom of the water filled beaker, though there may be suspended fines which result in some cloudiness to the wash water. The typical appearance is analogous to wetting sand.

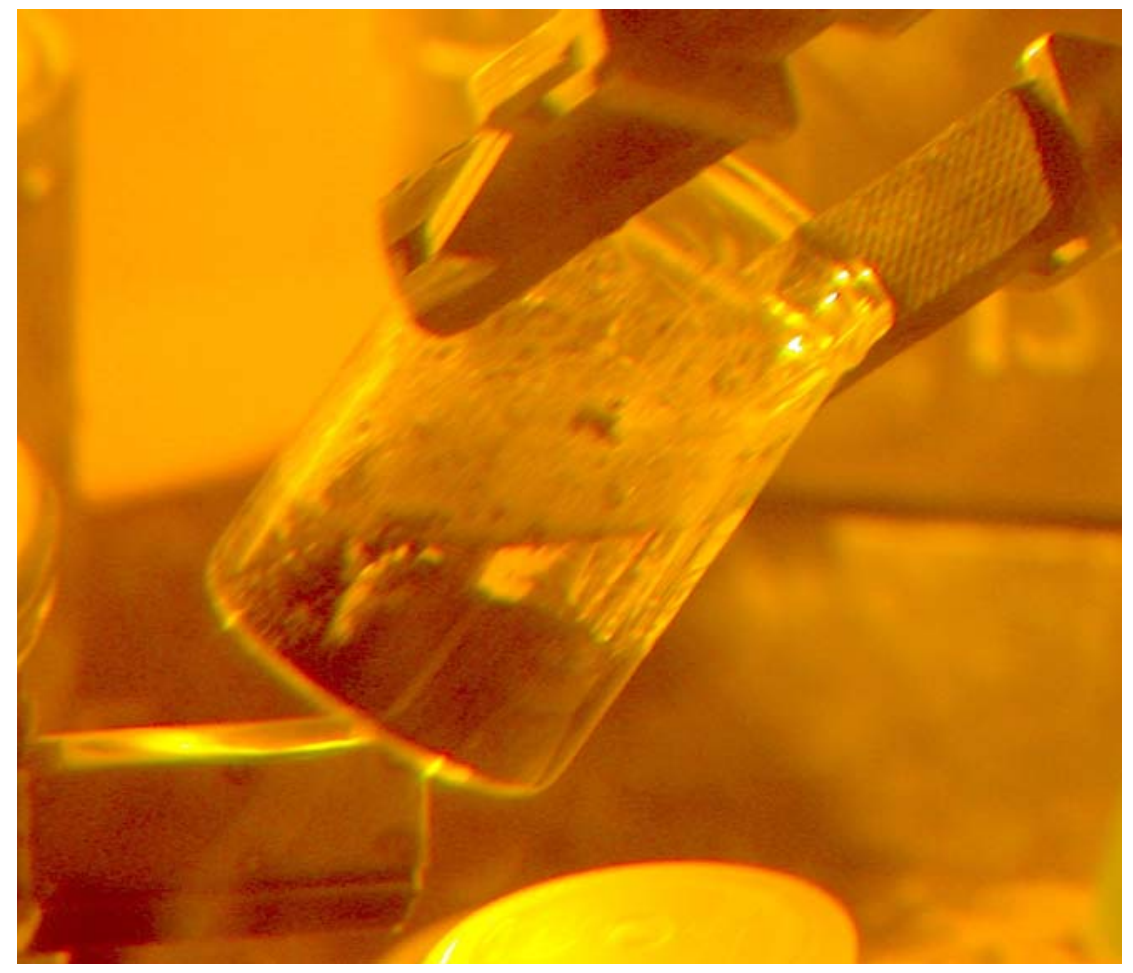

Figure 1-1. Behavior of DWPF Ground Pour Stream Glass Sample \#S02244 in the Presence of Water

The second observation was the presence of faint black rings at the initial and final solution levels in the Teflon vessels used for the mixed acid digestion of the S02244 glass conducted for compositional analysis. The digestion is composed of two stages, and at both the intermediate and the final content 
levels in the digestion vessel the rings were present. The rings had not been seen previously during glass digestions and were not present in the Analytical Reference Glass (ARG) standard samples digested, in separate vessels, along with the DWPF glass. The faint rings did not photograph well through the window of the Shielded Cell and thus have not been included.

The behavior of glass S02244 in water was deemed to be unacceptable for PCT analysis for several reasons. First, the glass could not be washed to remove fines per the ASTM procedure. Second, the failure of the glass to wet did not allow for a defined sample of the glass to be fully contacted with water over the course of the PCT test, i.e. a constant ratio of sample-surface (S) area to leachate volume (V). ${ }^{1}$ Finally, quantitative separation of the ground glass and leachate would be nearly impossible to achieve. What follows in this report are the results and analyses from various scoping experiments done in order to explain the anomalous behavior observed with DWPF glass S02244, along with a comparison with tests on sample S02247 where the anomalous wetting behavior was not observed. 


\subsection{EXPERIMENTAL}

The designators assigned to samples studied and referenced throughout this report are summarized in Table 2-1. Where letter designations have been skipped, e.g. S02247-D, the letter was assigned to other samples such as the +100 mesh PCT fraction that are not discussed in this report.

Table 2-1. Subsample Designators and Descriptions for DWPF Pour Stream Glass Samples

\begin{tabular}{cc}
\hline Sample Designator & Description \\
\hline S02244-A & unground, unwashed S02244 \\
S02244-B & dissolution subsample of S02244-A \\
S02244-C & $-100+200$ mesh, water/ethanol washed S02244-A \\
S02244-F & $n$-hexane washed S02244-C \\
S02244-G & $\mathrm{CH}_{2} \mathrm{Cl}_{2}$ washed S02244-F \\
& \\
S02247-A & unground, unwashed S02247 \\
S02247-B & $n$-hexane washed S02247-A \\
S02247-C & partially crushed, $\mathrm{CH}_{2} \mathrm{Cl}_{2}$ washed S02247-A and -B \\
S02247-E & $-100+200$ mesh, water/ethanol washed S02247-C \\
\hline
\end{tabular}

\subsection{Glass Receipt and Preparation for S02244 and S02247}

The initial bulk glass sample designated for analysis was not washed prior to grinding, but its appearance was black and shiny as observed for other glass samples received ${ }^{2,3,4,5,6}$. Figure 2-1 shows $33.959 \mathrm{~g}$ of glass S02244 as received from DWPF after removal from the primary container, PC0016. No Pt/Au sample cup was received with either pour stream glass sample S02244 or S02247.

The first glass sample was separated into two fractions specified with sample identification numbers S02244-A and S02244-B. S02244-A was designated the primary sample and was used for preparation of the PCT fraction of glass. S02244-B was designated for elemental and radiochemical analyses and was ground in an agate mill.

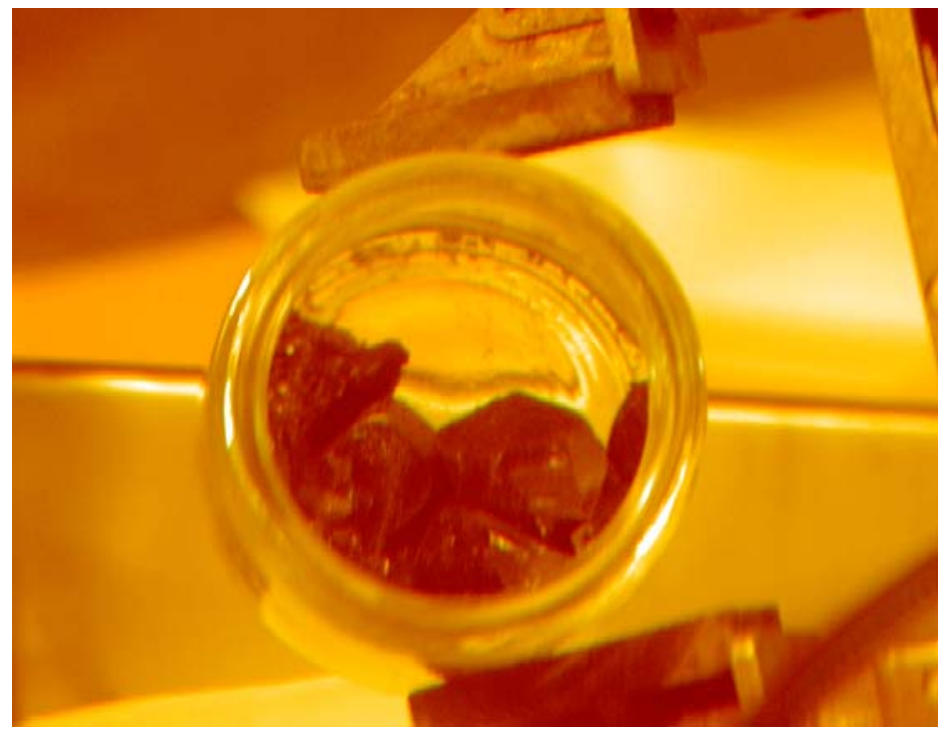

Figure 2-1. DWPF Pour Stream Glass Sample \#S02244 after Removal from the Primary Shipping Container 
DWPF pour stream glass S02247 was initially designated for archival storage. Following developments with the designated analysis sample S02244, S02247 underwent various tests in order to compare its behavior and characteristics with that of the first pour stream glass sample. These tests will be described fully later in this report.

\subsubsection{Glass Sample Fraction S02244-A}

The sample was transferred from the primary container, PC0016, to a clean jar upon receipt. The glass was already in reasonably sized chunks and shards (Figure 2-1), so initial breakup of the glass was unnecessary. After removal of $4.154 \mathrm{~g}$ of glass for elemental and radiochemical analyses (Sample S02244-B), the remaining $29.815 \mathrm{~g}$ of glass (Sample S02244-A) was moved from Shielded Cells ABlock to B-Block for PCT preparations and analysis.

The PCT is an ASTM standard test based on leaching in deionized water a powdered glass ground to a known surface area. The glass that passes through a 100 mesh standard sieve (hole size $0.149 \mathrm{~mm}$ ) but not through a 200 mesh standard sieve (hole size $0.074 \mathrm{~mm}$ ) is used for the PCT. Exactly $10 \mathrm{~mL}$ of the water is used per gram of ground glass. The glass is leached for 7 days at $90{ }^{\circ} \mathrm{C}$. Details are available in Reference 1. In each PCT at SRNL for DWPF glass, samples of the Analytical Reference Material 1 (ARM-1) and the Environmental Assessment (EA) are also tested with the DWPF glass. These glasses are non-radioactive. Results for the ARM-1 glass are compared to a database of earlier results for this glass to confirm that the PCT was performed correctly. Results for the EA glass are compared to those for the DWPF glass to compare the durabilities of the two glasses. Because the PCT was not completed on either the S02244 or S02247 only the grinding, sieving, and washing steps will be summarized in the report.

The glass was ground in an IKA A10 laboratory grinding mill distributed by IKA Works, Inc., Wilmington, NC. This mill is commonly called a Tekmar mill. The mill contains a stainless steel bowl and lid and a tungsten carbide blade. Because of the importance of these two DWPF glass samples (S02244 and S02247), two new grinding mills were modified for remote use with these glasses. For the S02244 glass, one new mill was used first to grind the non-radioactive ARM-1 and EA glasses since it was presumed that the PCT would be performed on the S02244 glass. After grinding the ARM-1 and EA glass, the mill was thoroughly wiped with a clean cloth and the mill placed into Cell 14 . For the S02247 glass, a new mill was used only to grind the radioactive sample.

When grinding a glass, approximately $10 \mathrm{~g}$ of crushed glass (no pieces larger than approximately $1 \mathrm{~cm}$ ) is placed into the bowl of the mill. The cover is placed on the mill and the glass pulverized with short, $10-20$ second, pulses. After several pulses the glass is allowed to settle in the grinding bowl for approximately 30 seconds. The cover is then removed, and the glass powder sieved through a 100 mesh sieve. Commercially available sieves with the standard 100 and 200 mesh sizes, fabricated of brass, are used. So that the sieves can be handled remotely in the Shielded Cells a steel band with a manipulator grip is placed around each sieve. A top cover and a bottom pan that fit on the sieves are also modified so they can be remotely handled. The sieves are then placed together so that the top sieve is the 100 mesh sieve. Ground glass is placed on the 100 mesh sieve and tapped through to the underlying pan. After the initial $10 \mathrm{~g}$ is sieved, what is left on the $>100$ mesh sieve is returned to the mill along with additional $<1$ $\mathrm{cm}$ pieces of glass. The cover is placed on the mill and the glass ground again with several short pulses. After the glass settles, the cover is removed and the glass poured onto the 100 mesh sieve and the sieving operation is repeated. These steps are repeated until $7-8 \mathrm{~g}$ of glass is obtained on the 200 mesh sieve. In the Shielded Cells, this is enough for quadruplicate PCT analyses on a DWPF glass. 


\subsubsection{Glass Sample Fraction S02244-B}

The S02244-B glass fraction in A-Block was moved from Cell 1 to Cell 3 for grinding in a Fritsch Pulverisette 0 agate mill in preparation for elemental and radiochemical analysis. The mill is composed of a remotely controlled (i.e., external to the cell) vibrating stage, an agate bowl, an agate ball approximately the size of a baseball, and an aluminum and Plexiglas lid. The bowl, ball and lid components were new and placed into the cell specifically for the pour stream glass preparation.

Approximately, $4.15 \mathrm{~g}$ of glass (Sample S02244-B1) was moved to the mill and ground for 20 minutes at the maximum amplitude achievable while keeping the agate ball from striking the Plexiglas lid. After milling, $3.985 \mathrm{~g}$ of ground glass powder (Sample S02244-B2) was recovered from the mill and transferred to a clean jar. This ground glass was transferred from A-Block, Cell 3 to B-Block, Cell 10 for dissolution in preparation for elemental and radiochemical analysis.

\subsubsection{Glass Sample S02247}

When the second glass sample was removed from the primary container, PC0008, it consisted of a couple large pieces and a few smaller chards with a combined mass of $23.578 \mathrm{~g}$. All of the glass was black and shiny. Initially, the larger pieces were segregated and designated sample S02247-A, and the smaller pieces designated sample S02247-B. The smaller pieces of S02247-A were initially $n$-hexane washed (see Section 2.2.3). Each fraction was then rinsed with methylene chloride and dried at $90{ }^{\circ} \mathrm{C}$ prior to any further activity. Glass washing will be described in Section 2.2 and discussed in Section 3.2. The now methylene chloride washed glass from S02247-A and S02247-B was transferred to another clean jar and designated sample S02247-C.

In an attempt to get a sufficient quantity of glass into a size range which would permit it to be ground in a Tekmar mill, washed and dried glass from sample S02247-A was placed into a clean polyethylene bag and struck with a hammer, but this failed to break the glass. The DWPF pour stream glass extraction tool was then used to break the largest glass piece of sample S02247-A. This method produced sufficiently small glass chucks for use in the Tekmar mill. The broken glass was transferred to the jar designated for washed, unground glass (Sample S02247-C).

A -100 +200 mesh size fraction was obtained for this sample as previously described in Section 2.1.1. This fraction was washed with deionized water and ethanol as described below and designated sample S02247-E.

\subsection{Glass Washing Behavior}

Over the course of the investigation, ground glass from S02244 was subjected to a series of washing steps, first as part of the PCT and then in an attempt to remove any external contamination that may be present on the glass. Lessons learned from these experiments were later applied to glass S02247 and will be discussed in Section 3.2

\subsection{1 $\mathrm{H}_{2} \mathrm{O}$ Washing}

ASTM-Type 1 water ${ }^{1}$ was used for all glass water washing. As part of the preparation of -100 to +200 mesh ground glass for the PCT, the $7.593 \mathrm{~g}$ of glass sample S02244-C was exposed to water in order to wash away fine glass particles per the ASTM PCT procedure ${ }^{1}$. Glass sample S02247-E, 6.171 g, was also washed with ASTM-Type 1 water twice and decanted between rinses. Both glass samples in water were also placed in an ultrasonic cleaner for a few minutes and then the water decanted off prior to the next washing step. 


\subsubsection{Ethanol Washing}

Absolute ethanol was used to rinse each glass sample at least three times. Sample S02244-C was cycled between deionized water and ethanol several times during the course of its examination. The final rinse of sample S02247-E in ethanol included a couple minutes in an ultrasonic cleaner prior to decanting the ethanol from the glass. Both S02244-C and S02247-E were sampled and submitted for scanning electron microscopy (SEM) analysis.

\subsection{3 n-Hexane Washing}

Glass sample S02244-C and its primary container PC0016 along with a subsample of S02247-A were soaked in $n$-hexane (re-designated S02247-B) overnight in an attempt to dissolve and collect any external contaminates on the glass. Samples of the hexane rinses were placed in clean vials with Teflon cap liners and submitted for gas chromatography - mass spectrometry (GC-MS) analysis. Following hexane washing and drying for four hours at $90{ }^{\circ} \mathrm{C}$, glass sample S02244-C was re-designated sample S02244-F.

\subsubsection{Methylene Chloride Washing}

Glass sample S02244-F was soaked in $15 \mathrm{~mL}$ of methylene chloride for 30 minutes and re-designated as sample S02244-G. A sample of the methylene chloride rinse was placed in a clean vial with a Teflon cap liner and submitted for GC-MS and infrared analyses. The remaining methylene chloride layer, which appeared hazy rather than clear, was decanted off the glass. Additional methylene chloride was added, the glass swirled in the solvent, and the mixture settled for 10 minutes before decanting this layer into a beaker with the first rinse. This procedure was repeated a third time. Following the methylene chloride wash, the glass was dried at $90{ }^{\circ} \mathrm{C}$ for three hours and sampled for SEM.

Glass samples S02247-A and S02247-B were both washed with methylene chloride, the solvent removed, and the glasses dried at $90{ }^{\circ} \mathrm{C}$ prior to being ground or further sampled and tested. The washed glass was re-designated S02247-C

\subsection{Analytical Measurements}

A number of analytical measurements were made either on the glass itself, digested glass, or wash solutions contacted with the glass. Not all techniques were applied to all samples of glass, but rather they were applied selectively during the course of the investigation as needed to answer specific questions. The techniques applied, and to which samples, are outline in the following subsections of this report.

\subsubsection{Inductively Couple Plasma - Atomic Emission Spectroscopy (ICP-AES)}

ICP-AES measurements were made on both the mixed acid and peroxide fusion digestions of glass sample S02244-B2. For the mixed acid digestions an approximately $0.25 \mathrm{~g}$ sample of ground glass (performed in quadruplicate) was placed in a Teflon digestion vessel along with $5 \mathrm{~mL}$ each of concentrated $\mathrm{HF}$ and $\mathrm{HNO}_{3}$. The vessels were capped and placed in a $115 \pm 5^{\circ} \mathrm{C}$ oven for two hours. After cooling for 30 minutes, the vessels were uncapped and $40 \mathrm{~mL}$ of $0.6 \mathrm{M}$ boric acid added to each vessel. The contents were swirled for a few minutes and then $5 \mathrm{~mL}$ concentrated $\mathrm{HCl}$ added. The vessels were recapped and returned to the oven for an additional hour at $115 \pm 5^{\circ} \mathrm{C}$. After an additional 30 minute cooling period, each vessel was uncapped, the contents transferred quantitatively to a $100 \mathrm{~mL}$ plastic volumetric flask, diluted to $100 \mathrm{~mL}$ with deionized water, and mixed. Samples of each glass digestion along with triplicate digestions of an ARG, duplicate samples of a multielement standard and a blank were submitted for ICP-AES analysis.

The peroxide fusion digestions were also conducted on an approximately $0.25 \mathrm{~g}$ sample of ground glass in quadruplicate. Each replicate was placed in a new $\mathrm{Zr}$ crucible along with $1.5 \mathrm{~g} \mathrm{Na}_{2} \mathrm{O}_{2}$ and $1.0 \mathrm{~g}$ 
$\mathrm{NaOH}$. The covered crucible was placed in a muffle furnace pre-heated to $675 \pm 10{ }^{\circ} \mathrm{C}$. After the furnace returned to $675{ }^{\circ} \mathrm{C}$, the crucible was heated for an additional 10 minutes. Each crucible was cooled for 3-4 minutes and then about $5 \mathrm{~mL}$ of deionized water added under the crucible lid. The lid and crucible were then quantitatively rinsed with deionized water and the contents transferred to a $100 \mathrm{~mL}$ plastic volumetric flask using a plastic funnel. $25.0 \mathrm{~mL}$ of $\mathrm{HCl}$ was added to the crucible and the contents transferred to the volumetric flask. This was followed with $10 \mathrm{~mL}$ of deionized water to the crucible and another transfer to the flask. The contents of the volumetric flask were mixed prior to final dilution to $100 \mathrm{~mL}$.

Samples of each digestion along with triplicate digestions of an ARG, duplicate samples of a multielement standard and a blank were submitted for ICP-AES analysis.

\subsubsection{Gas Chromatography - Mass Spectrometry (GC-MS)}

Samples from washing various glass samples and primary container PC0016 with $n$-hexane and/or methylene chloride were submitted for semivolatile organic compound analysis (SVOC) using a GCMS. Analytical separations were carried out on a Hewlett-Packard 6890 GC equipped with a 30 m DB-5 column having a $0.25 \mathrm{~mm}$ diameter and $0.25 \mu \mathrm{m}$ film thickness. Quantitation was performed using a Hewlett-Packard 5973 mass selective detector. Tuning of the mass spectrometer was confirmed within 24 hours of each measurement using perfluorotributylamine. The samples analyzed were derived from S02244-C (n-hexane rinse), S02244-G (methylene chloride rinse), and S02247-A (n-hexane rinse). Blanks of $n$-hexane and methylene chloride were also analyzed. The detection limit for the method was $1 \mathrm{ppm}$.

\subsubsection{Fourier Transform Infrared (FT-IR) Spectroscopy}

A small portion of the methylene chloride rinse solution from sample S02244-G was evaporated on an aluminum weighing dish and the residue analyzed by specular reflectance FT-IR with a portable fiber optics spectrometer. The sample was compared to a blank of the same methylene chloride solution that was used in the glass washing operation.

\subsubsection{Scanning Electron Microscopy (SEM)}

SEM photographs and x-ray fluorescence (XRF) spectra (Energy Dispersive Spectroscopy, EDS) were collected on glass samples S02244-C, S02244-G, and S02247-E. Additional samples examined for comparison purposes included EA glass (-100 to +200 mesh), DWPF Frit 418 (Lot \# 418L8), silicon carbide, anthracite coal, and sludge batch 3 (SB3) solids. Radioactive samples were mounted in the shielded cells, and all samples were coated with carbon prior to analysis. Images were collected with both a quadrant backscatter detector (QBSD) and secondary electron detector (SE1). Most x-ray fluorescence measurements were made with an electron beam strength of $25.0 \mathrm{kV}$, but some were taken at $15.0 \mathrm{kV}$ and $30.0 \mathrm{kV}$ to evaluate depth profiles.

\subsubsection{Thermal Gravimetric Analysis with Mass Spectrometry (TGA-MS)}

Approximately $50 \mathrm{mg}$ samples of glass S02244-G and S02247-E were submitted for TGA-MS. Sample S02244-G was analyzed in air, while S02247-E was analyzed both in air and in argon up to $850{ }^{\circ} \mathrm{C}$ and then switched to air. These sample results were then compared with the spectrum obtained earlier by Damon Click (of the Analytical Development Section (ADS)) for anthracite coal. Neither glass sample was dried to remove surface water, if any, prior to analysis.

\subsection{Glass Density Determinations}

The density of glass samples S02244-A and S02247-A were determined using a graduated cylinder, $11 \mathrm{~g}$ and $19 \mathrm{~g}$ of each glass, respectively, and assuming a density of water of $1.00 \mathrm{~g} / \mathrm{mL}$. The density of each glass was determined two to three times and the values averaged. 


\subsection{Non-Radioactive Simulant Studies}

A series of experiments were performed to assess the behavior of simulated DWPF pour stream glass with and without potential contaminates. The target glass composition used to perform these experiments is summarized in Table 2-2 (last column). The SME 308 column represents the conversion of the elemental values measured by DWPF (and reported on server WG09) to oxides. DWPF analysis of SME 308 did not include several minor components (including $\mathrm{BaO}, \mathrm{La}_{2} \mathrm{O}_{3}, \mathrm{PbO}, \mathrm{SO}_{4}, \mathrm{ThO}_{2}$, and $\mathrm{ZnO}$ ). "Nominal" concentrations of these "minor" components were added to SME 308 composition based on concentrations used in previous SB3 studies. The fourth column normalizes the target glass composition to $100 \%$. The fifth and last column provides the target composition of the non-radioactive (normalized composition without $\mathrm{U}_{3} \mathrm{O}_{8}$ and $\mathrm{ThO}_{2}$ ) glass used for this series of experiments.

Table 2-2. SME 308 Glass Compositions

\begin{tabular}{|c|c|c|c|c|}
\hline Oxide & $\begin{array}{c}\text { DWPF } \\
\text { SME } \\
\text { Batch } 308 \\
\end{array}$ & $\begin{array}{c}\text { SME } 308+ \\
\text { Nominal } \\
\text { Minors }\end{array}$ & Normalized & $\begin{array}{c}\text { Normalized } \\
\text { without } \mathrm{U}_{3} \mathrm{O}_{8} \\
\text { and } \mathrm{ThO}_{2}\end{array}$ \\
\hline $\mathrm{Al}_{2} \mathrm{O}_{3}$ & 5.408 & 5.408 & 5.489 & 5.679 \\
\hline $\mathrm{B}_{2} \mathrm{O}_{3}$ & 4.725 & 4.725 & 4.796 & 4.962 \\
\hline $\mathrm{BaO}$ & 0.000 & 0.052 & 0.053 & 0.055 \\
\hline $\mathrm{CaO}$ & 0.958 & 0.958 & 0.972 & 1.006 \\
\hline $\mathrm{Cr}_{2} \mathrm{O}_{3}$ & 0.072 & 0.072 & 0.073 & 0.076 \\
\hline $\mathrm{CuO}$ & 0.015 & 0.015 & 0.015 & 0.016 \\
\hline $\mathrm{Fe}_{2} \mathrm{O}_{3}$ & 11.136 & 11.136 & 11.302 & 11.694 \\
\hline $\mathrm{K}_{2} \mathrm{O}$ & 0.205 & 0.205 & 0.208 & 0.215 \\
\hline $\mathrm{La}_{2} \mathrm{O}_{3}$ & 0.000 & 0.043 & 0.044 & 0.046 \\
\hline $\mathrm{Li}_{2} \mathrm{O}$ & 4.717 & 4.717 & 4.788 & 4.954 \\
\hline $\mathrm{MgO}$ & 1.124 & 1.124 & 1.141 & 1.181 \\
\hline $\mathrm{MnO}$ & 1.999 & 1.999 & 2.029 & 2.099 \\
\hline $\mathrm{Na}_{2} \mathrm{O}$ & 11.818 & 11.818 & 11.995 & 12.411 \\
\hline $\mathrm{NiO}$ & 0.569 & 0.569 & 0.577 & 0.597 \\
\hline $\mathrm{PbO}$ & 0.000 & 0.051 & 0.052 & 0.054 \\
\hline $\mathrm{SiO}_{2}$ & 51.752 & 51.752 & 52.526 & 54.348 \\
\hline $\mathrm{SO}_{4}$ & 0.000 & 0.400 & 0.406 & 0.420 \\
\hline $\mathrm{ThO}_{2}$ & 0.000 & 0.012 & 0.012 & 0.000 \\
\hline $\mathrm{TiO}_{2}$ & 0.061 & 0.061 & 0.062 & 0.064 \\
\hline $\mathrm{U}_{3} \mathrm{O}_{8}$ & 3.290 & 3.290 & 3.339 & 0.000 \\
\hline $\mathrm{ZnO}$ & 0.000 & 0.055 & 0.056 & 0.058 \\
\hline $\mathrm{ZrO}_{2}$ & 0.063 & 0.063 & 0.064 & 0.066 \\
\hline Total & 97.913 & 98.526 & 100.000 & 100.000 \\
\hline
\end{tabular}

The non-radioactive SME 308 target glass composition was produced by batching reagent grade oxides, carbonates, and boric acid and melting for two hours at $1150^{\circ} \mathrm{C}$. The glass was subsequently poured onto a stainless plate and was characterized as "black and shiny" (see Figure 2-2). Once cool, this glass was placed into a plastic bag (double-bagged) and broken with a hammer - see Figure 2-3 for the resulting product. These fragmented pieces became the sampling stock for subsequent testing. 


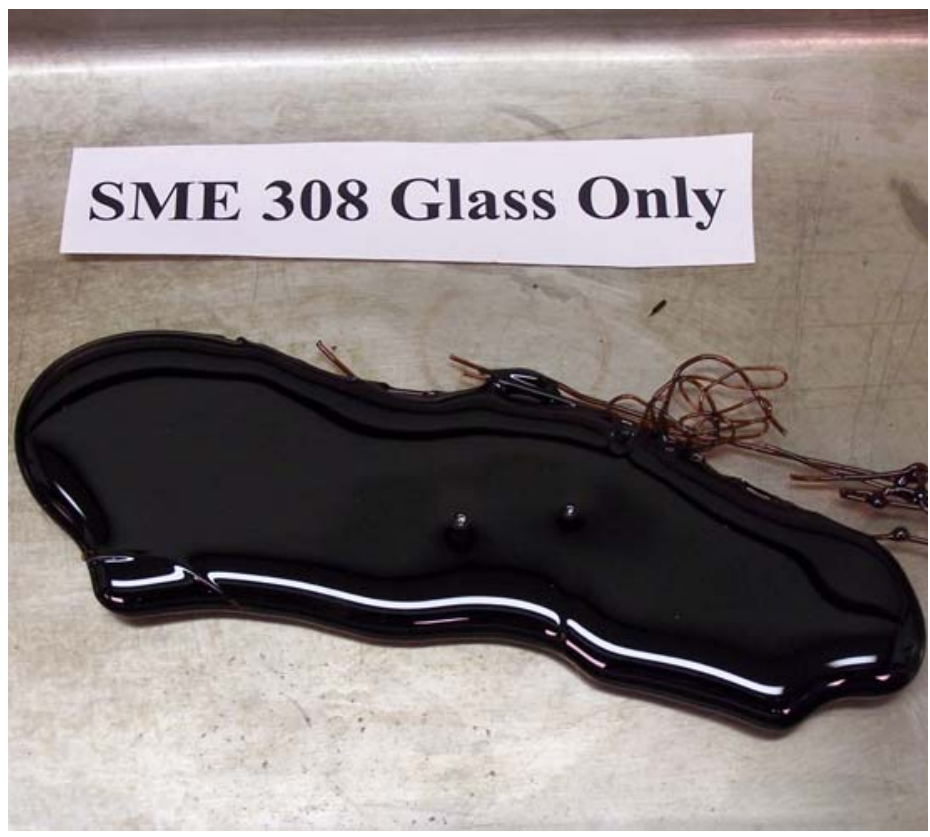

Figure 2-2. Non-Radioactive SME 308 Glass as Fabricated

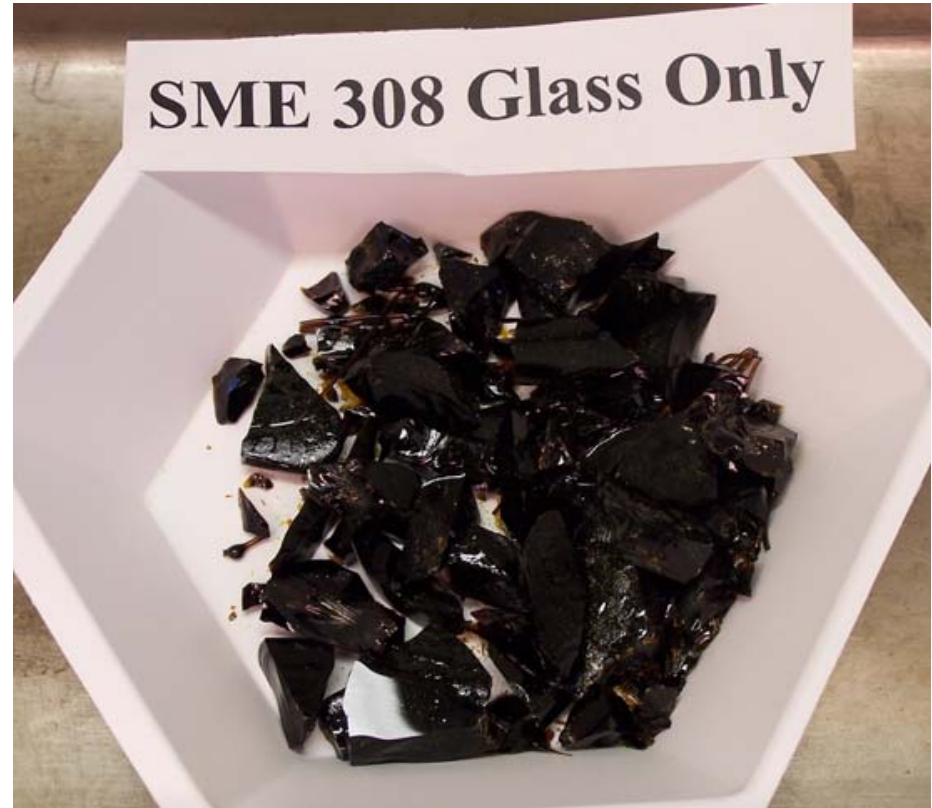

Figure 2-3. Crushed Non-radioactive SME 308 Glass

The following series of tests were conducted to see if the source of the hydrophobic behavior of the DWPF glass could be isolated or to see if behavior consistent with that observed by personnel working with the DWPF S02244 glass could be recreated. It was postulated prior to these experiments following a review of the radioactive glass data that the behavior could be a result of the:

(1) Glass

(2) Presence of coal or graphite in the glass

(3) Presence of a silicone-based lubricant, alone or in combination with (1) or (2), in the glass 
The experiments were performed in series to isolate each possible cause. Initially, the glass was tested by itself, followed by the glass plus coal, and finally the glass plus grease (a silicone lubricant). In general, fragmented pieces of the non-radioactive SME 308 glass (see Figure 2-3) were obtained, and either ground with or without one of the two potential additives (grease or coal) in a Tekmar mill. The ground material was subsequently sieved to obtain a -100 to +200 mesh size fraction. The specific size fraction was then placed into a $50 \mathrm{~mL}$ glass beaker and deionized water was used to rinse the sieved material. It should be noted, that in each series of tests only one wash or rinse was performed and the PCT was not carried out to completion. More specifics regarding the application and use of the coal and silicon lubricant are provided below along and general observations for each of the three tests are discussed in Section 3.5.

\subsubsection{Glass-Only}

Figure 2-4 shows the sieved -100 to +200 fraction of the non-radioactive SME 308 glass (without any additives). The sieved material was subsequently placed into a $50 \mathrm{~mL}$ beaker and deionized water was used to wash or rinse the material.

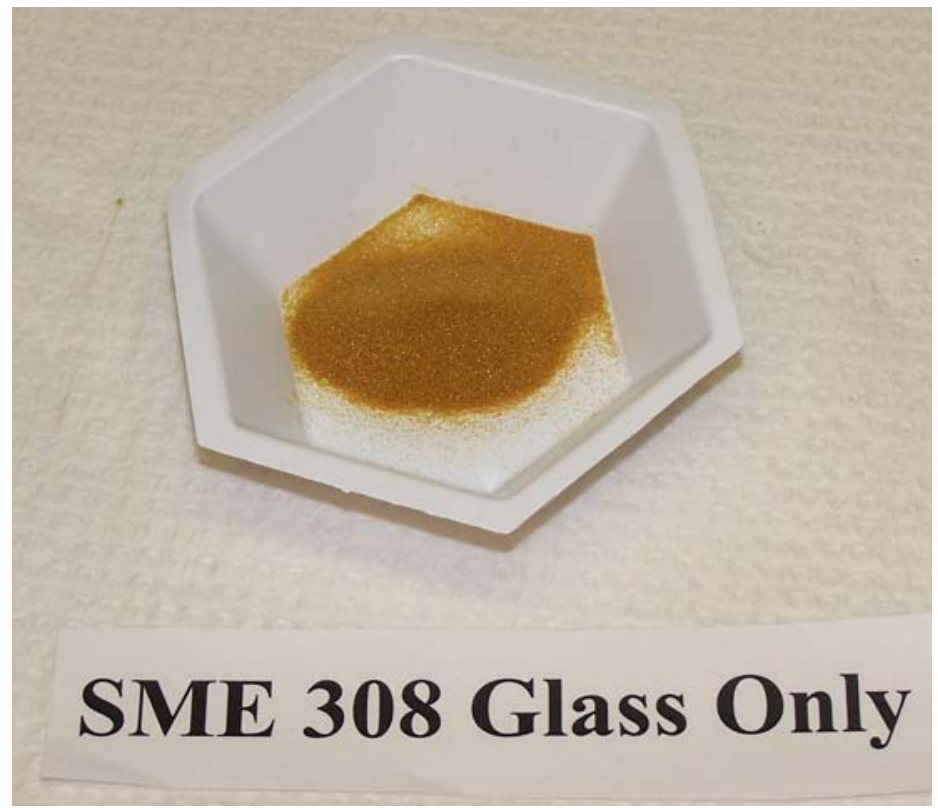

Figure 2-4. SME 308 Glass Ground and Sieved for PCT

\subsubsection{Glass with Coal}

Pristine SME 308 glass fragments (see Figure 2-3) were placed into a clean Tekmar mill. Approximately $2-3 \mathrm{~g}$ of anthracite coal (source being that used for previous SB3 Slurry Receipt and Adjustment Tank (SRAT)/SME runs) was placed into the mill with the larger glass fragments. The two materials were ground together, sieved, and the -100 to +200 mesh size fraction placed into a clean 50 $\mathrm{mL}$ beaker. Deionized water was then used to rinse the material to simulate the initial rinse for the PCT.

\subsubsection{Glass with Grease Contamination}

Without knowing the exact lubricant being considered as a possible candidate for the hydrophobic nature of the glass, a Dow Corning silicone-based lubricant for high vacuum applications, referred to as stopcock grease was selected - see Figure 2-5. 


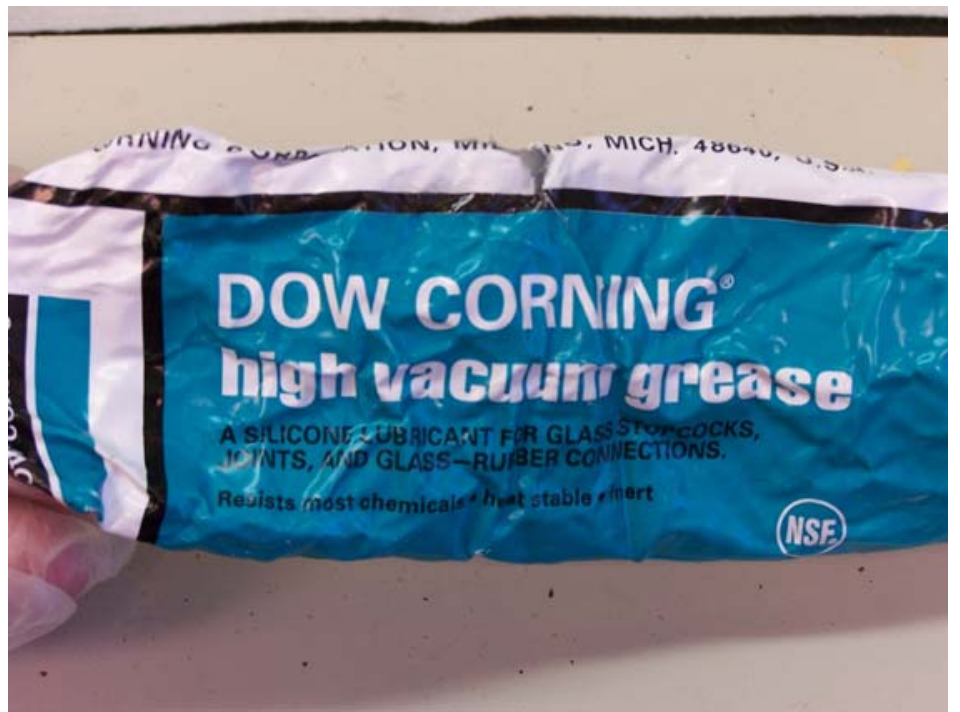

Figure 2-5. Silicone Lubricant: High Vacuum Grease

The initial test with the silicone lubricant was based on placing approximately five fragmented pieces of SME 308 glass in the Tekmar mill. A Q-tip was then used to "dab” a small amount of silicon grease onto two of the approximately five glass pieces. Note: the grease was not smeared on the particle surfaces but was just placed on the two glass pieces in the form of a "glob" or "clump". Figure 2-6 shows the SME 308 glass plus grease while in the Tekmar mill prior to milling. The "globs" of grease are extremely hard to see but are located at the 12 o'clock and 6 o'clock positions on part of the glass.

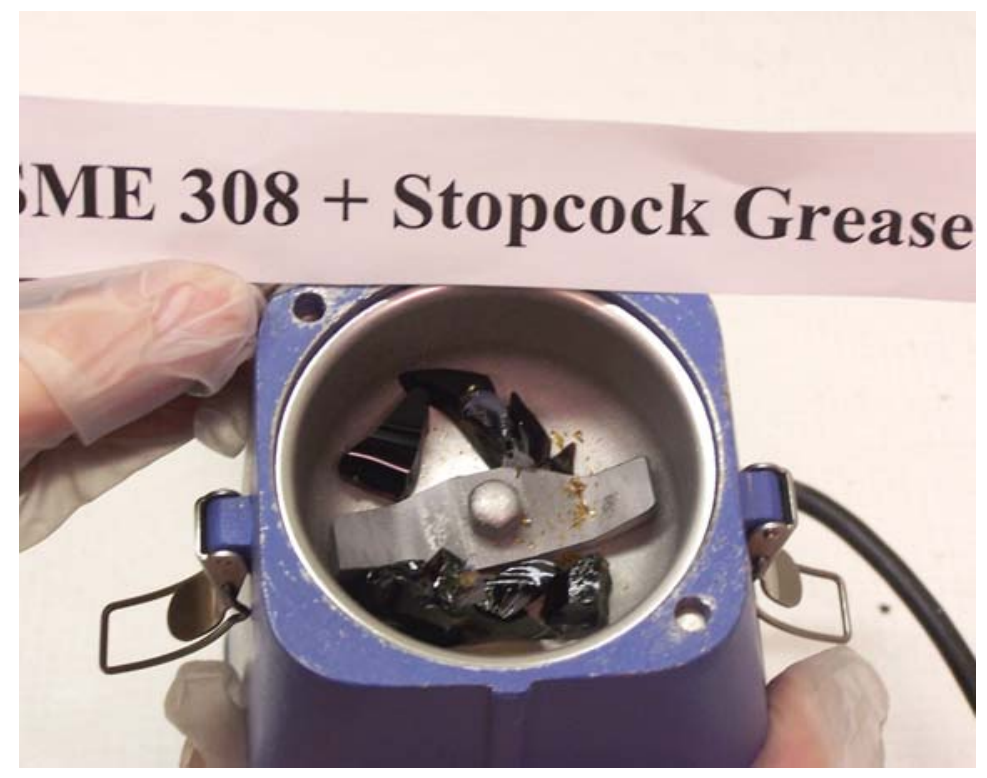

Figure 2-6. SME 308 Glass with “Dabs” of Silicone Grease Prior to Grinding

The glass plus grease were then ground in the Tekmar mill, and the resulting mixture shown in Figure 2-7 was then sieved and a sample of the -100 to +200 mesh powder was obtained. The screened material was then transferred to a $50 \mathrm{~mL}$ beaker and deionized water was used to rinse the material. 


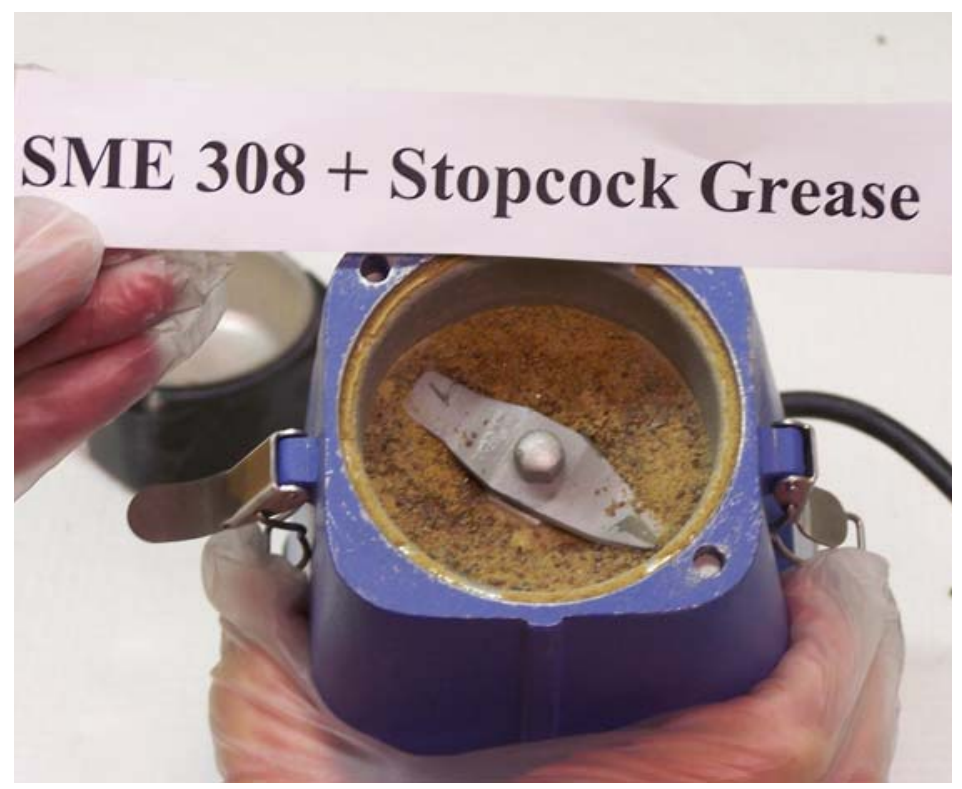

Figure 2-7. SME 308 with Silicone Grease after Grinding

Two additional silicon lubricant based tests were performed varying in the application of the grease. Instead of applying "globs" of lubricant to two of the glass pieces (see Figure 2-6), a thin layer of lubricant was applied to one side of four pieces, placed in the Tekmar mill, and ground (referred to as Test \#2). Once the -100 to +200 mesh powder was obtained, it was placed in a $50 \mathrm{~mL}$ beaker and rinsed with deionized water.

The third test with the silicon lubricant also had a slight variation of when and how the lubricant was applied. In this test (referred to as Test \#3), pristine SME 308 glass was partially ground in the Tekmar mill. The resulting particle size was not substantially reduced (estimated to be primarily -40 to +100 mesh). While still in the Tekmar mill, two to three small quantities ("dabs") of silicon lubricant were added with a Q-tip. The glass plus lubricant were then ground and sieved to obtain the -100 to +200 mesh size fraction. 


\subsection{RESULTS AND DISCUSSION}

\subsection{Glass Receipt and Preparation for S02244 and S02247}

Inspection of the primary containers which housed both S02244 (PC0016) and S02247 (PC0008) were carried out in the shielded cells. Both containers had glass stuck to the bottom of the vessels, though the amount in PC0016 was slightly more than in PC0008, but this may have been related to the fact that S02244 contained many more fines at the time of its removal from the primary container than did the second glass sample (S02247). Since the primary container (PC0034) from the Sludge Batch 2 (SB2) pour stream glass sample was available in the shielded cells, it too was inspected. Upon inspection it appeared identical inside as those from the SB3 samples.

\subsubsection{Glass Sample Fraction S02244-A}

During grinding of this glass fraction in the Tekmar mill, to obtain the eventual PCT size fraction of -100 to +200 mesh (Sample S02244-C), the usually observed puff of ground glass upon initial opening of the mill was not observed. Additionally, no glass was seen on a white cloth during a tap test of the 200 mesh screen. Both these observations did not have a great deal of significance initially, but were consistent with later observations of the glass's behavior.

Later examination of the mill revealed a swirl pattern of ground glass on the top lid of the Tekmar mill. See Figure 3-1. Additionally, when the mill was moved to the front of the shielded cell, adhered glass deposits were visible in the bowl. This observation led to the suspicion that there was something "on" the glass causing it to adhere to the lid surface. These deposits, shown in Figure 3-2 as a brown film on the bottom and side of the bowl surface were not visible when the mill was in its working position towards the rear of the cell.

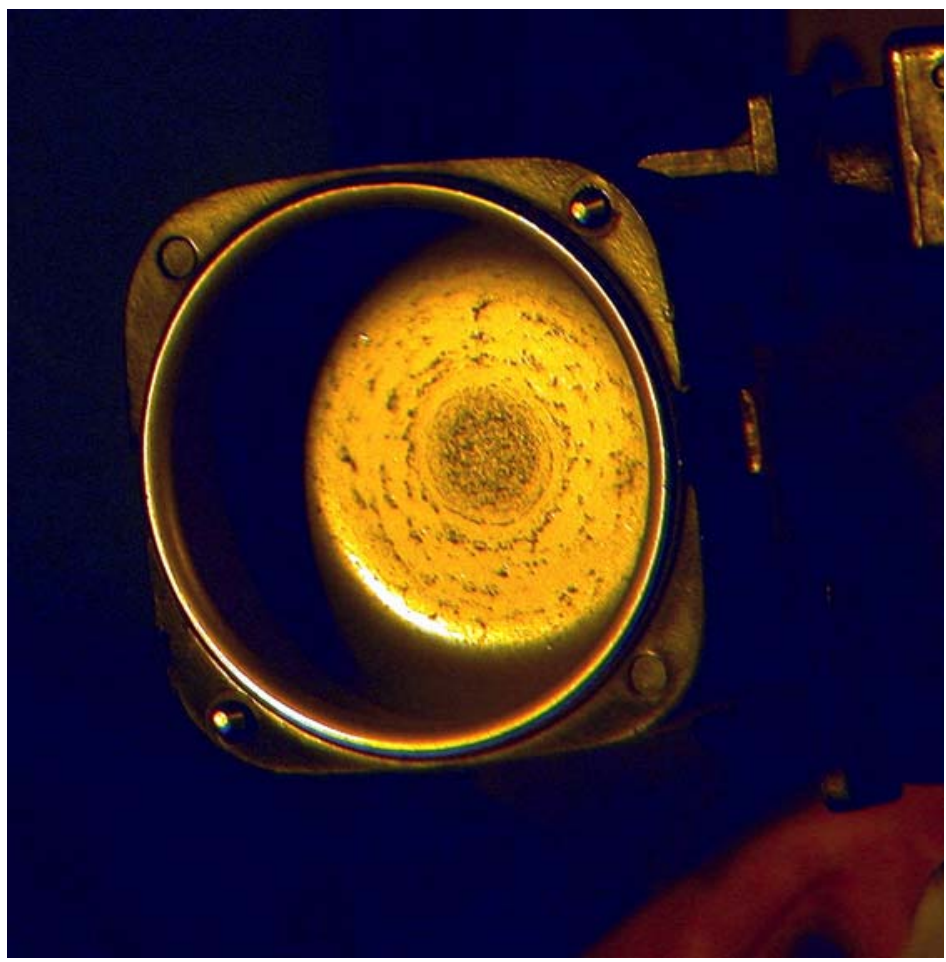

Figure 3-1. Tekmar Mill Lid Following Grinding of Sample S02244-A 


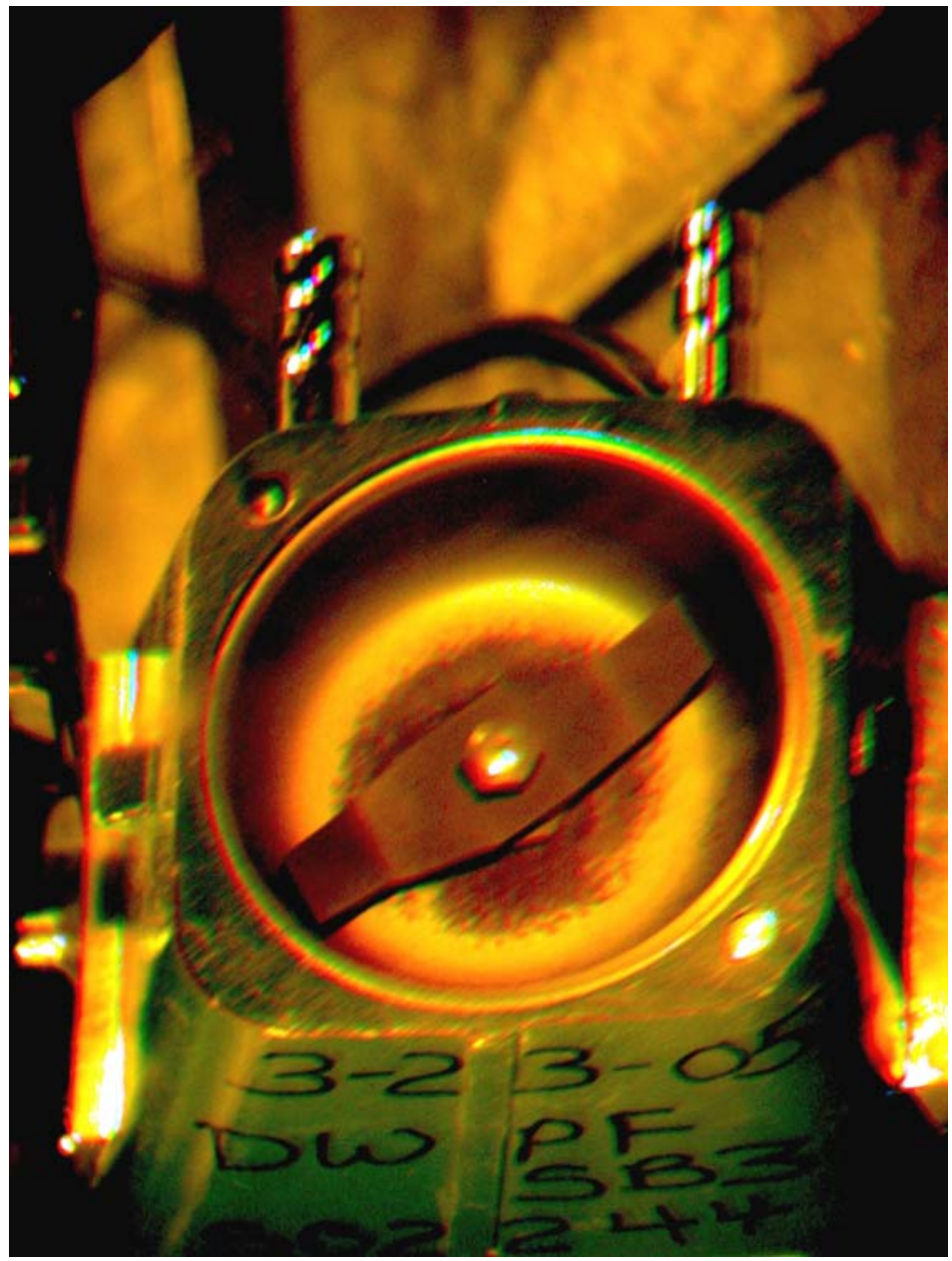

Figure 3-2. Tekmar Mill Bowl Following Grinding of Sample S02244-A

\subsubsection{Glass Sample Fraction S02244-B}

Nothing unusual was observed during the preparation and handling of this glass fraction for the elemental and radiochemical analyses. After milling, the fraction was designated S02244-B2. It was not until the mixed acid dissolution, that anything unusual was observed. See Section 3.3.1 for further discussion of the mixed acid dissolution.

This fraction of glass was poured into a separate clean jar from the bulk of the as-received sample just after removal of the glass from the primary container. It was never in contact with the Tekmar mill, the sieves used in collecting the -100 to +200 mesh fraction, or any of the miscellaneous support equipment such as other jars, beakers, plastic weigh boats, or tweezers.

\subsubsection{Glass Sample S02247}

When this glass was ground in the Tekmar mill there was a distinct puff of ground glass upon initial opening of the mill. This observation was consistent with the behavior of ground glass following grinding in this type of mill. 


\subsection{Glass Washing Behavior}

\subsection{1 $\mathrm{H}_{2} \mathrm{O}$ Washing}

The addition of deionized water to the -100 to +200 mesh ground glass fraction (Sample S02244-C) during the preparation of the glass for the PCT was the first point at which the behavior of the glass was significantly unusual. Figure 3-3 shows the appearance of the ground and sieved glass in water.

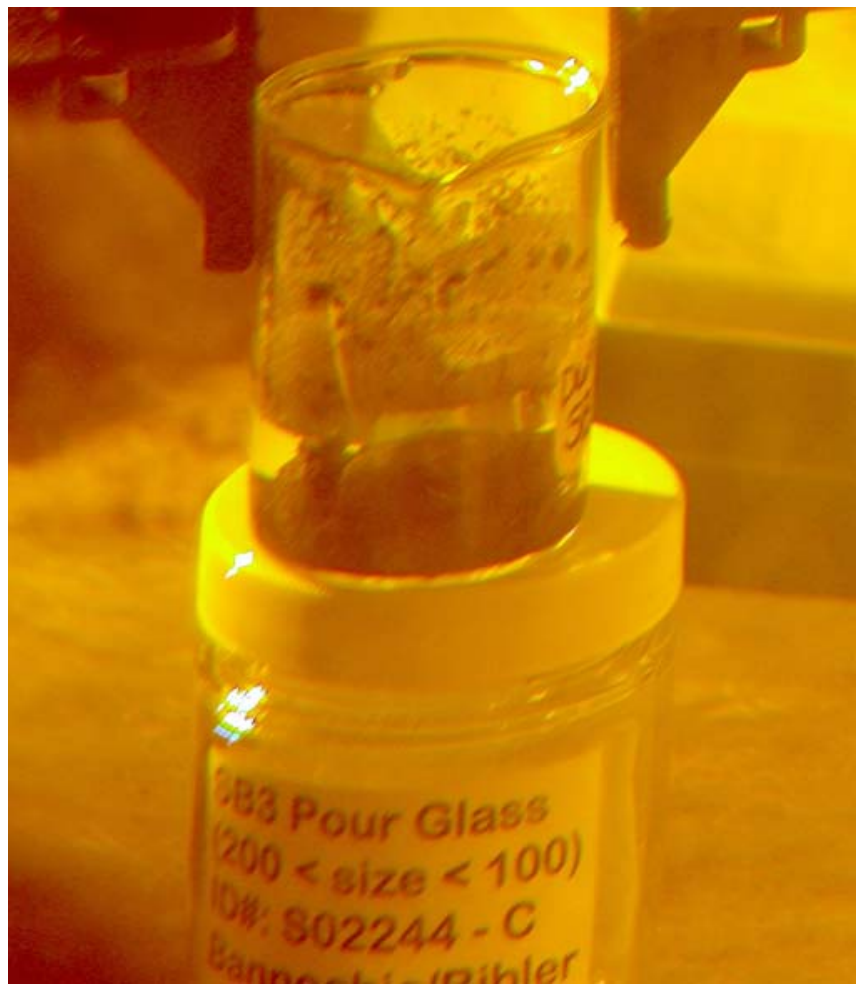

Figure 3-3. DWPF Pour Stream Glass Sample S02244-C in Water

The glass formed clumps and fines "crawled" up the sides of the beaker, both classic behaviors of a hydrophobic solid, such as an organic compound, when exposed to a highly polar solvent such as water. Probing the clumped glass at the bottom of the beaker with a pipette revealed that each clump contained "dry" glass inside. When swirled, the glass clumps move as single, intact groups. The failure of the water to wet or coat the glass was initially of concern to the successful removal of fines, the purpose of the deionized water wash, and to the ability to perform the PCT with a defined portion of glass in contact with a defined amount of deionized water.

Further water tests conducted with samples S02244-B2 (milled fraction for elemental and radiochemical analysis) and S02244-D (-200 mesh fraction of S02244-A) both revealed the same hydrophobic behavior. Therefore it was apparent that the size of the glass fraction was not the cause of the behavior nor was it due to contamination in the Tekmar mill, sieves, or miscellaneous equipment used in Cell 14 in preparation for the PCT since S02244-B2 did not come into contact with any of this equipment.

When the second ground and sieved glass sample, S02247-E, was exposed to deionized water the glass wet in a typical manner, see Figure 3-4. It should be noted that this behavior was observed after the original sample, S02247-A, was rinsed with methylene chloride and dried prior to grinding and sieving. 


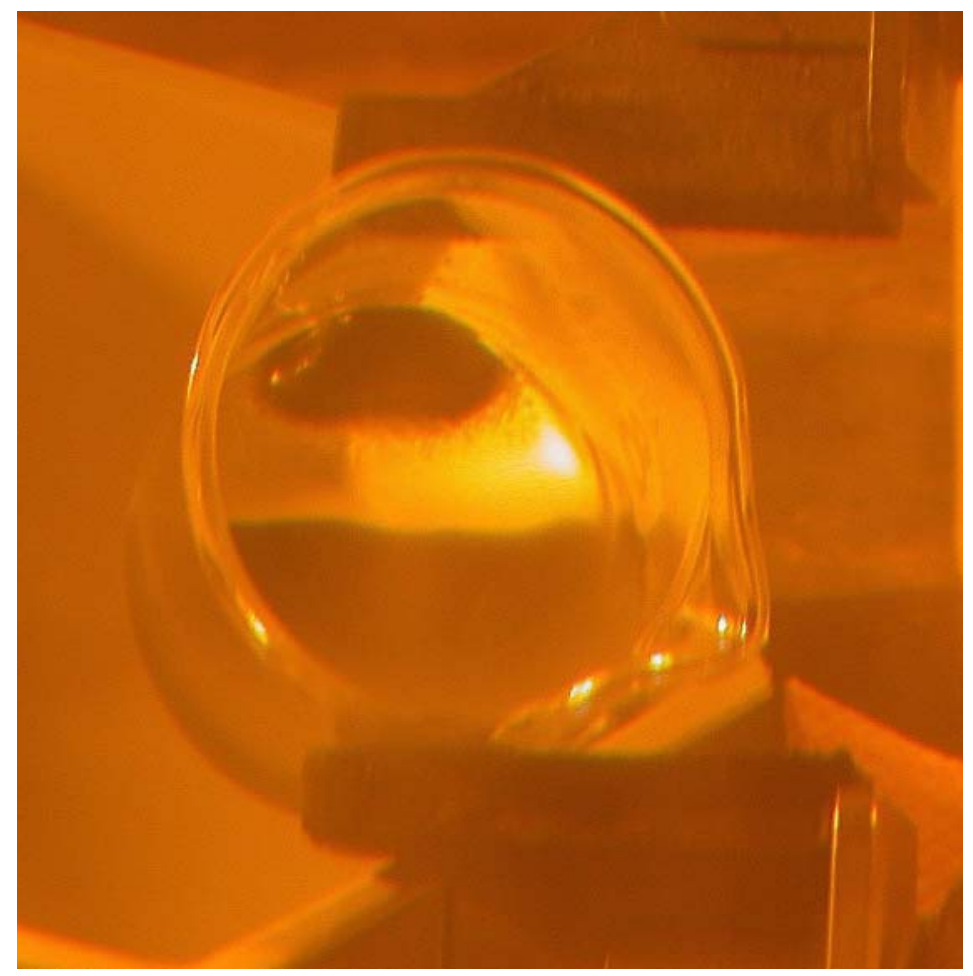

Figure 3-4. DWPF Pour Stream Glass S02247-E in Water

\subsubsection{Ethanol Washing}

It was not possible to decant the water away from glass S02244-C without losing a significant portion of the ground glass, but the addition of 190-proof ethanol and ten minutes in an ultrasonic cleaner allowed the glass to settle to the bottom of the beaker. A slurry pipette was then used to remove as much of the free liquid as possible. Repeated ethanol additions followed by ultrasonic bath treatments and careful removal of the supernatant liquid allowed glass sample S02244-C to return to a normal wetted glass state appearance, see Figure 3-5.

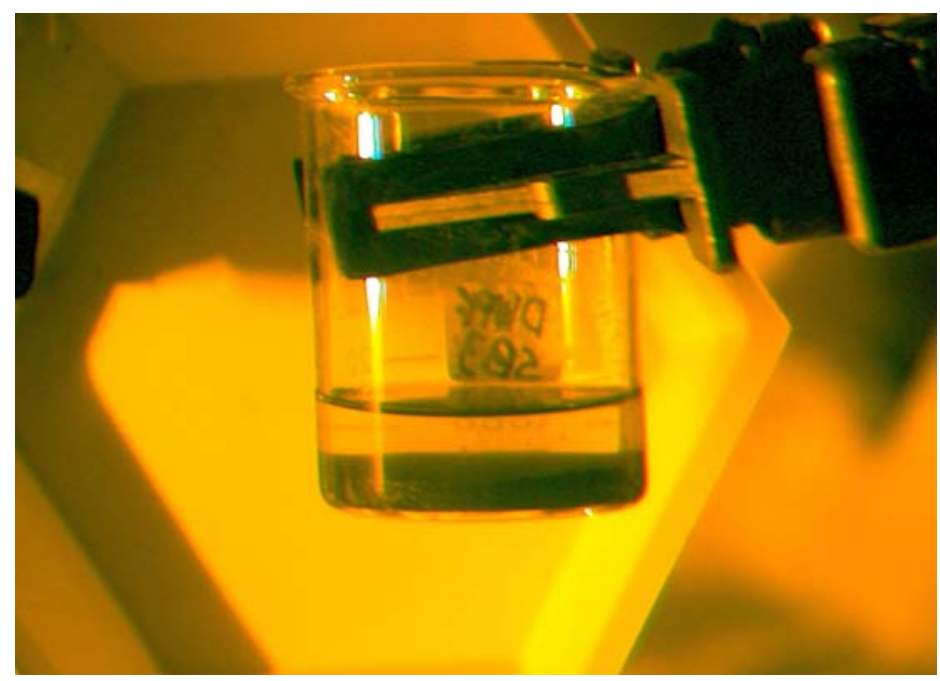

Figure 3-5. DWPF Pour Stream Glass Sample S02244-C in Ethanol 
If the glass was returned to deionized water following ethanol rinses, the characteristic hydrophobic behavior returned, see Figure 3-6. This behavior was repeated by cycling between ethanol and water a number of times.

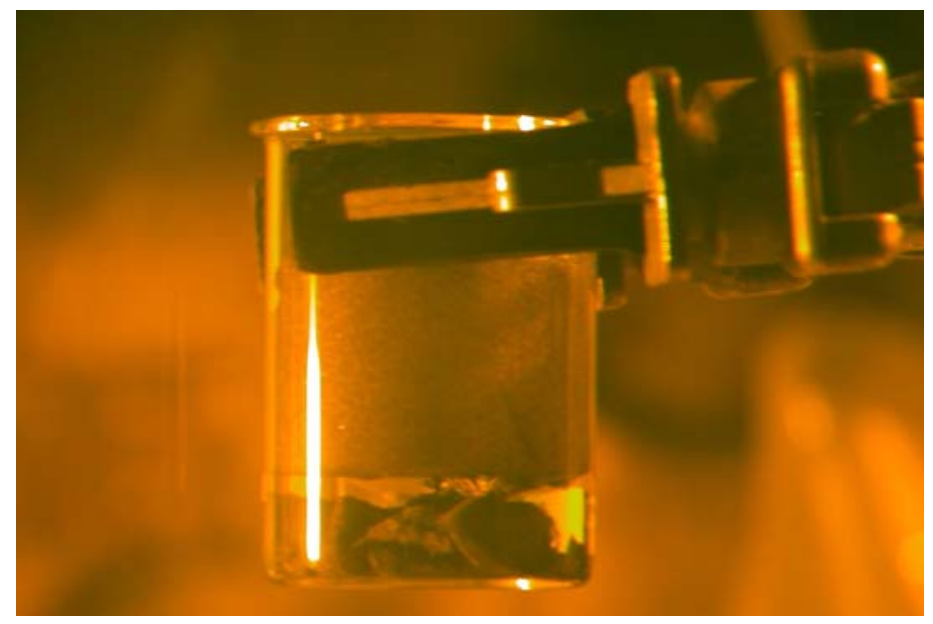

Figure 3-6. DWPF Pour Stream Glass Sample S02244-C in Water Following Ethanol Washes

The behavior of the glass in ethanol was not unexpected. Ethanol, while still a polar molecule, is less polar than water and does not form as strong a matrix of hydrogen bonds as water does. What was not expected was that ethanol would not remove, i.e. dissolve, whatever external contaminant that was now suspected to be present on the glass and causing its observed behavior in water.

\subsection{3 n-Hexane Washing}

$n$-Hexane was the next solvent explored to dissolve a suspected contaminant on the glass surface. As a non-polar, organic solvent, most oils and greases were thought to be soluble in it. $n$-Hexane wet the glass sample S02244-C just like ethanol, but it was no more effective at removing fines from the glass than ethanol had been (see SEM discussion in Section 3.3.4). When the $n$-hexane was removed and the sample (re-designated S02244-F) was re-exposed to water, the hydrophobic behavior returned. Figure 3-7 shows sample S02244-F in water.

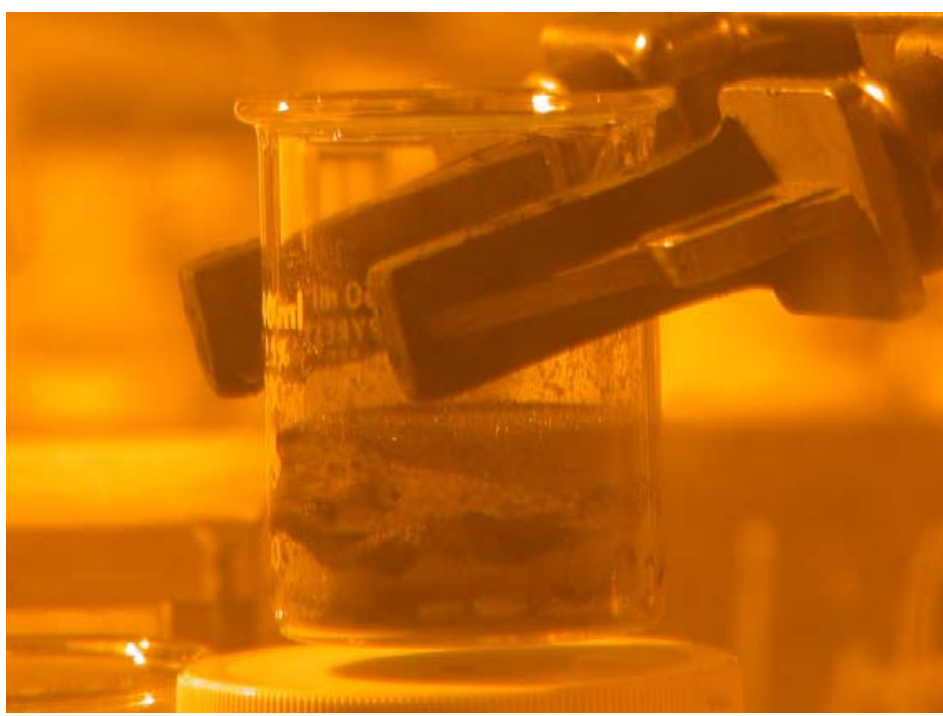

Figure 3-7. DWPF Pour Glass Sample S02244-F in Water Following $n$-Hexane Wash (Side View) 
There were, however, more fines floating on the surface of the water than had been seen previously. This layer of fines can be seen more clearly in Figure 3-8. This top layer of glass appeared completely dry. Samples of the $n$-hexane wash were analyzed by GC-MS; these results are discussed in Section 3.3.2.

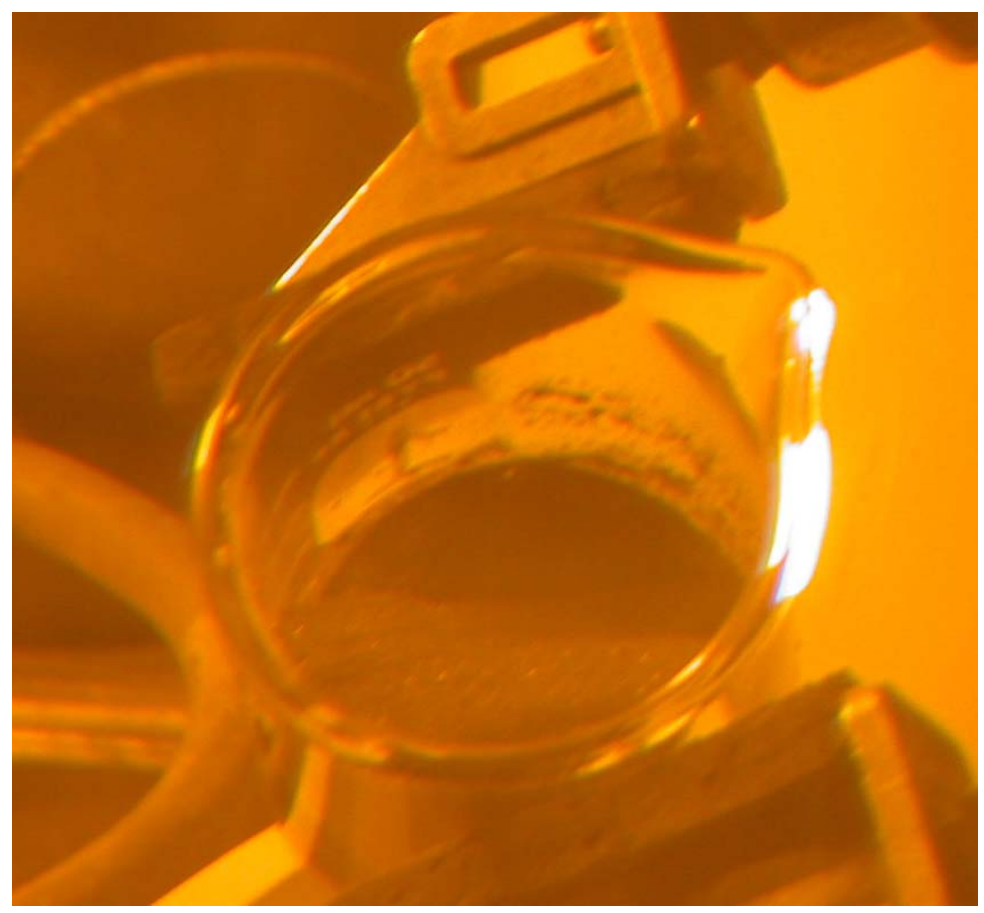

Figure 3-8. DPWF Pour Stream Glass Sample S02244-F in Water Following $n$-Hexane Wash (Top View)

\subsubsection{Methylene Chloride Washing}

The methylene chloride wash was the only one of the three solvents tested that appeared to suspend fine glass particles, becoming hazy following contact with glass sample S02244-F. When deionized water was added to the methylene chloride washed and dried first glass sample (designated S02244-G), the previously observed hydrophobic behavior returned. Hence, this solvent was unable to completely remove any contaminant on the glass even after three rinse-and-decant cycles. The appearance of dried glass sample S02244-G in contact with water was similar to that seen in Figure 3-7.

\subsection{Analytical Measurements}

Results from the various analytical methods applied to the glass samples either directly or indirectly (such as by analyzing a wash solution generated from contact with a given glass sample) are presented and discussed in the following sections. Not all methods were applied to all samples.

\subsubsection{Inductively Couple Plasma - Atomic Emission Spectroscopy (ICP-AES)}

The data in Table 3-1 is from the digestions of the first pour stream glass sample, S02244. Values obtained from both digestions have been combined and averaged where possible, i.e. when both methods had satisfactory blanks and/or are applicable to the element in question. In other instances, either the mixed acid or peroxide fusion values for four samples have been averaged and provided in the table. 
Table 3-1. Elemental Composition of DWPF Pour Stream Glass S02244 (Std. Dev., \% RSD)

\begin{tabular}{cccc}
\hline Element & $\mu \mathbf{g} / \mathbf{g}$ glass & Element & $\mu \mathbf{g} / \mathbf{g}$ glass \\
\hline $\mathbf{A g}$ & $136(2,1.7)$ & $\mathbf{M n}$ & $16,300(3242.0)$ \\
$\mathbf{A l}$ & $25,000(1200,4.8)$ & $\mathbf{M o}$ & $271(16,6.0)$ \\
$\mathbf{B}$ & $13,500(82,0.6)$ & $\mathbf{N a}$ & $85,000(700,0.8)$ \\
$\mathbf{B a}$ & $332(22,6.8)$ & $\mathbf{N i}$ & $4540(99,2.2)$ \\
$\mathbf{B e}$ & $0.903(0.032,3.5)$ & $\mathbf{P}$ & $1190(99,8.3)$ \\
$\mathbf{C a}$ & $8140(1090,13)$ & $\mathbf{P b}$ & $330(20,5.9)$ \\
$\mathbf{C d}$ & $740(25,3.4)$ & $\mathbf{S}$ & $1690(46,2.7)$ \\
$\mathbf{C e}$ & $641(50,7.7)$ & $\mathbf{S b}$ & $539(16,3.0)$ \\
$\mathbf{C r}$ & $617(59,9.5)$ & $\mathbf{S i}$ & $254,000(600,0.2)$ \\
$\mathbf{C u}$ & $107(5,5.1)$ & $\mathbf{S n}$ & $2560(130,5.1)$ \\
$\mathbf{F e}$ & $77,300(1980,2.6)$ & $\mathbf{S r}$ & $2030(110,5.4)$ \\
$\mathbf{G d}$ & $224(33,15)$ & $\mathbf{T i}$ & $379(16,4.3)$ \\
$\mathbf{K}$ & $1140(226,20)$ & $\mathbf{U}$ & $27,000(900,3.3)$ \\
$\mathbf{L a}$ & $184(7,3.8)$ & $\mathbf{V}$ & $61.0(37,62)$ \\
$\mathbf{L i}$ & $25,700(1430,5.6)$ & $\mathbf{Z n}$ & $256(17,6.6)$ \\
$\mathbf{M g}$ & $7160(90,1.3)$ & $\mathbf{Z r}$ & $441(5,1.2)$ \\
\hline
\end{tabular}

Data in Table 3-1 for glass S02244 was converted to an oxide basis and compared with the DWPF SME 308 composition in Table 3-2. All elements measured in the DWPF SME except Al, Li, and Si agreed to within $0.5 \mathrm{wt} \%$. This indicates that if there is a contaminant and/or carbon-based component (see Section 3.3.4) in the sample, it comprises a very small fraction of the total mass.

Table 3-2. Comparison of SME Batch 308 and Glass S02244 Compositions

(Wt.\% Oxide)

\begin{tabular}{ccc}
\hline Oxide & SME 308 & S02244 \\
\hline $\mathrm{Al}_{2} \mathrm{O}_{3}$ & 5.41 & 4.71 \\
$\mathrm{~B}_{2} \mathrm{O}_{3}$ & 4.72 & 4.35 \\
$\mathrm{CaO}$ & 0.958 & 1.14 \\
$\mathrm{Cr}_{2} \mathrm{O}_{3}$ & 0.072 & 0.090 \\
$\mathrm{CuO}$ & 0.015 & 0.013 \\
$\mathrm{Fe}_{2} \mathrm{O}_{3}$ & 11.1 & 11.0 \\
$\mathrm{~K}_{2} \mathrm{O}$ & 0.205 & 0.137 \\
$\mathrm{Li}_{2} \mathrm{O}$ & 4.72 & 5.52 \\
$\mathrm{MgO}$ & 1.12 & 1.19 \\
$\mathrm{MnO}$ & 2.00 & 2.11 \\
$\mathrm{Na}_{2} \mathrm{O}$ & 11.8 & 11.5 \\
$\mathrm{NiO}_{\mathrm{SO}}$ & 0.569 & 0.578 \\
$\mathrm{SiO}_{2}$ & - & 0.51 \\
$\mathrm{TiO}_{2}$ & 51.8 & 54.2 \\
$\mathrm{U}_{3} \mathrm{O}_{8}$ & 0.061 & 0.063 \\
$\mathrm{ZrO}_{2}$ & 3.29 & 3.19 \\
$\mathrm{Total}$ & 0.063 & 0.060 \\
\hline
\end{tabular}




\subsubsection{Gas Chromatography - Mass Spectrometry (GC-MS)}

Six samples were submitted for SVOC analysis by GC-MS. The samples included rinse solutions from S02244-C (n-hexane), S02244-G (methylene chloride), and S02247-A (n-hexane), as well as blanks of $n$-hexane and methylene chloride. The only compound detected was bis (2-ethylhexyl) phthalate in the 1-6 ppm range. This compound is a common plasticizer and most likely resulted from contamination of the solvents due to contact with a plastic pipette. Compounds, such as silicone oils or polymeric materials with very high boiling ranges would not be detected by this method of analysis.

\subsubsection{Fourier Transform Infrared (FT-IR) Spectroscopy}

A portion of the methylene chloride rinse of glass S02244-F analyzed by GC-MS, along with a blank of methylene chloride were mounted on an aluminum dish and the FT-IR spectrum taken of each dried residue, see Figure 3-9. The spectra shown in Figure 3-10 and Figure 3-11 were collected.

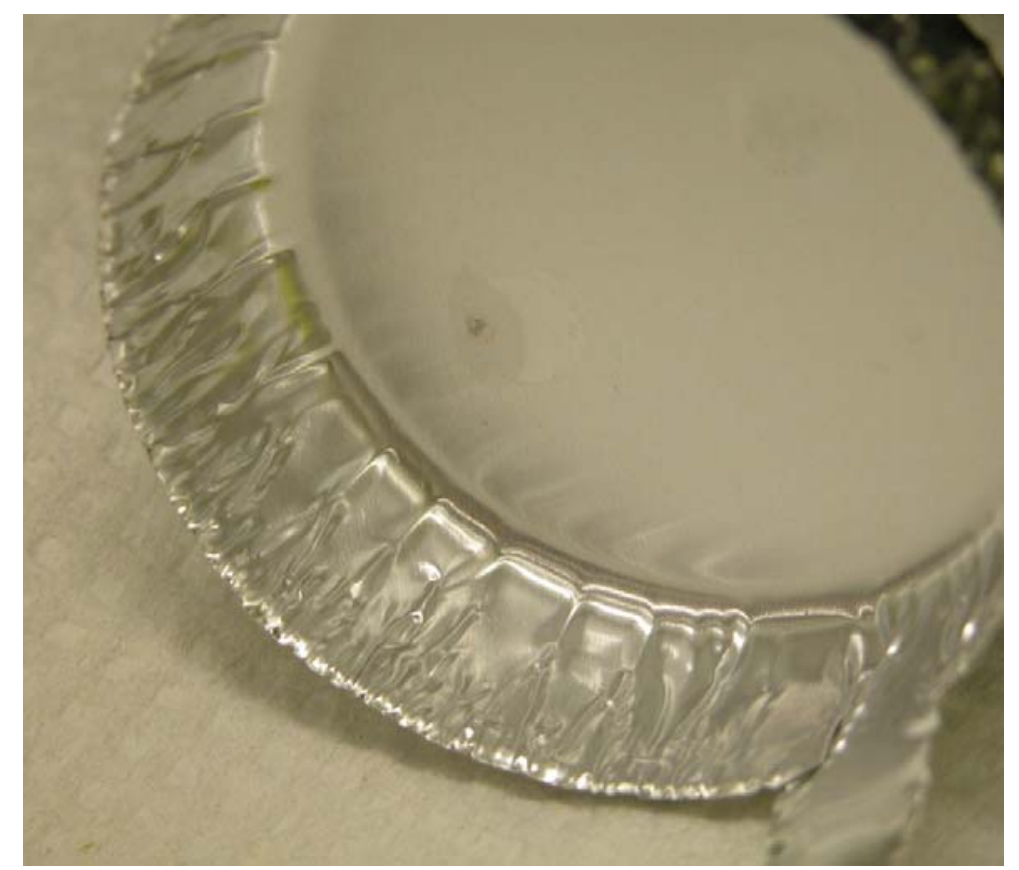

Figure 3-9. Aluminum Dish Showing Dried Residues from Methylene Chloride Rinse of DWPF Pour Stream Glass Sample S02244-F (Left) and Methylene Chloride Blank (Right) 
WSRC-TR-2005-00240

Revision 0

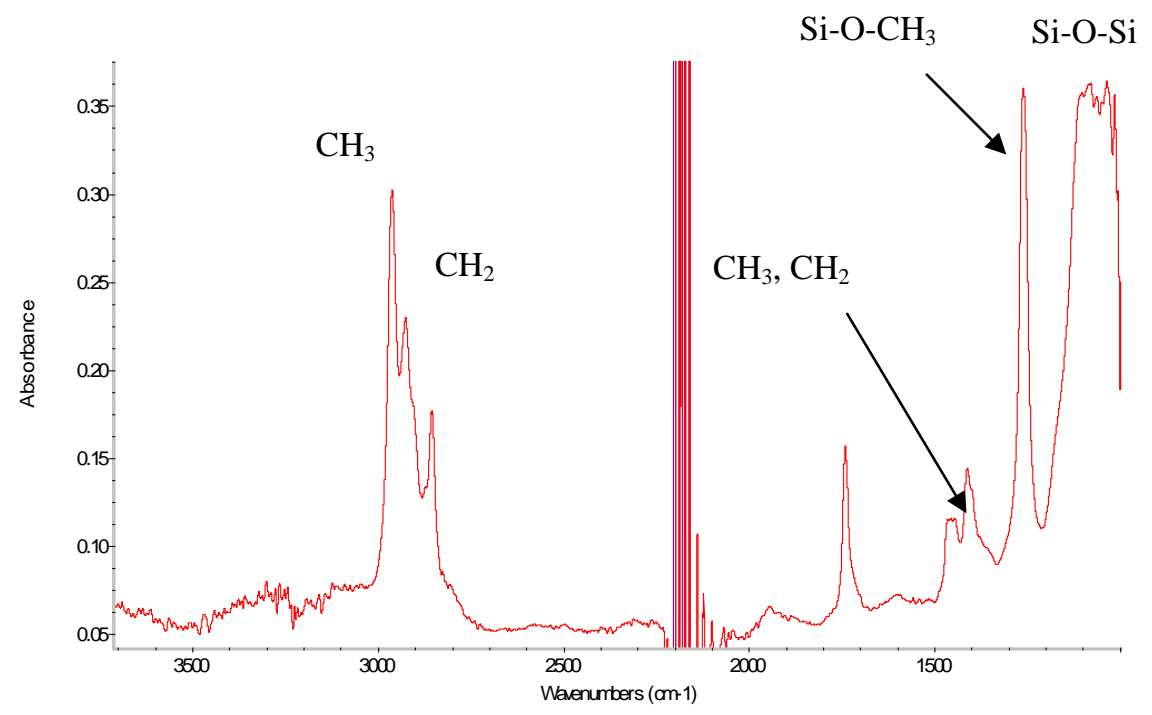

Figure 3-10. FT-IR Spectrum of Dissolved Compound from DWPF Pour Stream Glass Sample S02244-F in Methylene Chloride

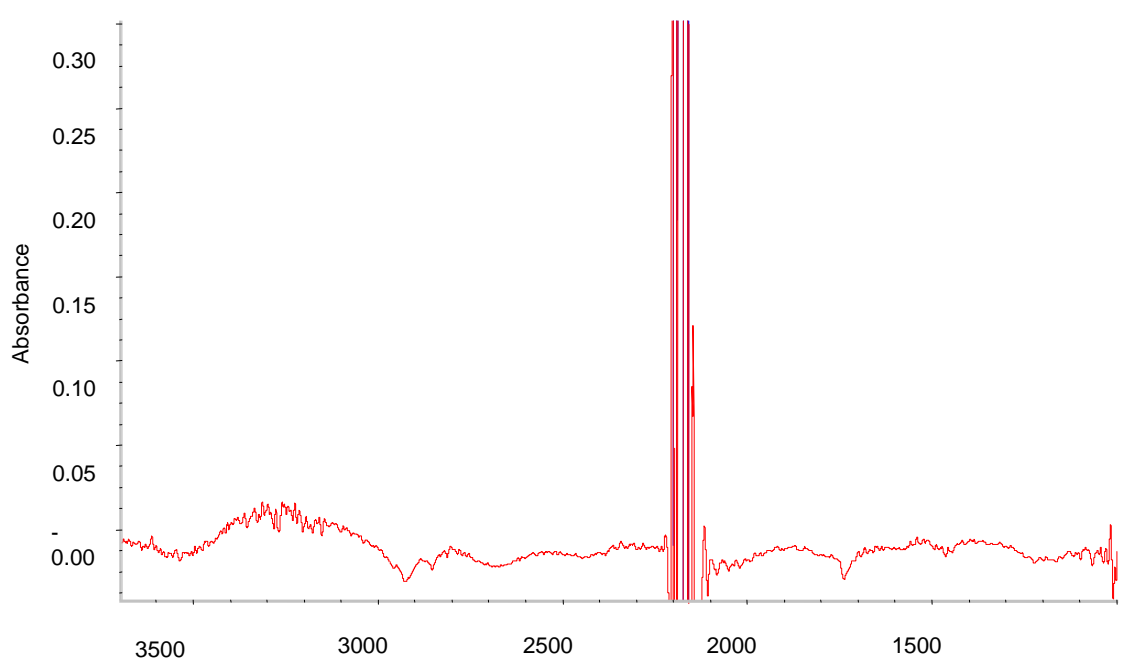

Figure 3-11. FT-IR Spectrum of Methylene Chloride Blank

The spectrum shown in Figure 3-10 indicates adsorption peaks due to an organic contaminant. Visible peaks were seen at $2960\left(\mathrm{CH}_{3}\right.$ asymmetric stretch), $2920\left(\mathrm{CH}_{2}\right.$ asymmetric stretch, $2849\left(\mathrm{CH}_{3}\right.$ symmetric stretch), 1738 ( $\mathrm{C}=\mathrm{O}$, ester carbonyl due to oxidation), 1455 ( $\mathrm{CH}_{3}$ bending), $1408\left(\mathrm{CH}_{2}\right.$ Bending), 1262 (Si-O- $\mathrm{CH}_{3}$ stretch), and 1083 \& 1031 (Si-O-Si stretch) $\mathrm{cm}^{-1}$. These adsorption peaks agree with the spectrum for the commercial silicone oil, Diacothine, and at the very least correspond to the spectrum of a silicone-based grease or lubricant. This compound lacks any hydroxyl peak in the spectrum which may help explain its hydrophobicity and the behavior of the glass when exposed to water if it is coated with this material.

\subsubsection{Scanning Electron Microscopy (SEM)}

DWPF pour stream glass samples, S02244 and S02247 were examined by SEM coupled with EDS and x-ray fluorescence spectra obtained of various spots on each submitted sample. The first pour stream glass was examined following the observed behavior in water after having been cycled through water 
and ethanol rinses (S02244-C) and then again following the methylene chloride washes (S02244-G). Selected images and x-ray spectra are given in Figure 3-12 through Figure 3-25.

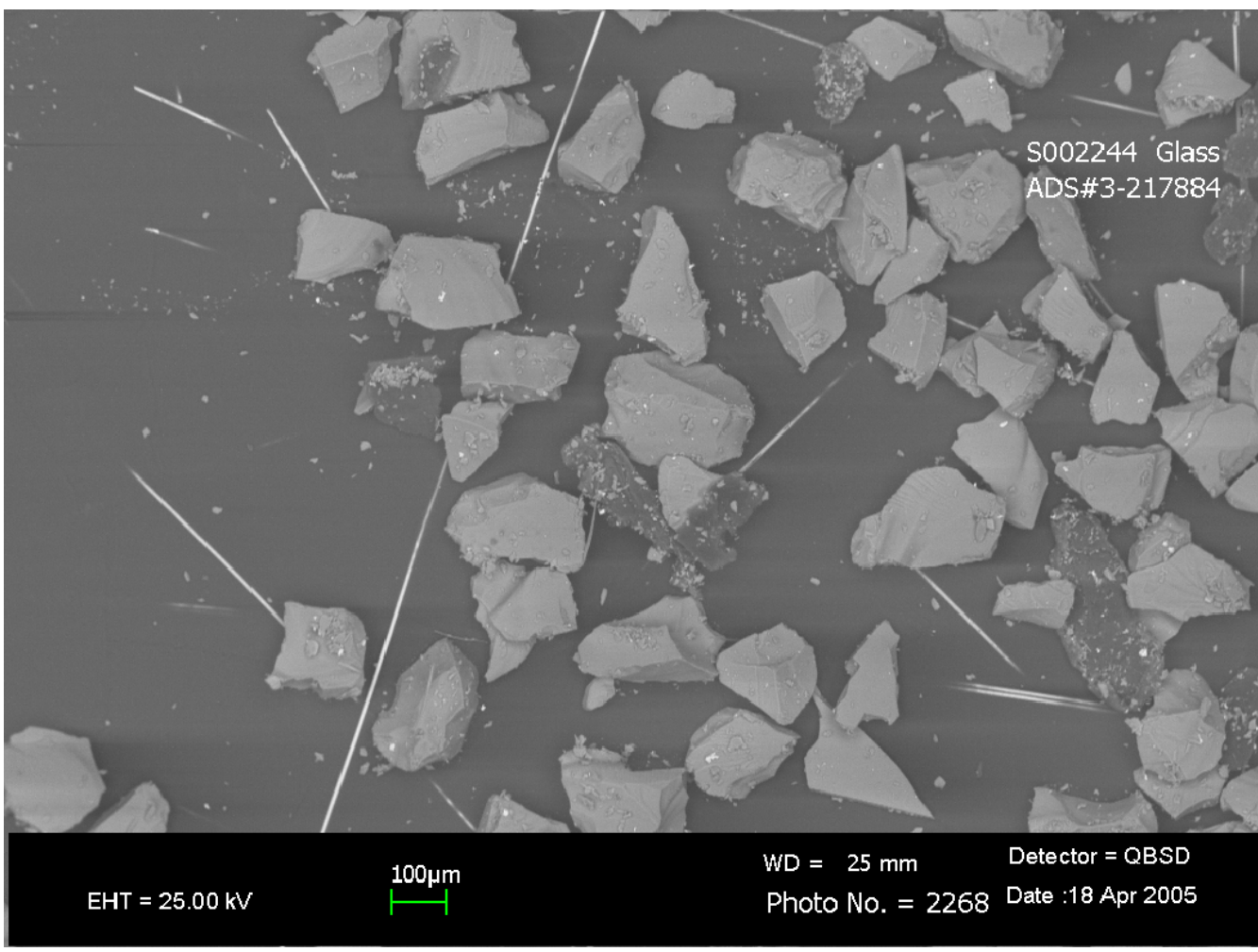

Figure 3-12. SEM Image of DWPF Pour Stream Glass S02244-C (QBS Detector) at 50X

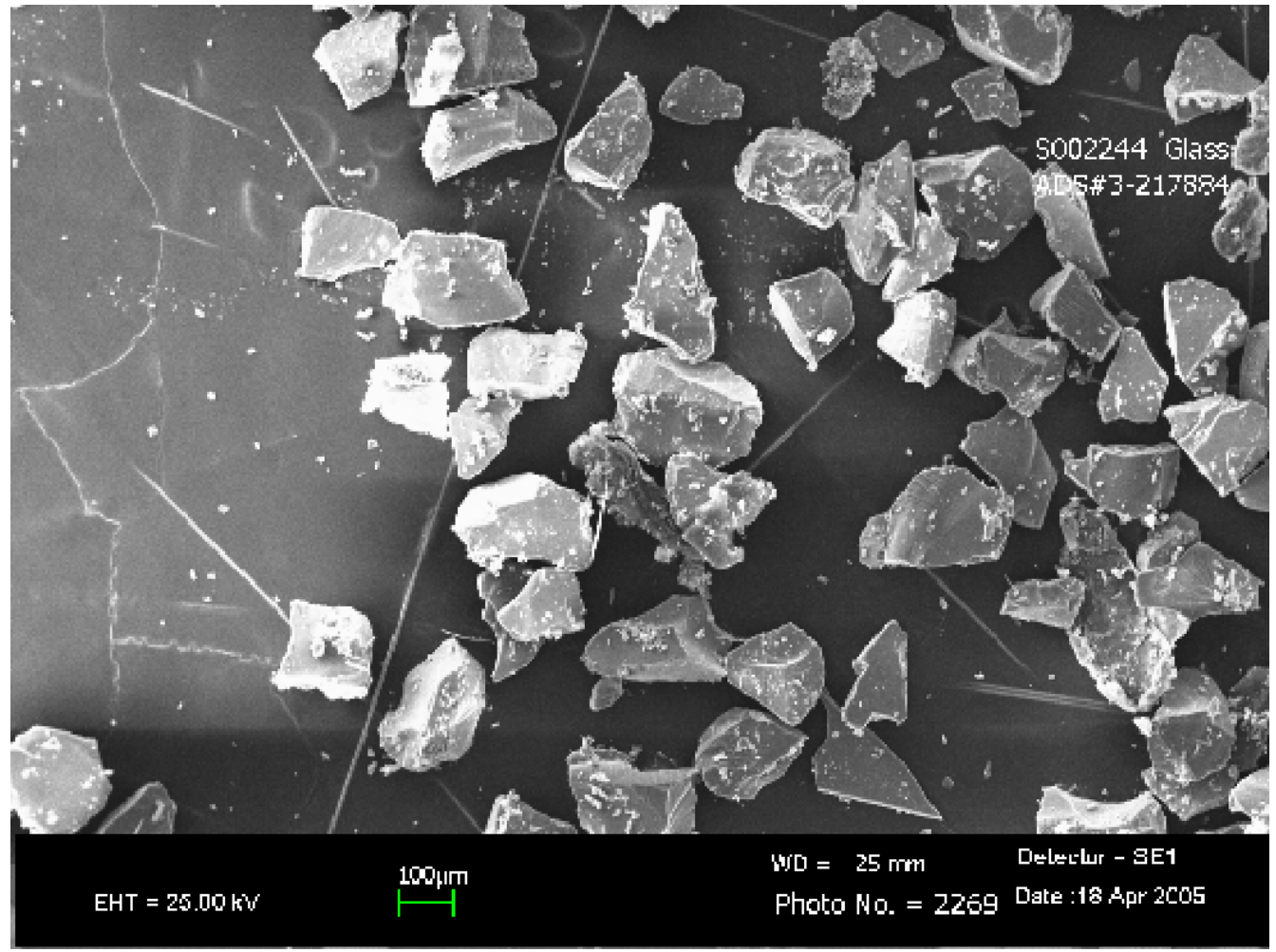

Figure 3-13. SEM Image of DWPF Pour Stream Glass S02244-C (SE1 Detector) at 50X 
The images in Figure 3-12 and Figure 3-13 show a number of fine glass particles and this was characteristic of all the images of the first pour stream glass due to the inability to successfully wash the glass with water per the PCT procedure ${ }^{1}$. Another significant feature is the "dark" and "light" particles which appear in the image taken with the QBS detector as compared to the SE1 detector image. The lighter the backscattered electron image (from the QSB detector) the denser the material and, correspondingly, generally the heavier the elemental composition of the material being imaged. Conversely, the darker the backscattered electron image, the less dense and lighter the elemental composition. For the remainder of this report, only the QBS detector images will be presented since they provide more distinctive images and better contrast for particles of different composition.

Several x-ray fluorescence spectra were taken of various spot locations on the sample. Figure 3-14 shows the first five spectral locations examined for sample S02244-C. The spectra obtained appear in Figure 3-15 through Figure 3-19.

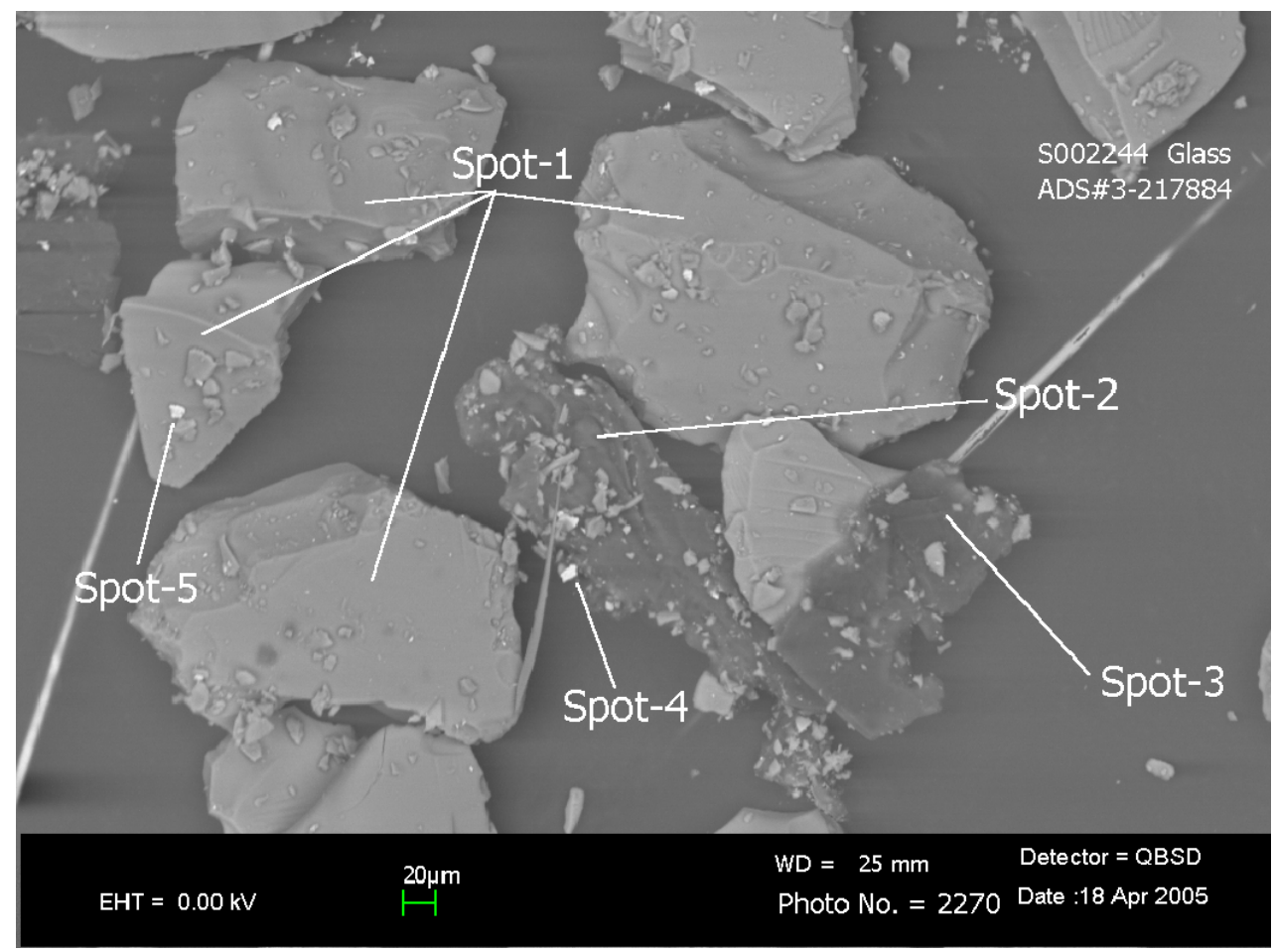

Figure 3-14. SEM Image of DWPF Pour Stream Glass S02244-C (QBS Detector) at 150X 
WSRC-TR-2005-00240

Revision 0

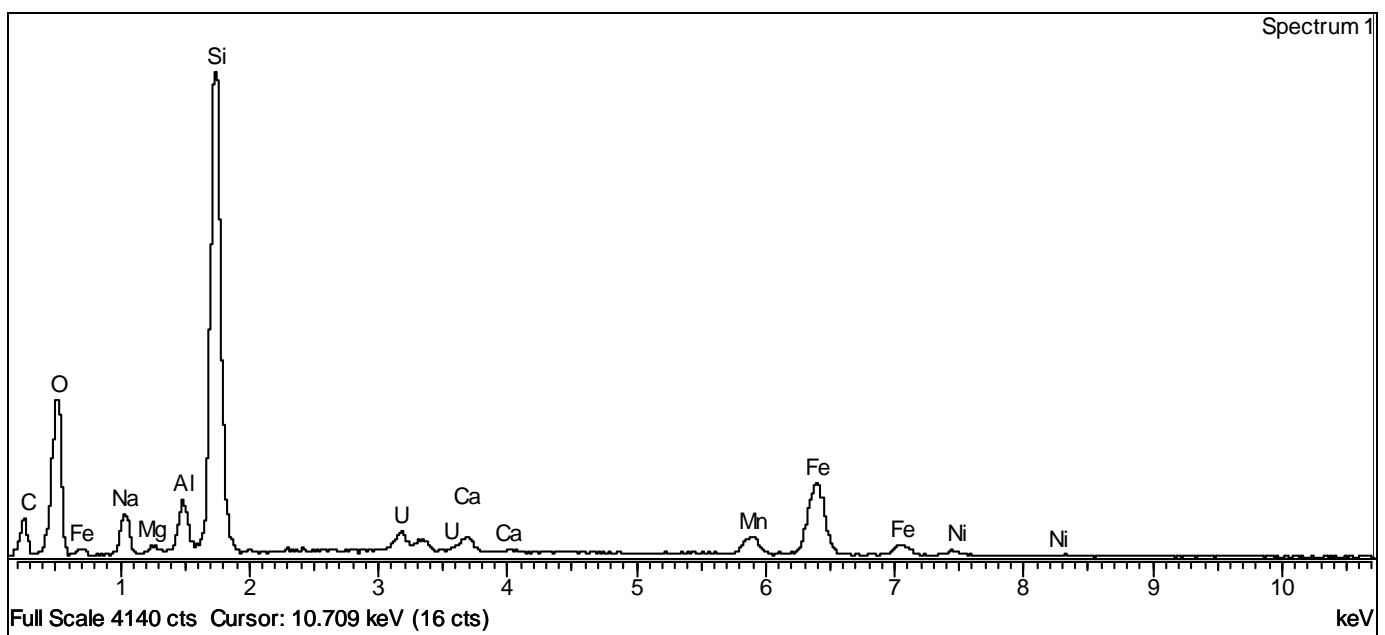

Figure 3-15. X-Ray Fluorescence Spectrum of Spot 1 in Figure 3-14 for DWPF Pour Stream Glass Sample S02244-C

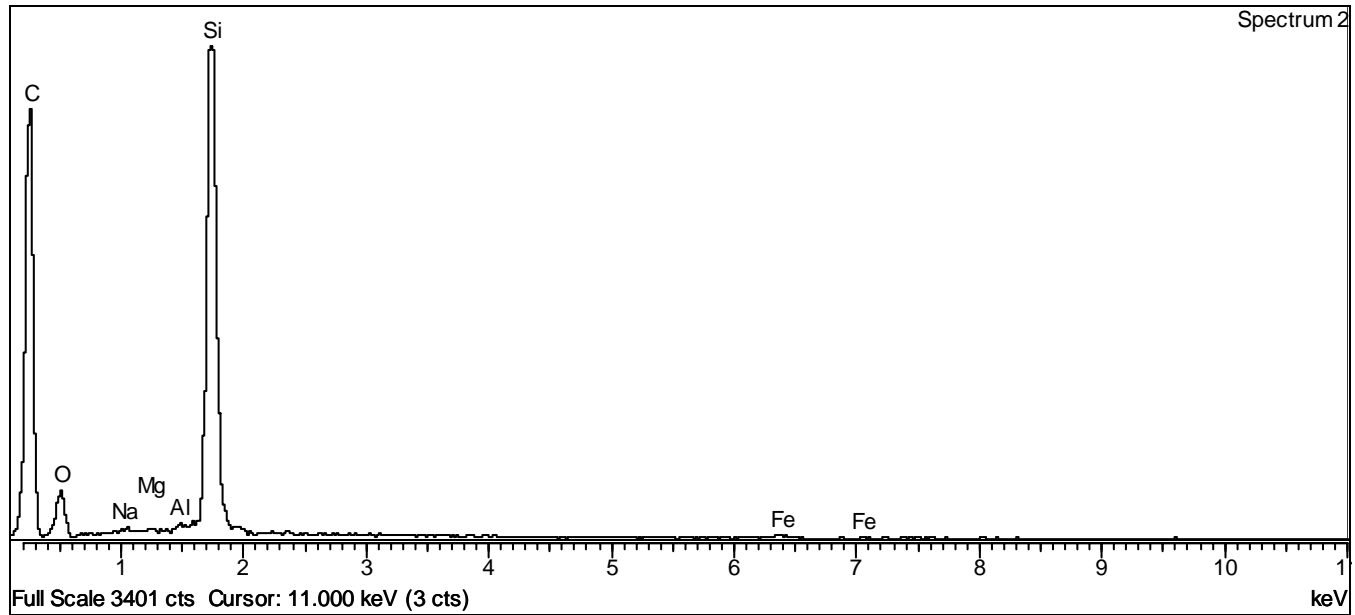

Figure 3-16. X-Ray Fluorescence Spectrum of Spot 2 in Figure 3-14 for DWPF Pour Stream Glass Sample S02244-C

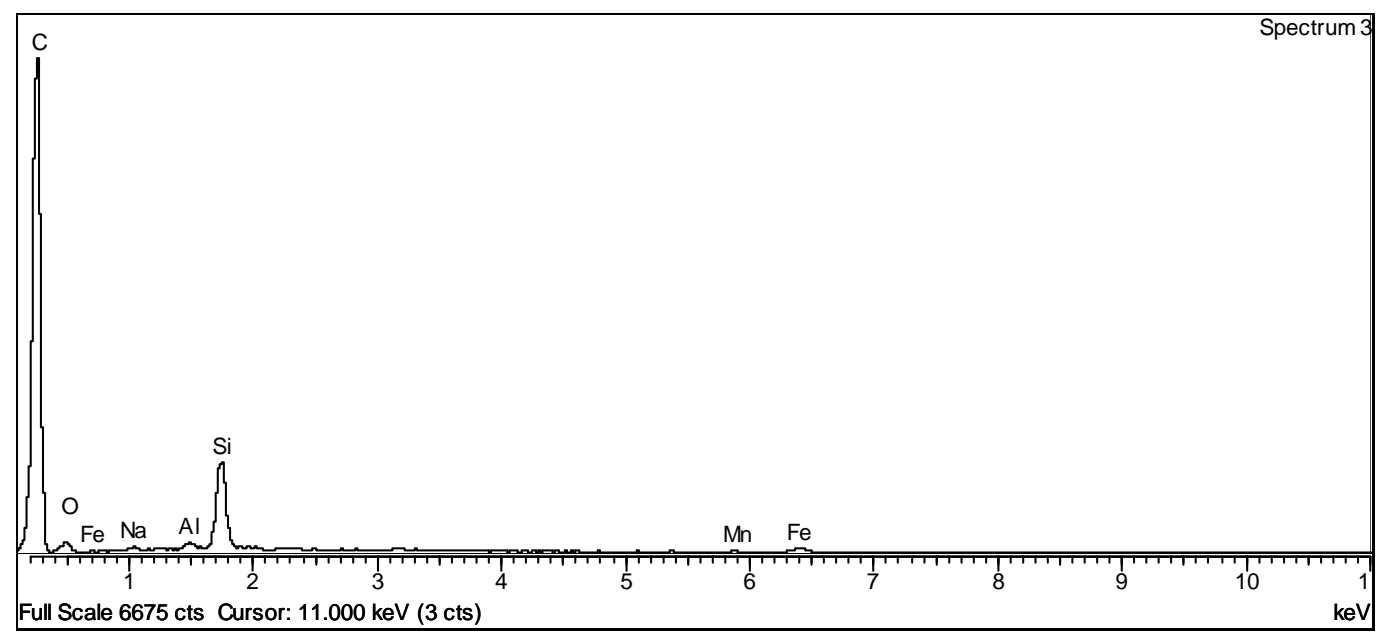

Figure 3-17. X-Ray Fluorescence Spectrum of Spot 3 in Figure 3-14 for DWPF Pour Stream Glass Sample S02244-C 


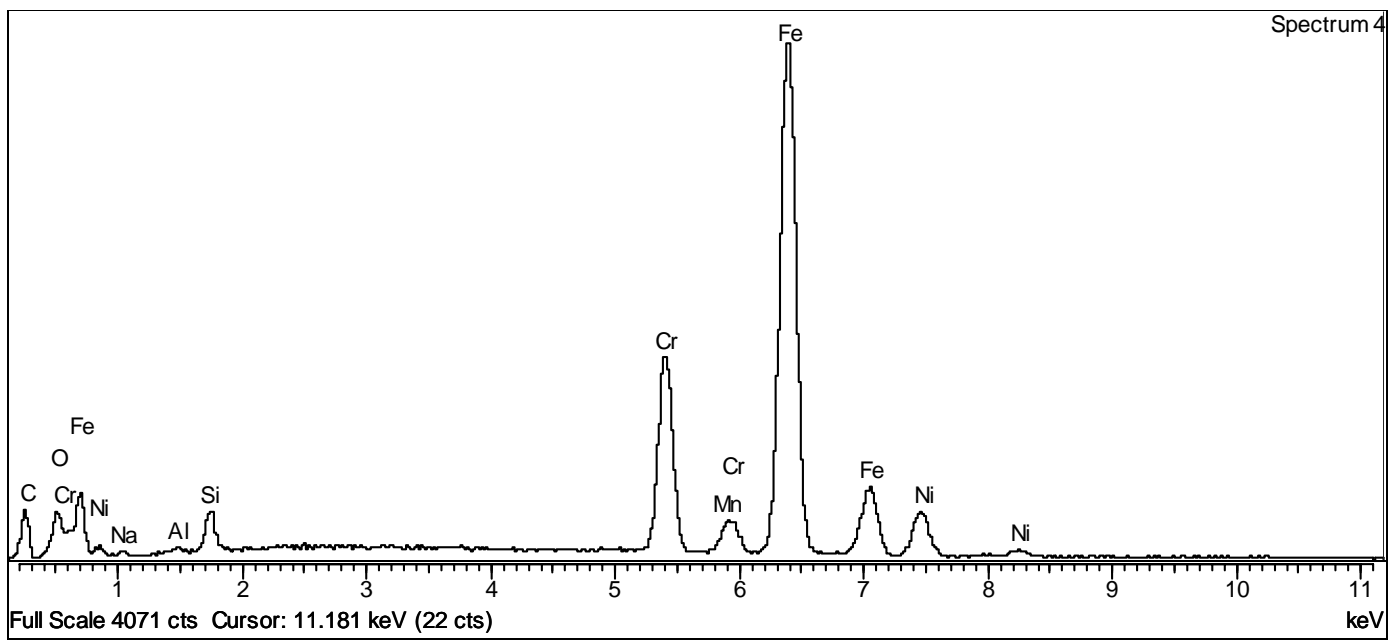

Figure 3-18. X-Ray Fluorescence Spectrum of Spot 4 in Figure 3-14 for DWPF Pour Stream Glass Sample S02244-C

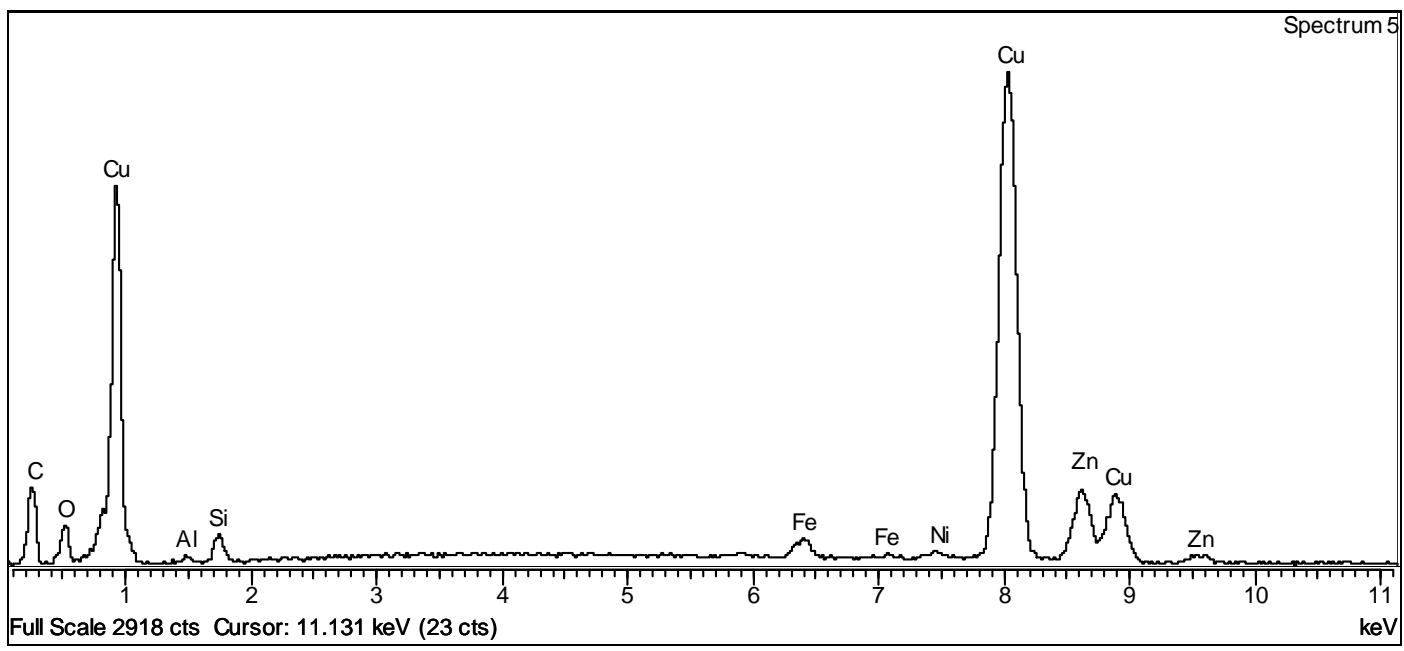

Figure 3-19. X-Ray Fluorescence Spectrum of Spot 5 in Figure 3-14 for DWPF Pour Stream Glass Sample S02244-C

The spectrum for Spot 1 (Figure 3-15) is characteristic for DWPF glass, and one can clearly see the major elements, $\mathrm{Si}, \mathrm{O}, \mathrm{Fe}, \mathrm{Al}, \mathrm{Na}, \mathrm{Mn}$, and $\mathrm{U}$. Note, glass components $\mathrm{Li}$ and $\mathrm{B}$ are too light to be detected by this method. Spot 2 (Figure 3-16), and to a lesser extent Spot 3 (Figure 3-17), correspond to a non-glass component that contains $\mathrm{C}$ and to a lesser extent Si. The other elements present in the spectrum are likely a result of $\mathrm{x}$-ray scattering from the coating of fine particles present on each of the larger particles in Figure 3-14. It is believed that this carbon compound is due to neither the coating process nor another layer of material on the surface because the electron beam would easily penetrate a coating and give the spectrum of the underlying material.

Other contaminants identified in the sample included stainless steel from the Tekmar mill bowl (Spot 4, spectrum in Figure 3-18) and brass from the sieves (Spot 5, spectrum in Figure 3-19). These are routinely seen in SEM images and x-ray fluorescence spectra of glass that has been ground with a Tekmar mill. 
Comparative images and spectra were taken of the first pour stream glass sample following methylene chloride washing - which was shown in Section 3.3.3 to solubilize a silicone-based lubricant from the glass sample. These images are shown in Figure 3-20 and Figure 3-21. The black particles are distributed throughout the sample, much as they were in S02244-C. The glass and unknown, black particles are distinctly cleaner than in the previous images, indicating that the methylene chloride wash was successful in removing some of the fine glass particles from the sample. The methylene chloride wash has reduced the signal due to $\mathrm{Si}$ in these images, likely through a reduction of the grease coating. The x-ray fluorescence spectra were taken at two beam energies to vary the depth to which the electron beam penetrates the sample. As can be seen by comparing the spectra for the spot pairs 1 \& 5 (Figure 3-22 and Figure 3-23) and 3 \& 4 (Figure 3-24 and Figure 3-25), there is little difference with a change in beam energy. Spot 1 (and 5) is clearly glass and Spot 3 (and 4) is clearly another material comprised largely of carbon. If it were just a coating, the elements in the glass would be more evident in the spectra obtained with the higher beam energy since it penetrates further into the sample.

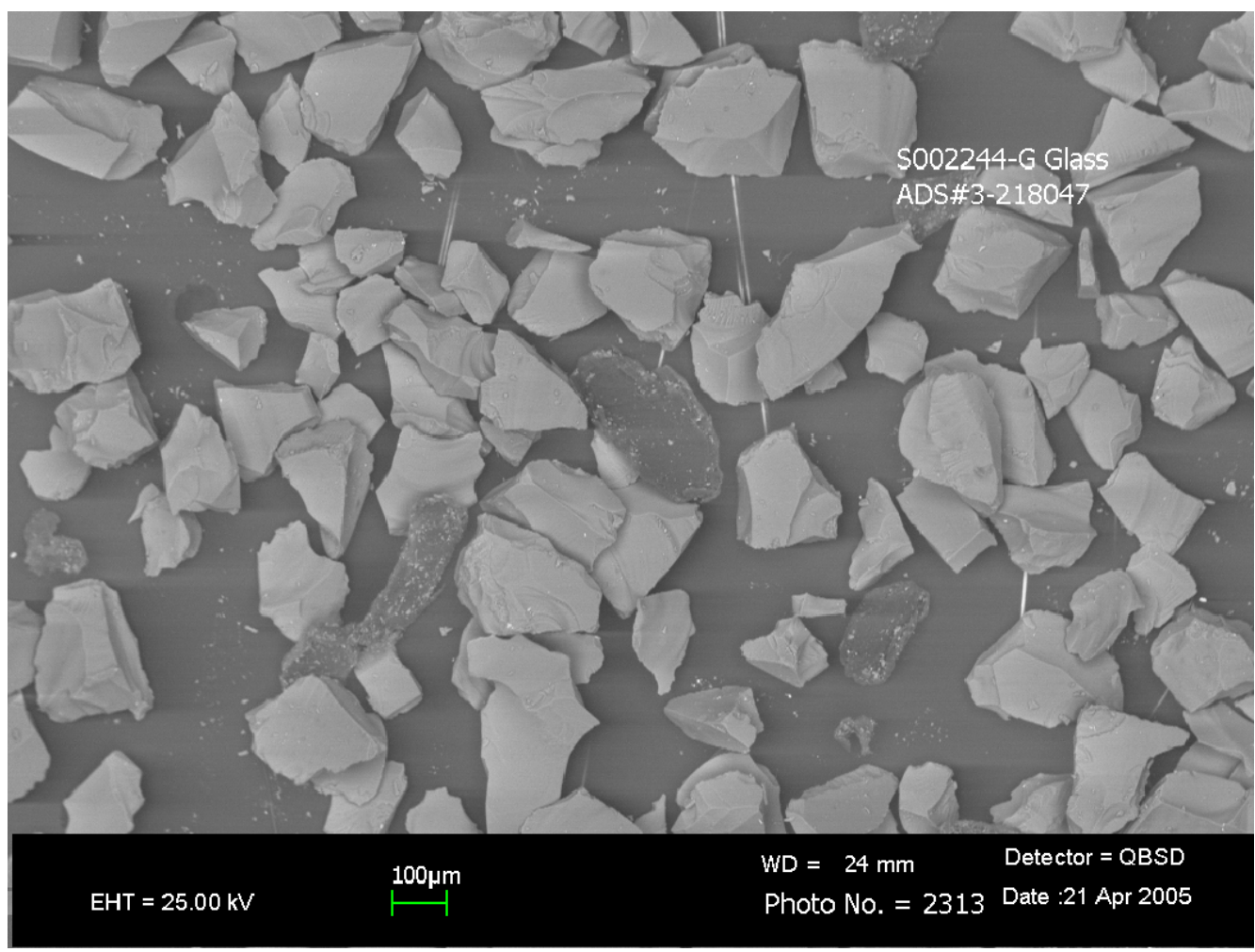

Figure 3-20. SEM Image of DWPF Pour Stream Glass S02244-G (QBS Detector) at 50X 


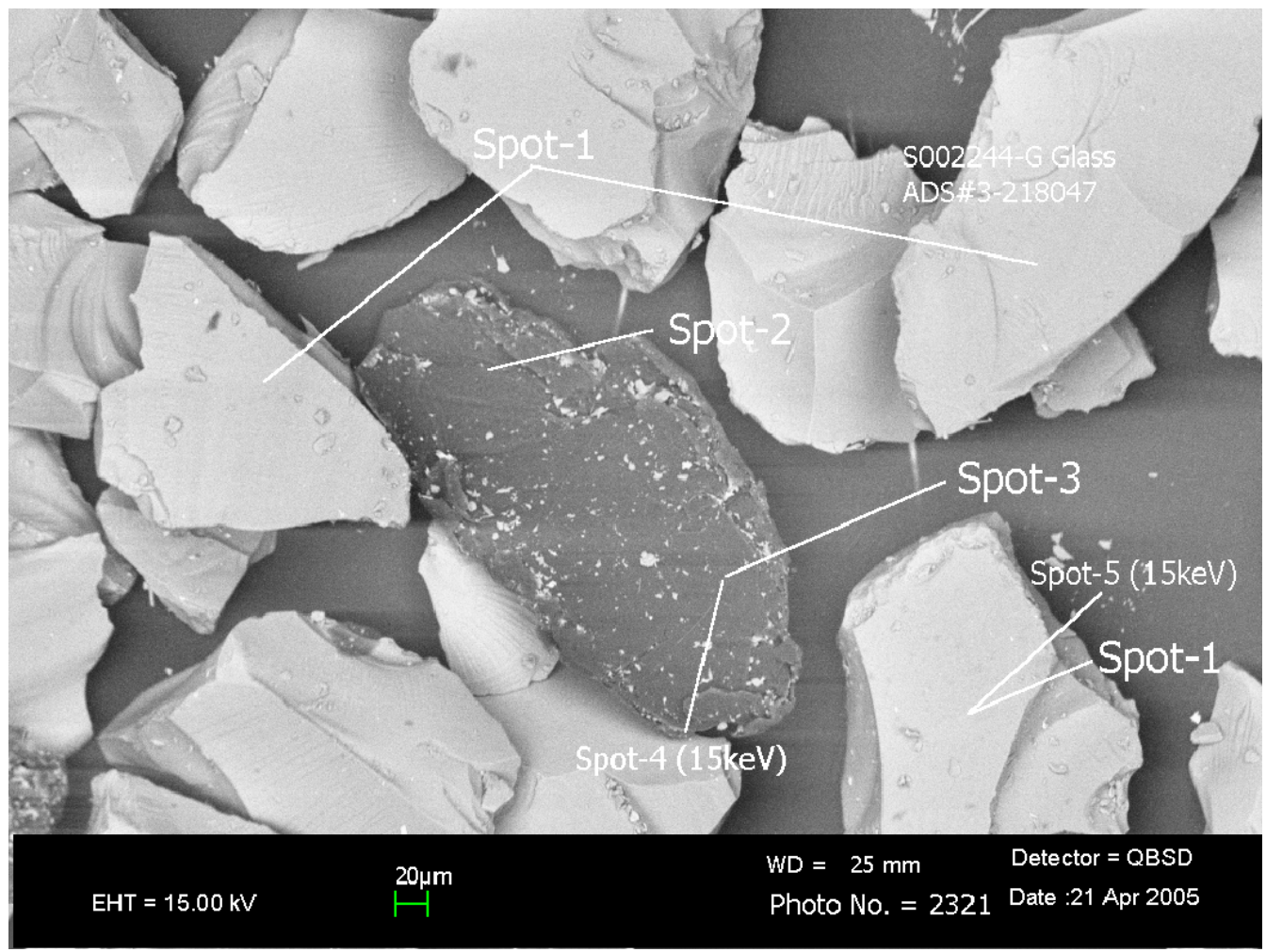

Figure 3-21. SEM Image of DWPF Pour Stream Glass S02244-G (QBS Detector) at 150X

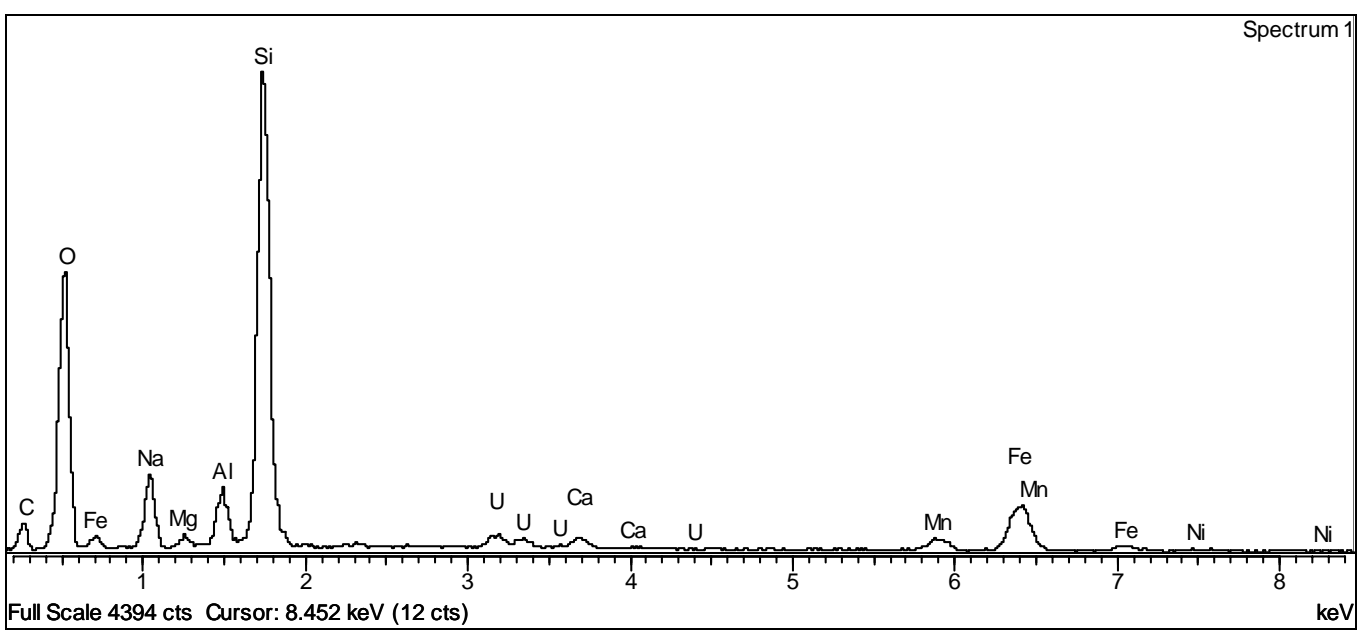

Figure 3-22. X-Ray Fluorescence Spectrum of Spot 1 in Figure 3-21 at $25 \mathrm{keV}$ Beam Energy for DWPF Pour Stream Glass Sample S02244-G 
WSRC-TR-2005-00240

Revision 0

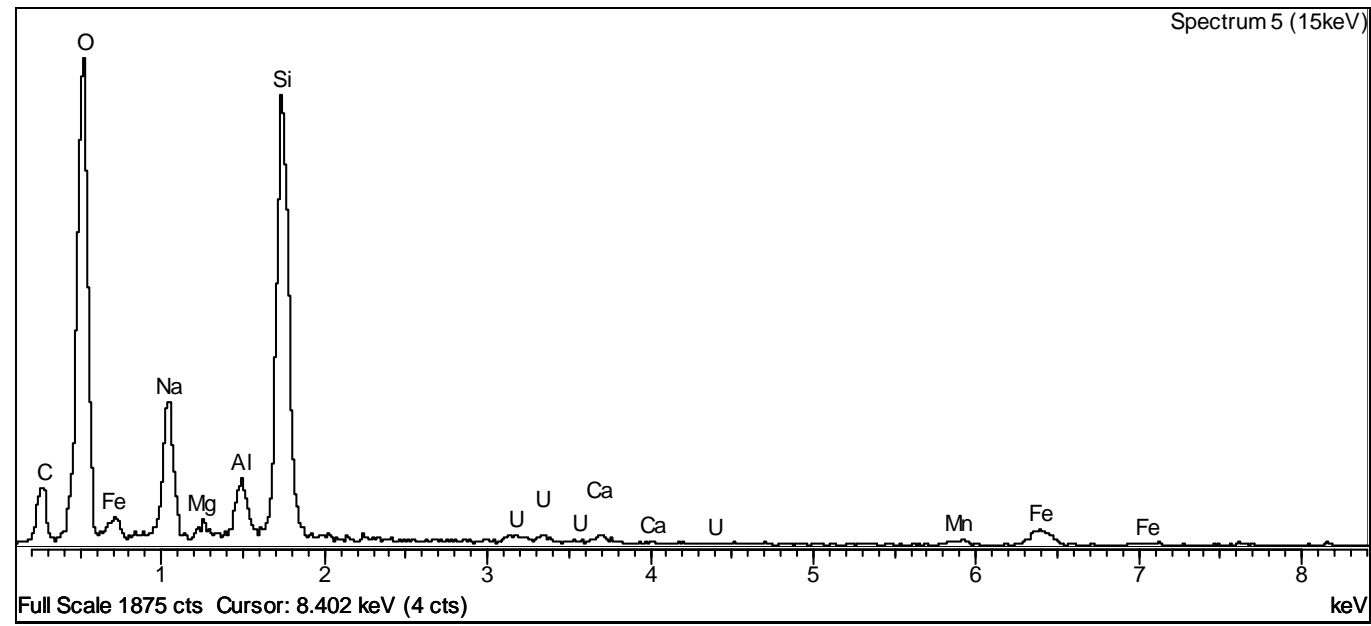

Figure 3-23. X-Ray Fluorescence Spectrum of Spot 5 in Figure 3-21 at $15 \mathrm{keV}$ Beam Energy for DWPF Pour Stream Glass Sample S02244-G

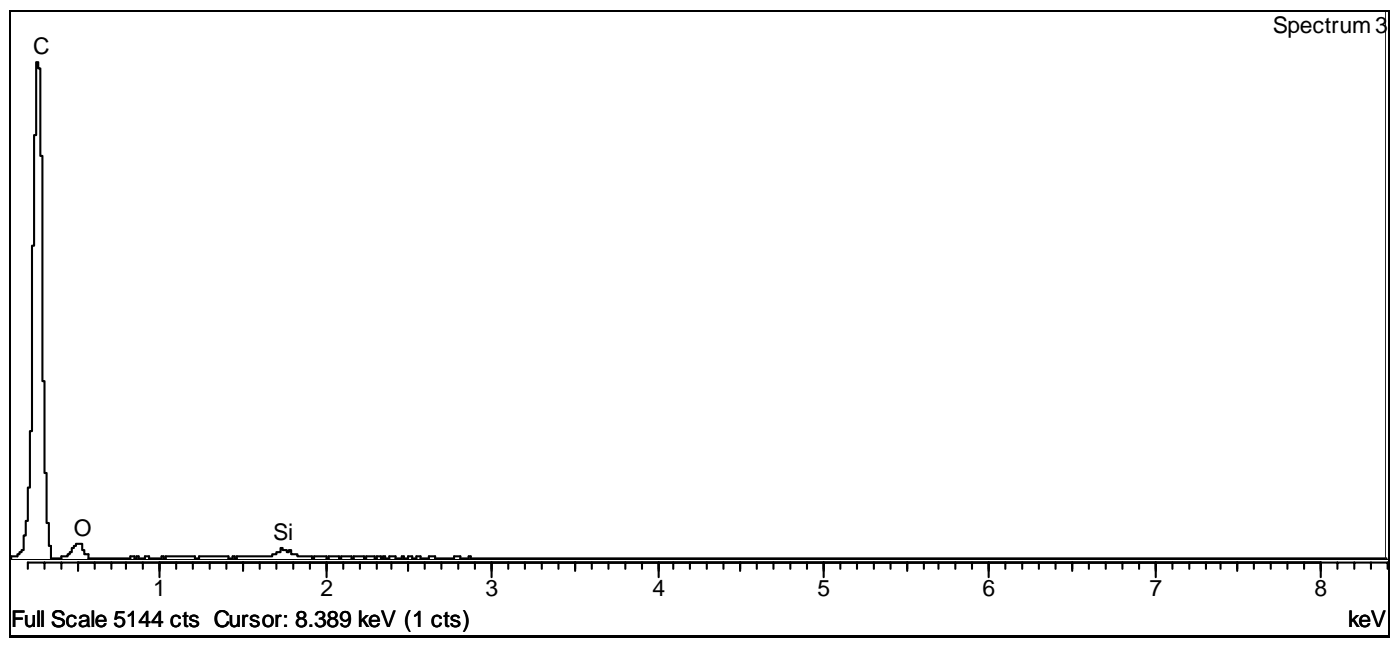

Figure 3-24. X-Ray Fluorescence Spectrum of Spot 3 in Figure 3-21 at $25 \mathrm{keV}$ Beam Energy for DWPF Pour Stream Glass Sample S02244-G

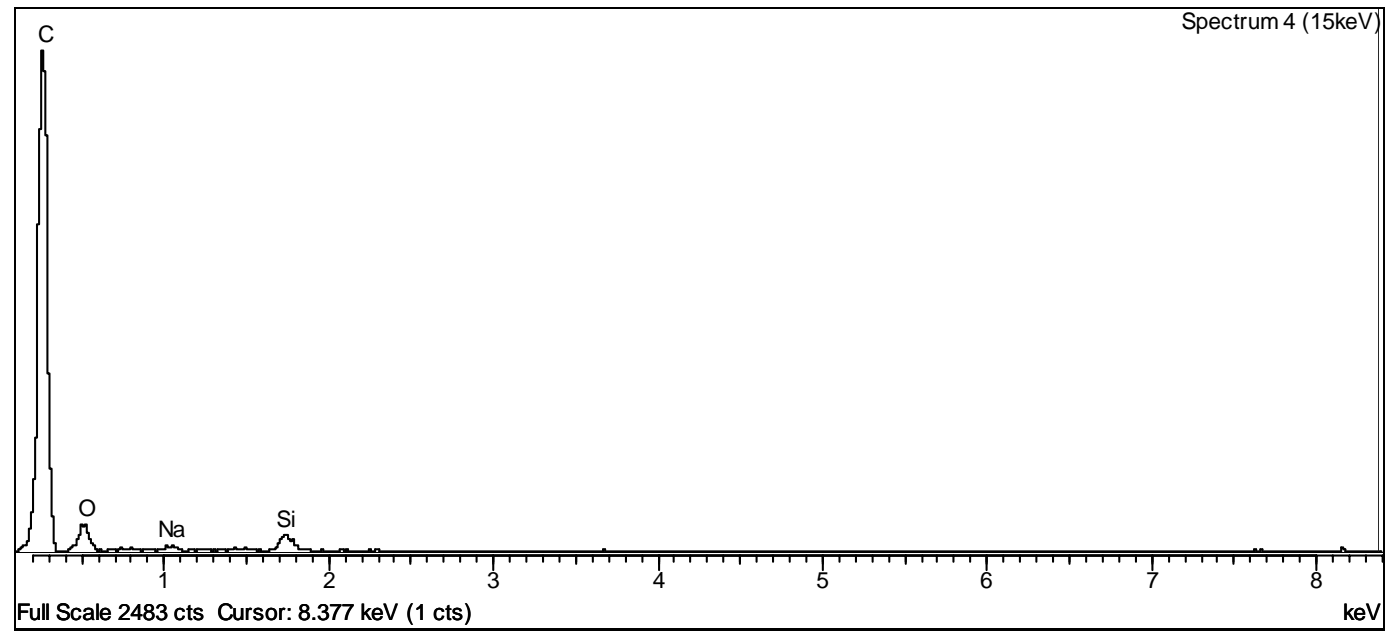

Figure 3-25. X-Ray Fluorescence Spectrum of Spot 4 in Figure 3-21 at $15 \mathrm{keV}$ Beam Energy for DWPF Pour Stream Glass Sample S02244-G 
When the second DWPF pour stream glass sample (S02247-E) was examined by SEM there were clearly no dark particles in the QBS detector images and no carbon-based spectra obtained by x-ray fluorescence. Images for the second glass are shown in Figure 3-26 and Figure 3-27 and a characteristic spectrum for the glass particles in Figure 3-28. Since the glass could be successfully washed in deionized water, it is much cleaner, i.e. free of fines.

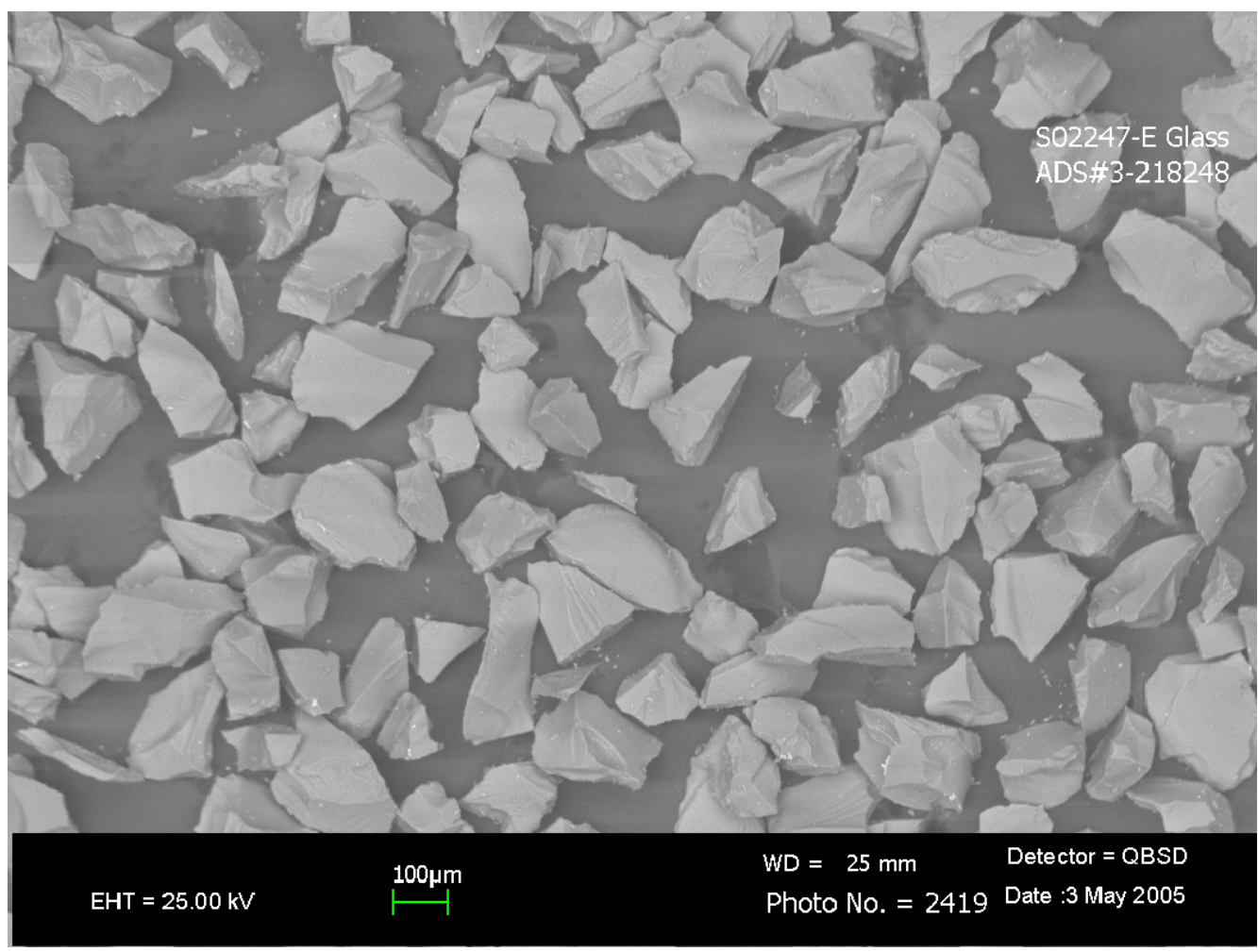

Figure 3-26. SEM Image of DWPF Pour Stream Glass S02247-E (QBS Detector) at 50X 


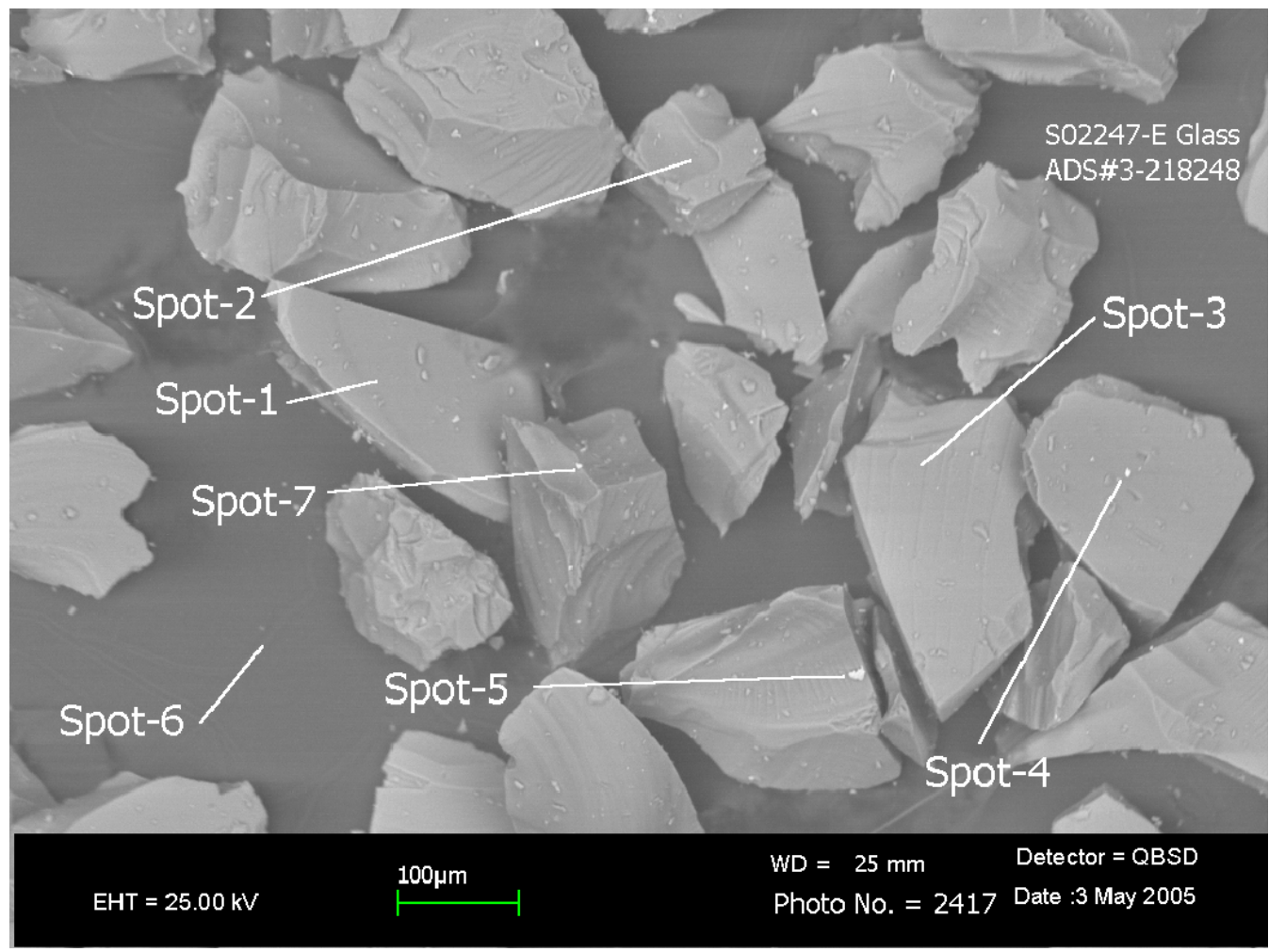

Figure 3-27. SEM Image of DWPF Pour Stream Glass S02247-E (QBS Detector) at 110X

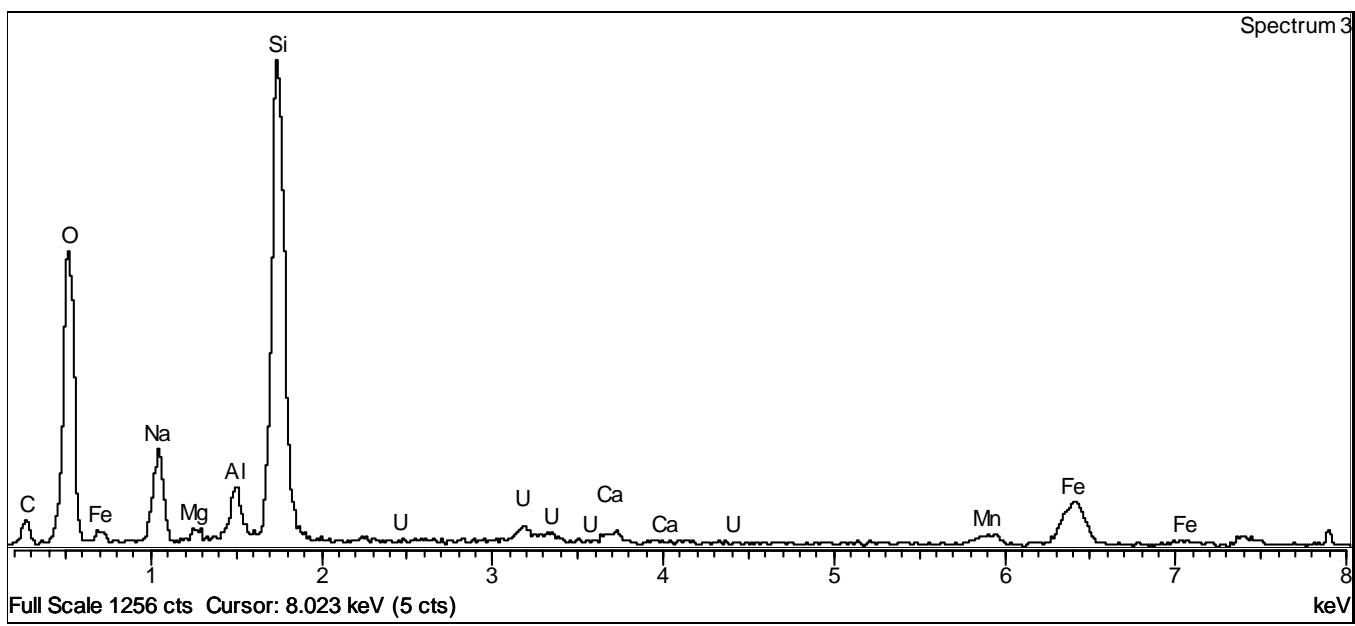

Figure 3-28. Characteristic X-Ray Fluorescence Spectrum for Spots 1-3 in Figure 3-27 for DWPF Pour Stream Glass Sample S02247-E

The few fine particles present in the SEM image are due to various contaminates: Spot 4 - solder, Spot 5 - brass, and Spot 7 - stainless steel. Spot 6 was for a spectrum taken of the adhesive backing material of the mount.

The images and spectra for S02244-C and -G were compared with those obtained for a sample of anthracite coal (same material evaluated during the SB3 qualification studies). Anthracite coal is believed to have been in Tank $7^{7}$. The SEM image shown in Figure 3-29 clearly shows that the coal sample was contaminated with glass (large light particles in the image), stainless steel (small light 
particles in the image), and glass/frit. The source of the stainless steel contamination is likely due to Tekmar milling and sieving with equipment previously used on glass. The x-ray fluorescence spectrum of the predominant, dark, coal particles is given in Figure 3-30. This spectrum is similar to that seen in Figure 3-24 from DWPF glass S02244.

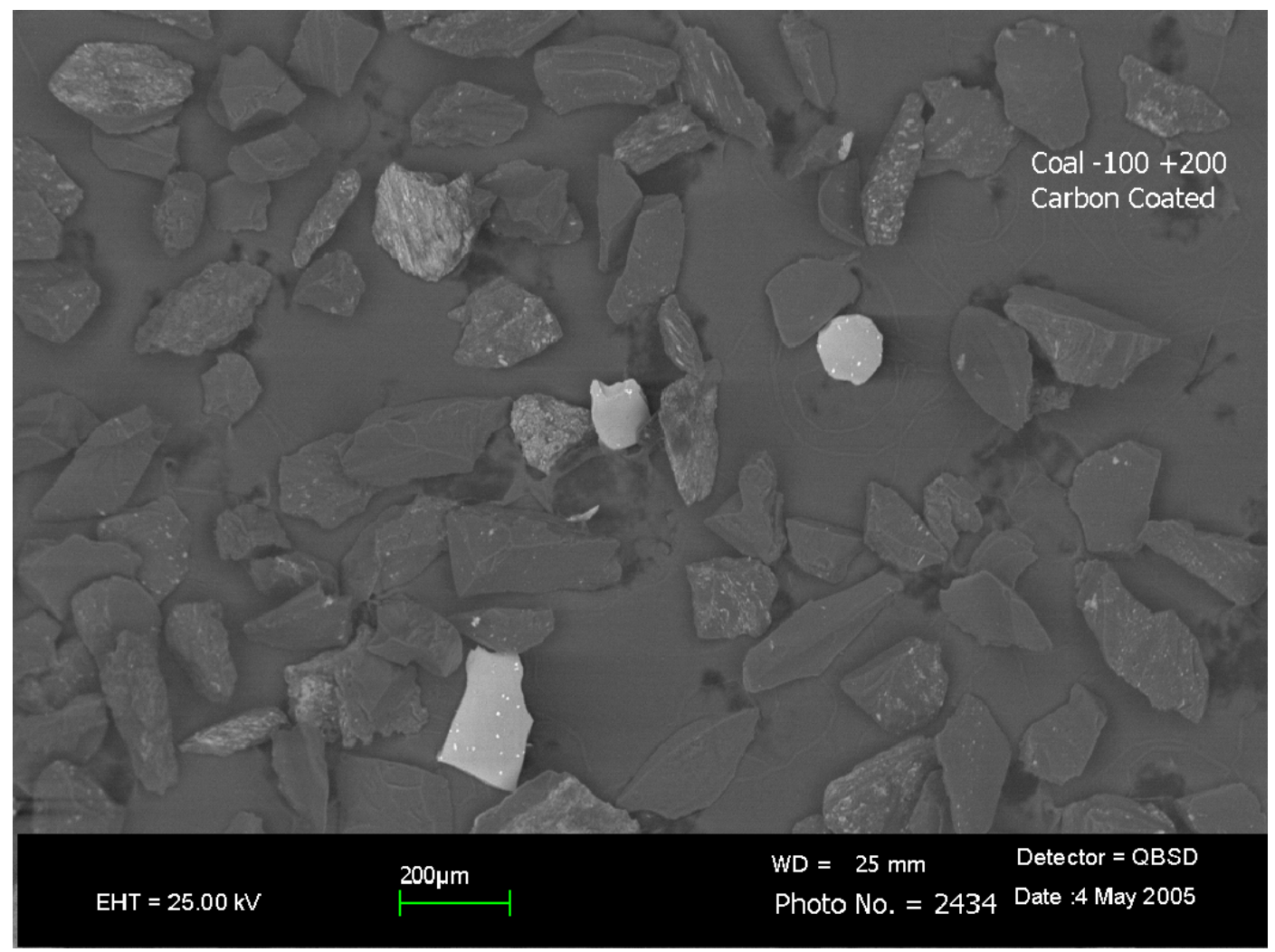

Figure 3-29. SEM Image of Anthracite Coal (QBS Detector) at 50X

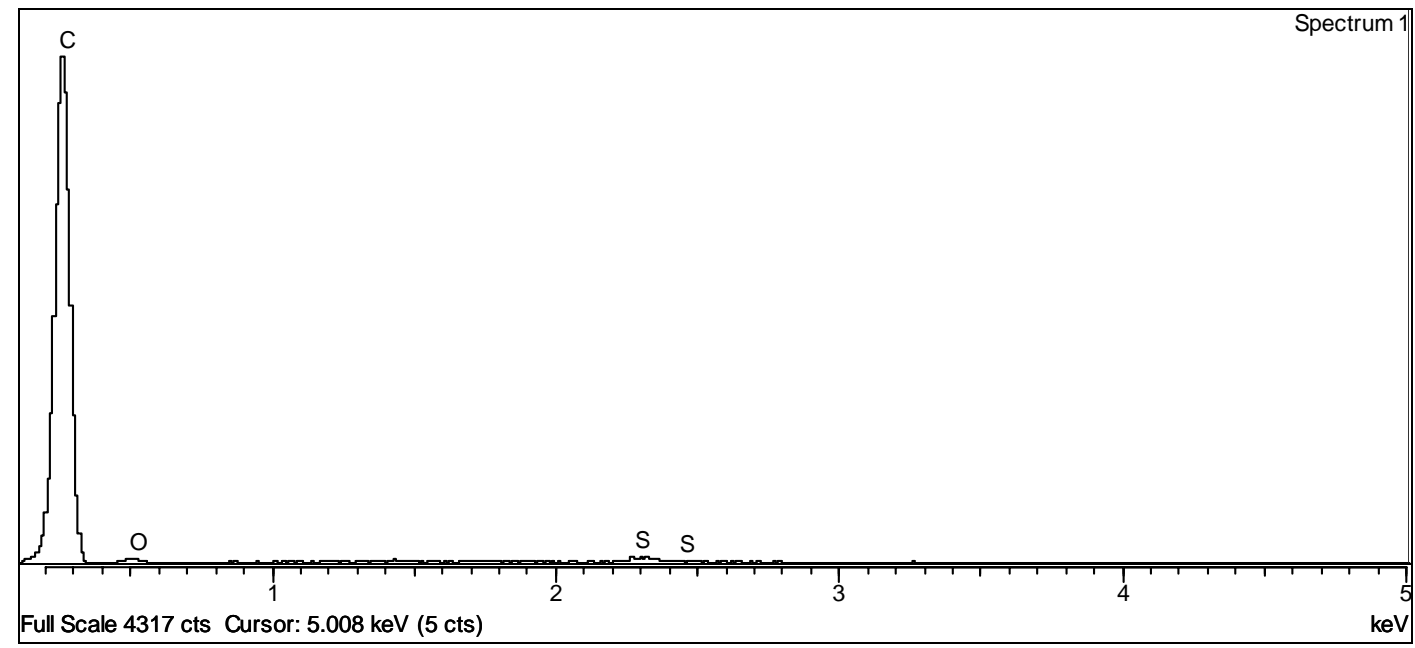

Figure 3-30. X-Ray Fluorescence Spectrum of Anthracite Coal Particles in Figure 3-29

While the images and x-ray fluorescence data support the interpretation that there are two distinct types of particles in the first DWPF pour stream glass sample, they do not tell enough about the identity of the non-glass particles. For additional data, samples of both the first and second DWPF pour stream glasses 
were submitted for thermal gravimetric analysis with mass spectrometry (TGA-MS) identification of the volatile products.

\subsubsection{Thermal Gravimetric Analysis with Mass Spectrometry (TGA-MS)}

TGA-MS data for the first DWPF pour stream glass sample are shown in Figure 3-31 and Figure 3-32.

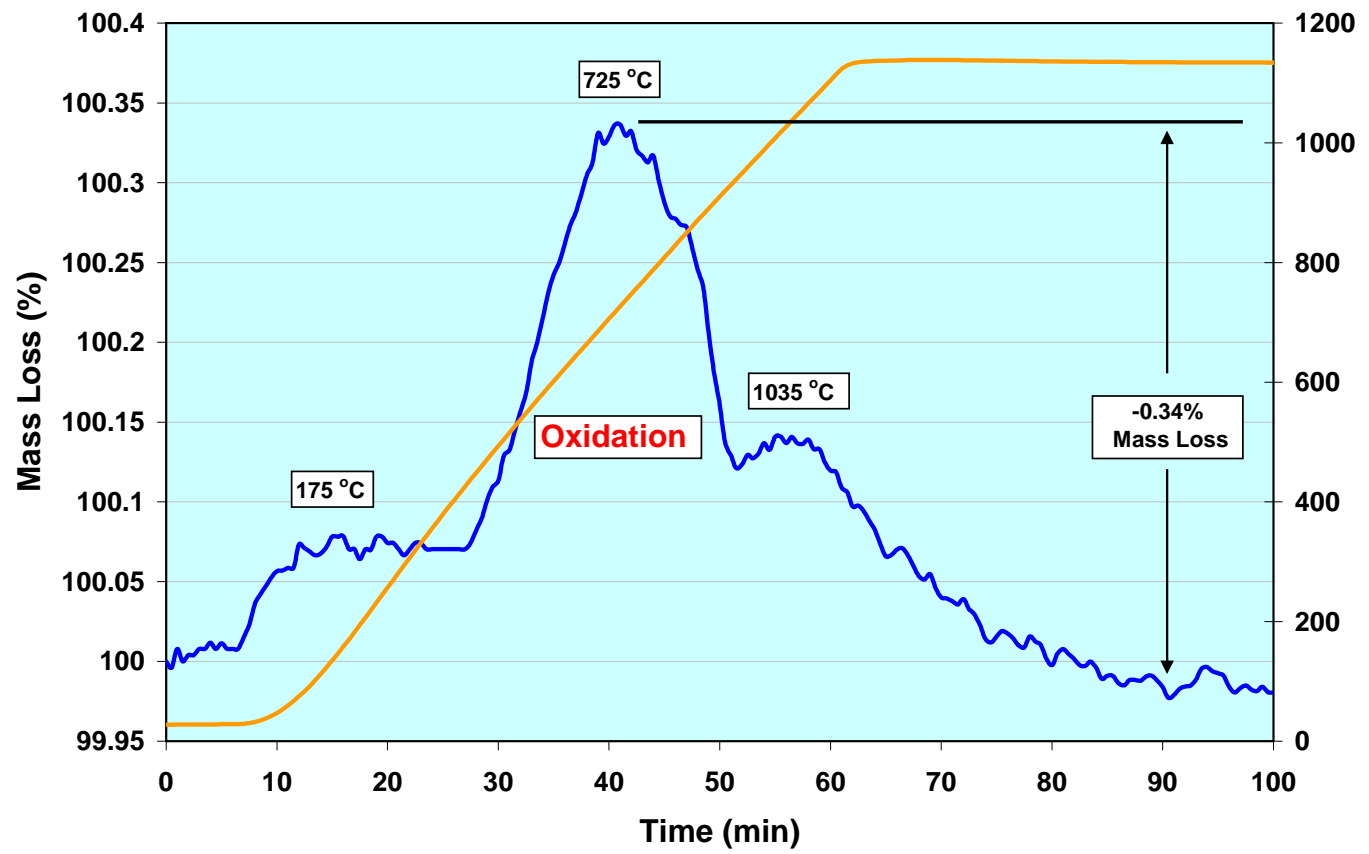

Figure 3-31. TGA-MS Mass Loss vs. Time for DWPF Pour Stream Glass S02244-G

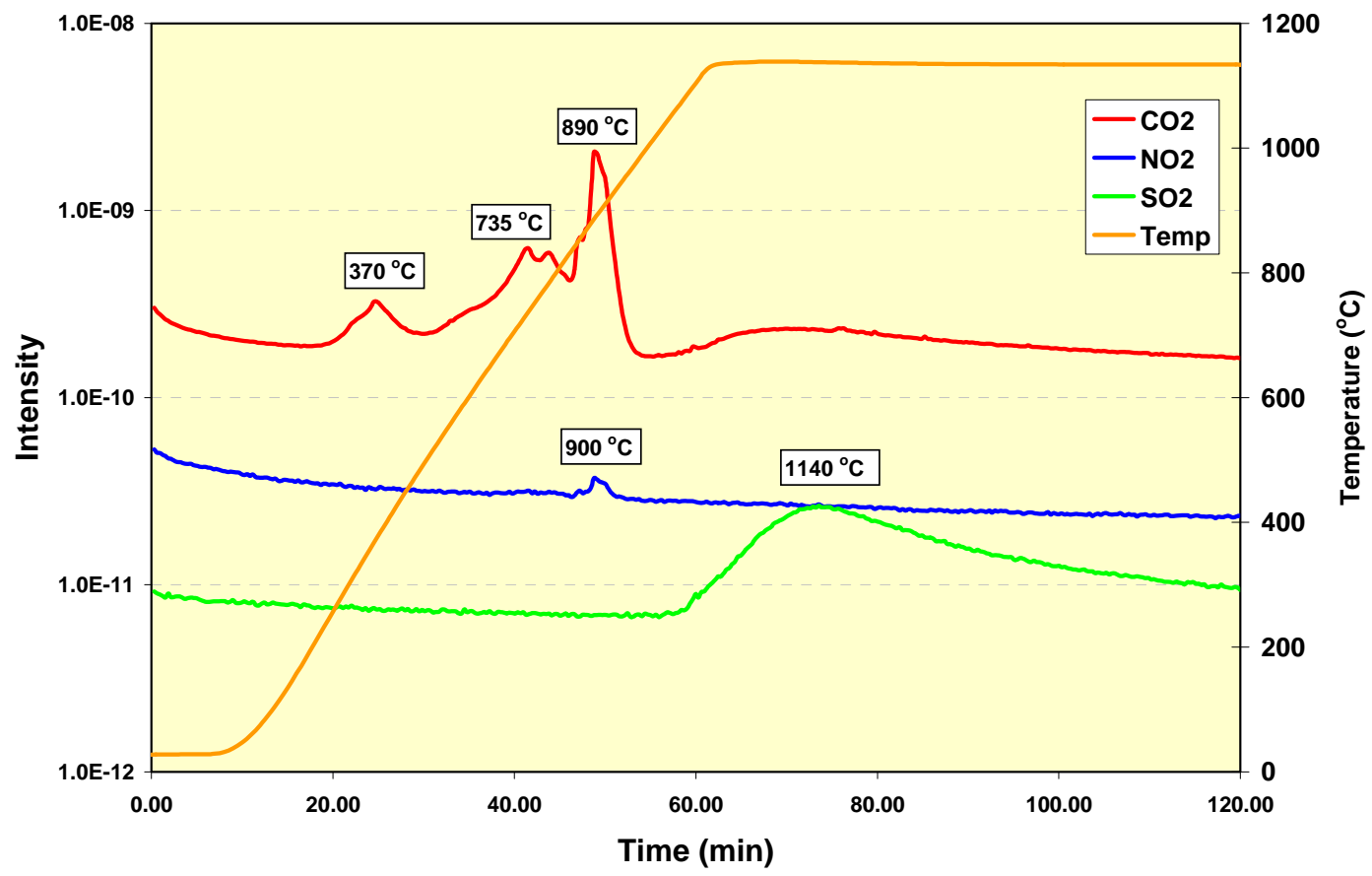

Figure 3-32. TGA-MS Species vs. Time for DWPF Pour Stream Glass S02244-G 
The rise in mass over time is due to oxidation of glass constituents such as $\mathrm{Fe}(\mathrm{II}), \mathrm{Mn}(\mathrm{II})$, and possibly $\mathrm{U}(\mathrm{IV})$ and the concurrent uptake of molecular oxygen. The overall weight loss is small, approximately $0.34 \%$. Volatile species identified during degradation of the sample included $\mathrm{CO}_{2}$ peaks at $370{ }^{\circ} \mathrm{C}, 735$ ${ }^{\circ} \mathrm{C}$, and $890{ }^{\circ} \mathrm{C}$. The latter peak at $890{ }^{\circ} \mathrm{C}$ is at a temperature too high to be due to a silicone-based lubricant or grease. Fluorinated polymers are among the most heat-resistant organic compounds known and these materials decompose by $600{ }^{\circ} \mathrm{C}$. Interestingly, the observed peak corresponds to the loss of $\mathrm{NO}_{2}$ at $900{ }^{\circ} \mathrm{C}$. At $1140{ }^{\circ} \mathrm{C}$ there is a slow loss of $\mathrm{SO}_{2}$. The presence of both nitrogen and sulfur components at these high temperatures is consistent with the presence of a coal-like material which is known to contain heterocyclic nitrogen and sulfur species in its structure ${ }^{8}$. While it should be pointed out that there is some sulfur in the waste glass which is not associated with coal-like material, as will be discussed further in this section, this sulfur was not seen in the second glass sample TGA-MS results.

The TGA-MS data for the second DWPF pour stream glass sample (S02247) are shown in Figure 3-33 and Figure 3-34. Again oxidation of glass constituents is evident. The overall weight loss is again small, but unfortunately nothing can be gathered from this value being essentially the same as in the first sample. Any inclusions in the first sample due to a coal-like material would reduce the mass of glass and the mass gain due to the oxidation of glass species but at the same time would result in additional mass loss from combustion of the coal-like material. The two impacts to the mass loss assessment would compete with one another. Glass sample S02247-E did show a minor weight loss (see Figure 3-32) due to water not observed in the first sample, but it was very small relative to the $\mathrm{CO}_{2}$ loss. TGAMS samples are not pre-dried prior to analysis, so the low temperature release could be due to a small amount of surface moisture.

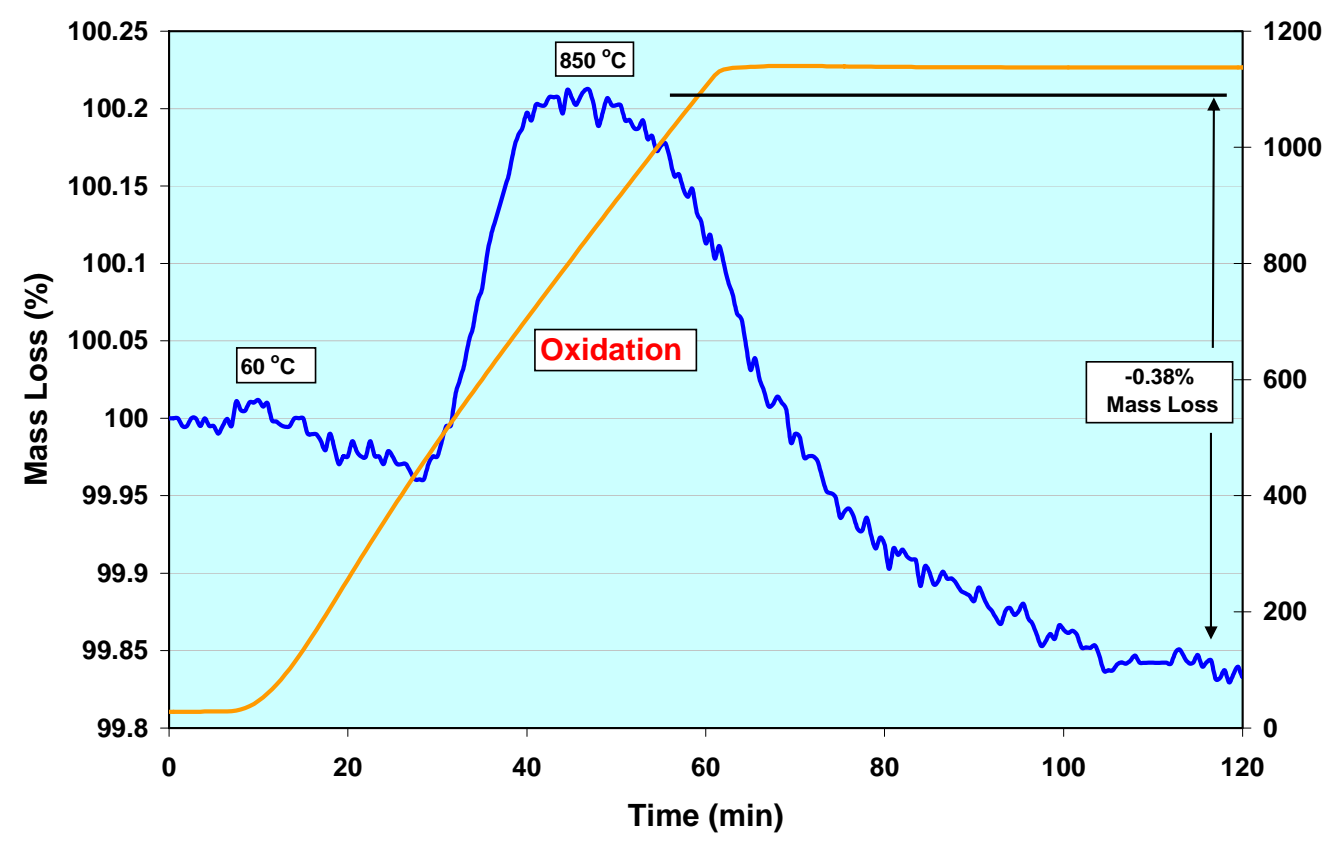

Figure 3-33. TGA-MS Mass Loss vs. Time for DWPF Pour Stream Glass S02247-E 
WSRC-TR-2005-00240

Revision 0

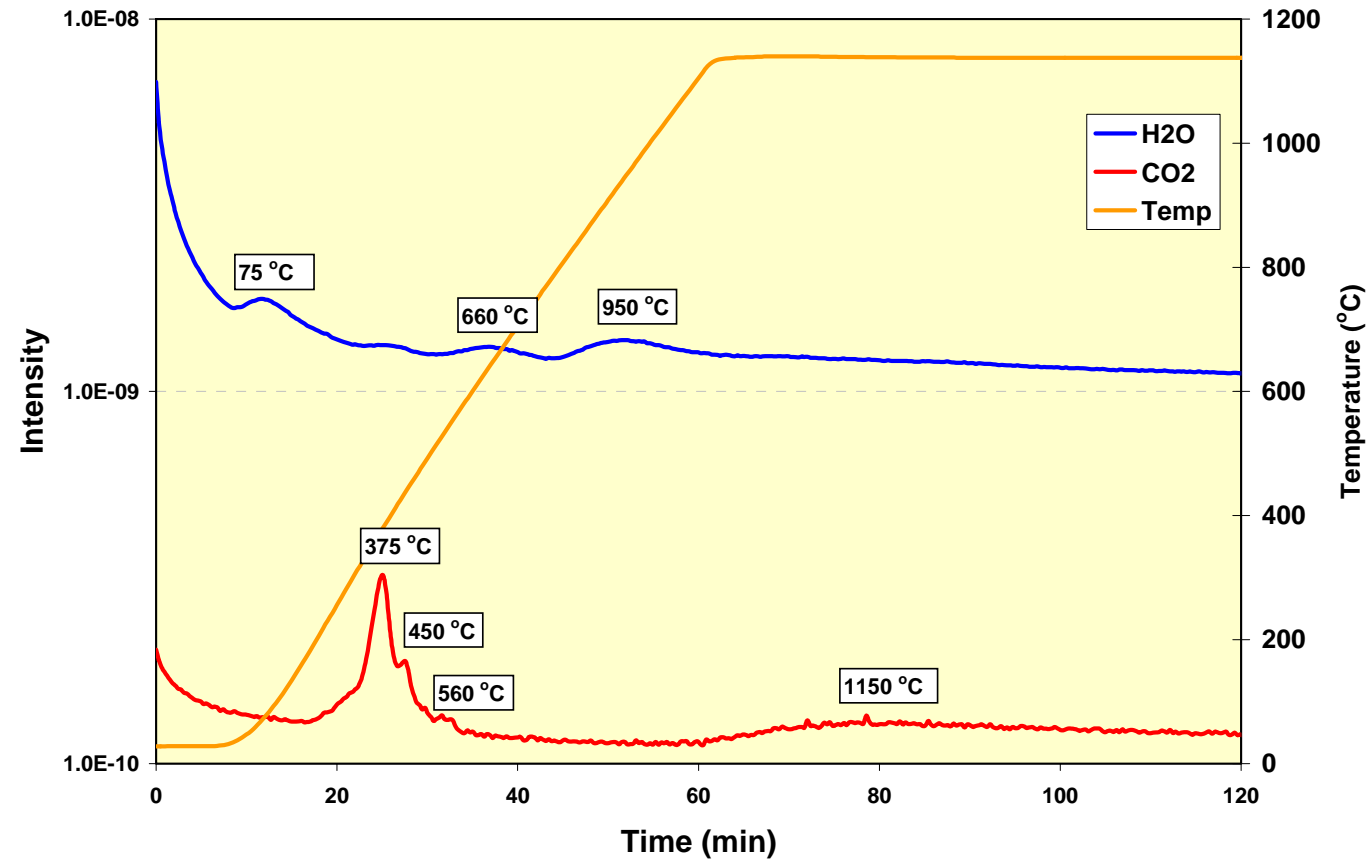

Figure 3-34. TGA-MS Species vs. Time for DWPF Pour Stream Glass S02247-E

The TGA-MS data for the degradation of glass S02247-E under argon up to $850{ }^{\circ} \mathrm{C}$ and then in air gave no additional insights into the system and therefore has not been included in this report. Figure 3-35 provides the TGA-MS data obtained for anthracite coal during the qualification work for SB3.

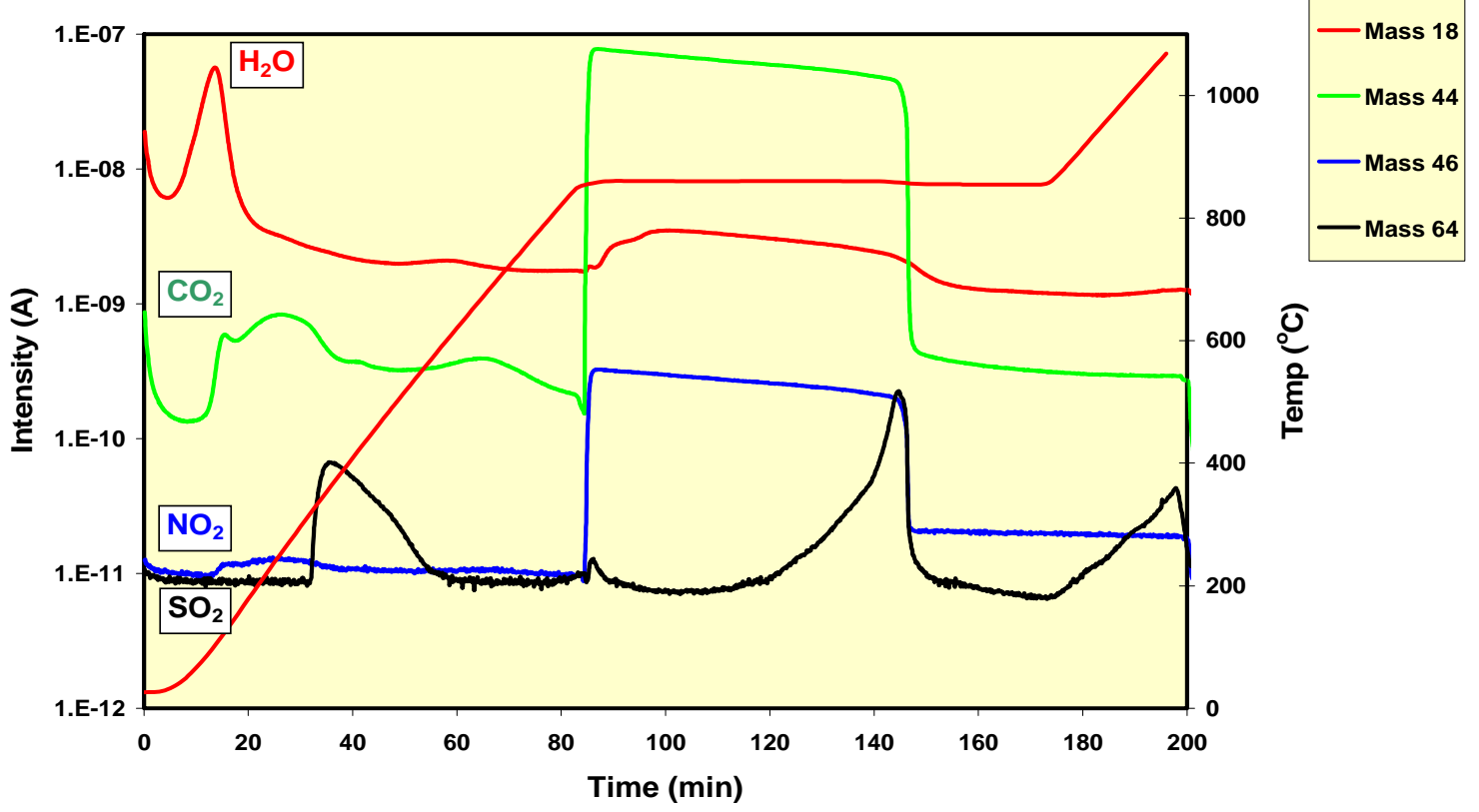

Figure 3-35. TGA-MS Species vs. Time for Anthracite Coal

When the data in Figure 3-35 is compared with that in Figure 3-32, there are distinct similarities with respect to the timing and composition of materials being released (the peak shapes will not be similar 
since the coal sample is a pure compound relative to the glass sample suspected to contain a minor secondary component). One can see that the coal begins to burn significantly at approximately $875{ }^{\circ} \mathrm{C}$ with the release of $\mathrm{CO}_{2}, \mathrm{NO}_{2}$, and $\mathrm{SO}_{2}$, and that the $\mathrm{SO}_{2}$ generation is delayed to the later portion of the coal combustion. This pattern was seen in the material releases from the $\mathbf{S} 02244$ glass (refer to Figure 3-32). This data supports a hypothesis that the first DWPF pour stream glass sample (S02244) contained some high temperature burning carbon compound, possibly coal or a coal-like component.

\subsection{Glass Density Determinations}

Table 3-3 gives the densities determined for both the first and second DWPF pour stream glass samples, S02244-A and S02247-A, respectively. Though it is difficult to say with confidence due to the uncertainties of the measurements, the first glass sample appears to be slightly less dense than the second glass sample. This density difference would be consistent with the incorporation of a small amount of lighter, carbon-based material, rather than a coating since large, $11 \mathrm{~g}$ and $19 \mathrm{~g}$ respectively, pieces of glass were used for the density determination, thus reducing the surface area to volume ratio.

Table 3-3. Density of DWPF Pour Stream Glass Samples, S02244 and S02247 (Std. Dev., \%RSD)

\begin{tabular}{cc}
\hline Glass Sample & Density $(\mathbf{g} / \mathbf{m L})$ \\
\hline S02244-A & $2.56(0.06,2.3)$ \\
S02247-A & $2.76(0.11,4.0)$ \\
\hline
\end{tabular}

\subsection{Non-Radioactive Simulant Studies}

\subsubsection{Glass-Only}

Upon completion of grinding process, a "cloud" of fines was very noticeable upon opening the Tekmar mill - consistent with historical observations when grinding glass for the PCT. Figure 3-36 shows the behavior of the simulated SME 308 glass without additives during the initial deionized water rinse. General observations included: (a) normal behavior of the glass, i.e., no hydrophobic nature observed with typical wetting properties and (b) suspended fines making the deionized water appear somewhat cloudy.

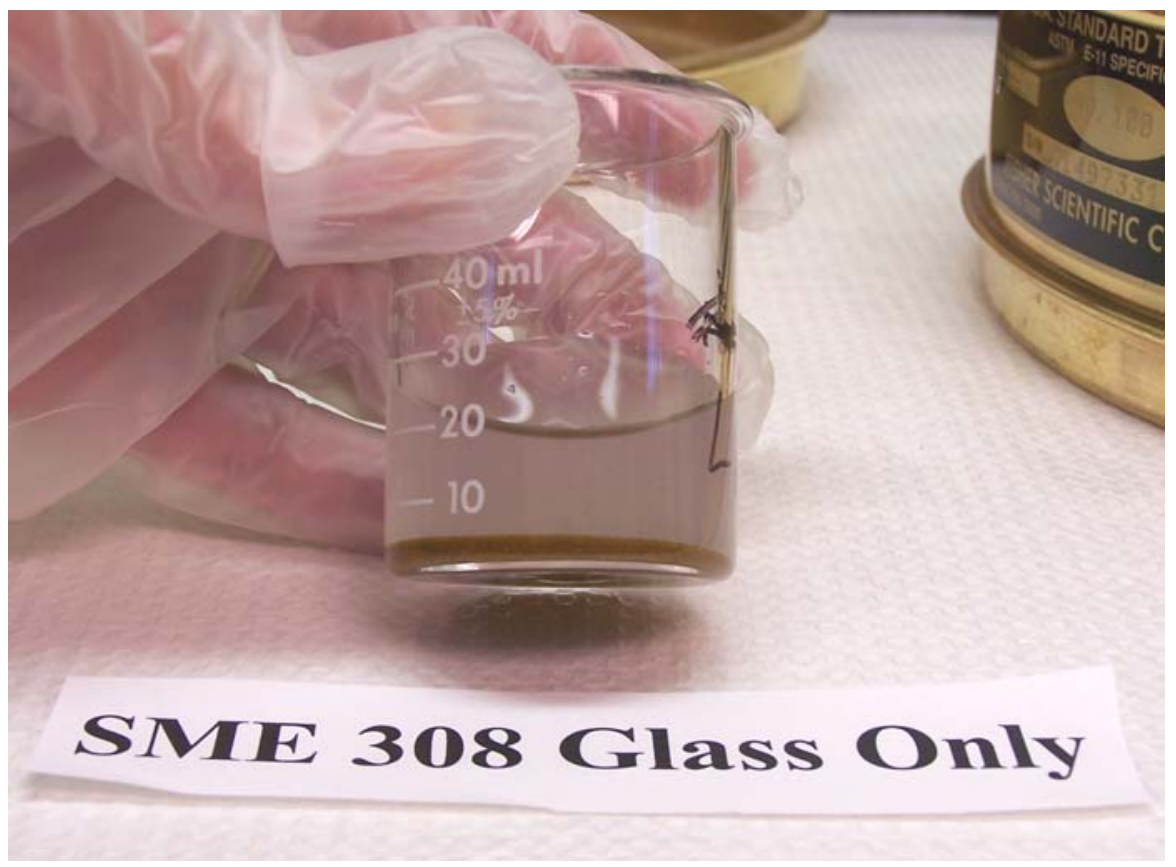

Figure 3-36. SME 308 Glass: First Deionized Water Rinse 


\subsubsection{Glass with Coal}

A "cloud" of fines was very evident upon removing the lid of the Tekmar mill. Figure 3-37 shows the resulting behavior of the glass plus coal mixture during the first water rinse. General observations include:

1. Either full or partial segregation of the glass and the coal - presumably the coal floated to the surface and/or was suspended in the deionized water along with the glass fines resulting in the cloudiness shown in Figure 3-37

2. Glass appeared to settle to the bottom of the beaker - similar to the glass-only test in Figure 3-36

3. Coal appears to adhered to the side of the beaker when the beaker was tilted (Figure 3-37)

4. No hydrophobic behavior was observed with either the glass and/or the coal.

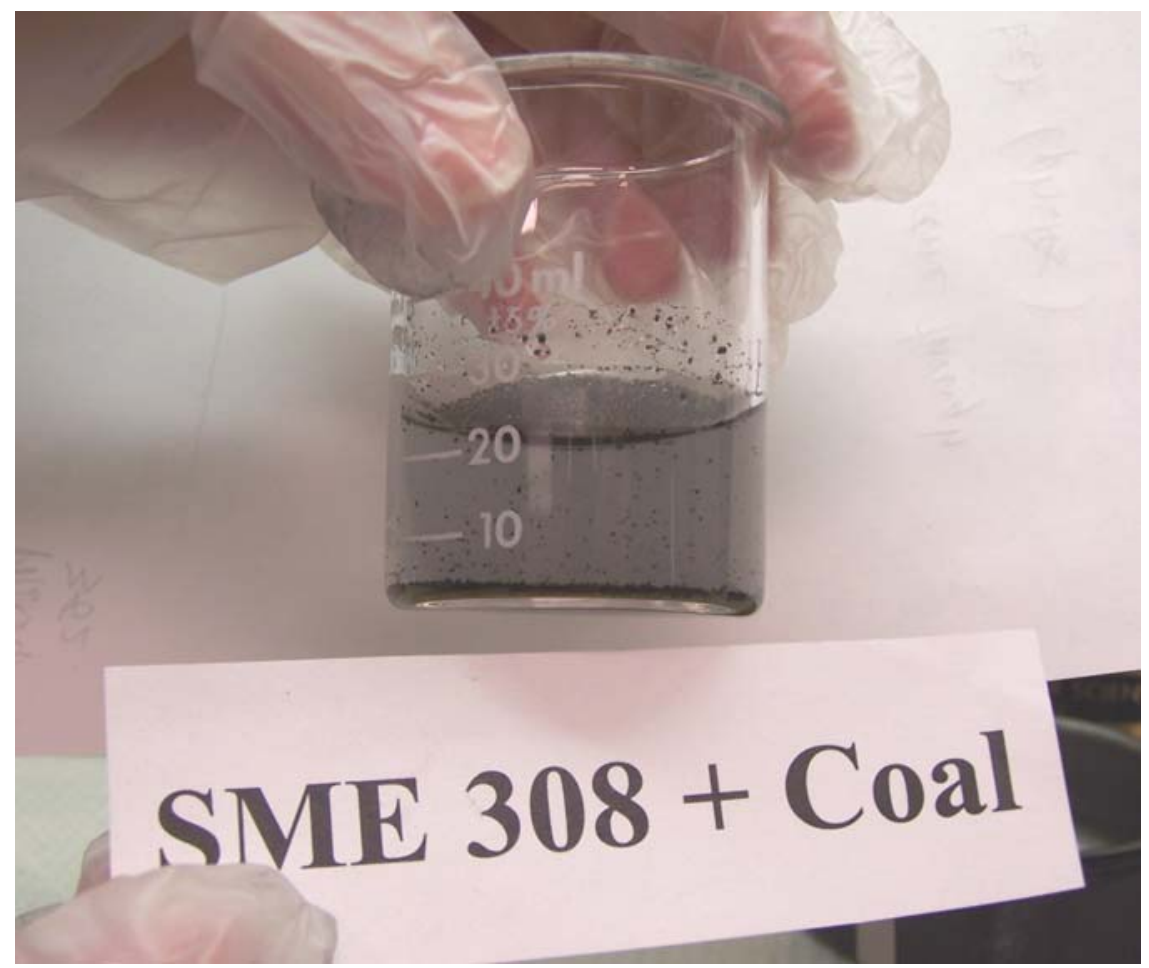

Figure 3-37. SME 308 Glass Ground with Coal: First Deionized Water Rinse

It should be noted that more anthracite coal was used in this study than is suspected in the first DWPF pour glass sample, S02244, hence the visual observations may be more striking than could be expected in the actual waste glass, i.e., a separation of coal and glass particles would not be expected to be visible in the water rinse. The weight loss due to the suspected coal from the TGA-MS data is very small, though it should also be noted that the $50 \mathrm{mg}$ sample size limitation, imposed by radiological concerns, makes it problematic to extrapolate the amount of contaminant material(s) present in the original bulk glass sample.

\subsubsection{Glass with Grease Contamination}

Upon removing the Tekmar mill lid, there was a noticeable reduction in the volume or size of the "cloud" resulting from glass fines as compared to previous tests. Two of the three personnel observing the test saw a small cloud while the third questioned its presence. There was some isolated evidence of clumping but in general the material behaved similar to the previous tests with glass-only and glass plus 
coal in terms of flow properties. No noticeable differences were noted during the sieving process, i.e., this material sieved very similar to the glass-only and glass plus coal systems previously discussed under the simulant testing.

Immediately upon contact with the deionized water, the glass plus lubricant material behaved differently. As more deionized water was added, the material started to form clumps. The behavior was very characteristic of a hydrophobic material. Figure 3-38 shows the behavior of the non-radioactive SME 308 glass with lubricant when subjected to the deionized water rinse.

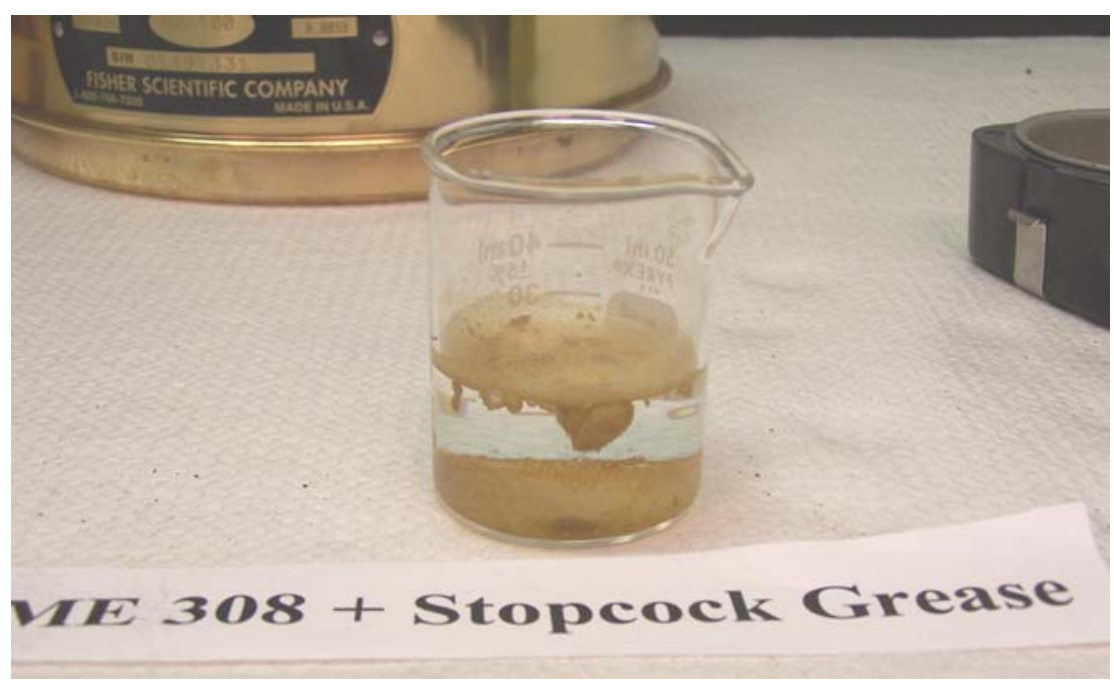

Figure 3-38. SME 308 Glass with Silicone Grease: First Deionized Water Rinse

Based on these observations, two additional silicon lubricant based tests were performed varying the application of the grease as described in the Experimental Section 2.5.3. Upon opening the Tekmar mill, no "cloud" of fines was apparent in either test. The glass plus grease mixture visually appeared similar to the first lubricant-based test (see Figure 2-7) but its flow characteristics were slightly different. Consistent with the initial lubricant based test observations; the material was hydrophobic - see Figure 3-39. In fact, there was no apparent free material on the bottom of the beaker. A comparison of Figure 3-38 with Figure 3-39 suggests a more uniform coverage of the grease given the different application method. 


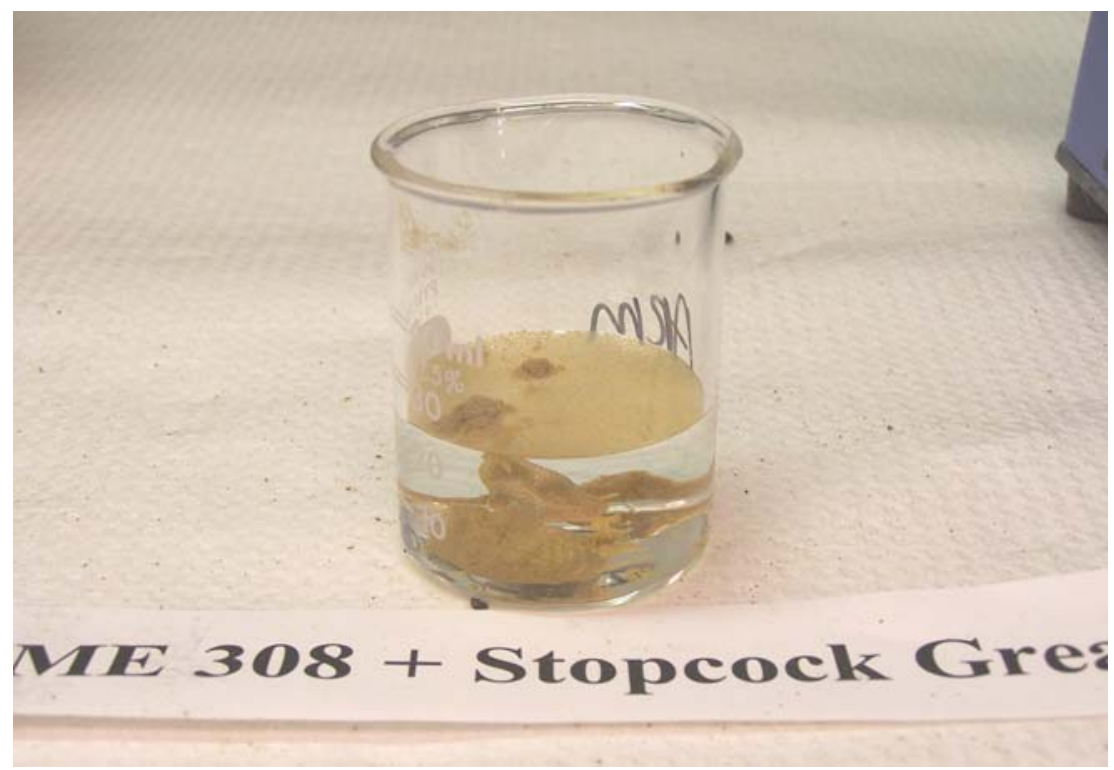

Figure 3-39. SME 308 Glass with Silicone Grease (Test \#2): First Deionized Water Rinse

Upon removal of the Tekmar mill lid after the third test with silicone lubricant, wherein the lubricant was added to the mill after partial grinding of the glass and prior to sieving, again there was no "cloud" of fines observed. Although visual appearance of the resulting ground product was similar to that shown in Figure 2-7, there was a difference in the flow characteristics of this material during sieving. The material appeared to adhere more readily (i.e., more "clumpy") but a $-100+200$ mesh fraction was obtained. As observed with the two other lubricant based tests, once deionized water contacted the material, the hydrophobic nature was clearly observed. Figure 3-40 shows the system during the deionized water rinse of Test \#3. In terms of the degree of hydrophobic behavior, Test \#3 was very similar to Test \#2 - very little, if any, residual material was isolated on the bottom of the beaker.

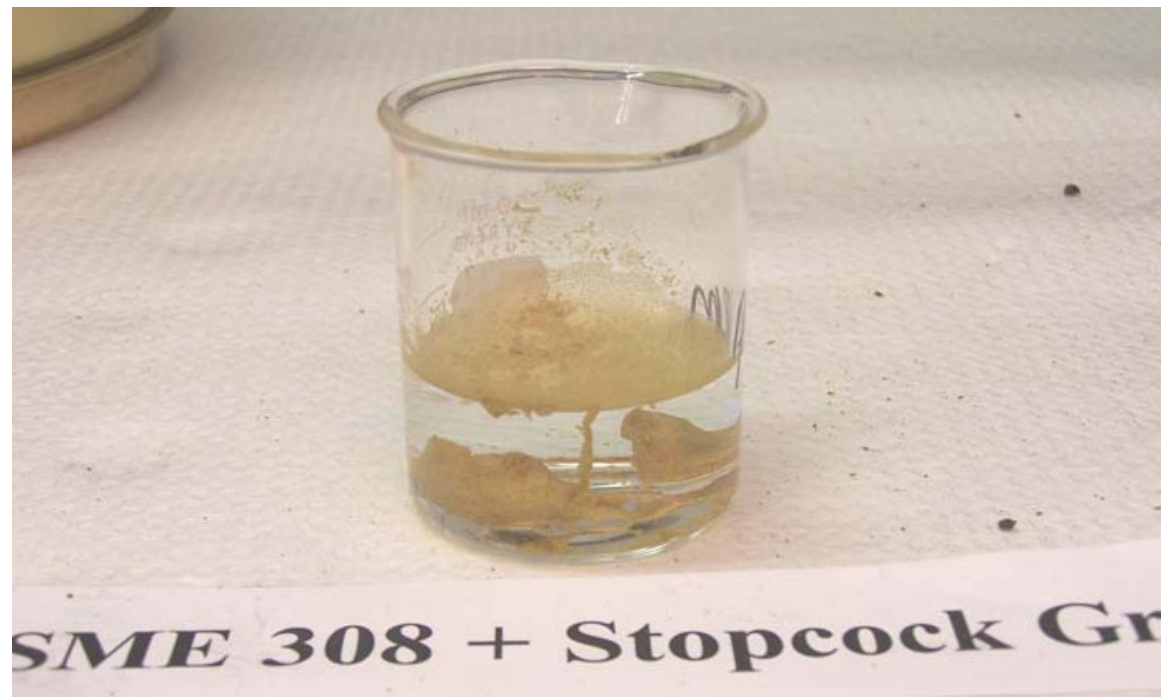

Figure 3-40. SME 308 Glass with Silicone Grease (Test \#3): First Water Rinse

Figure 3-41 shows a side-by-side comparison of the non-radioactive SME 308 glass-only with the nonradioactive SME 308 glass plus silicon lubricant (from Test \#3). Clearly the presence of a small amount 
of contaminant grease can significantly alter the water behavior of ground glass. These observations are consistent with the behavior observed for the radioactive glass S02244.

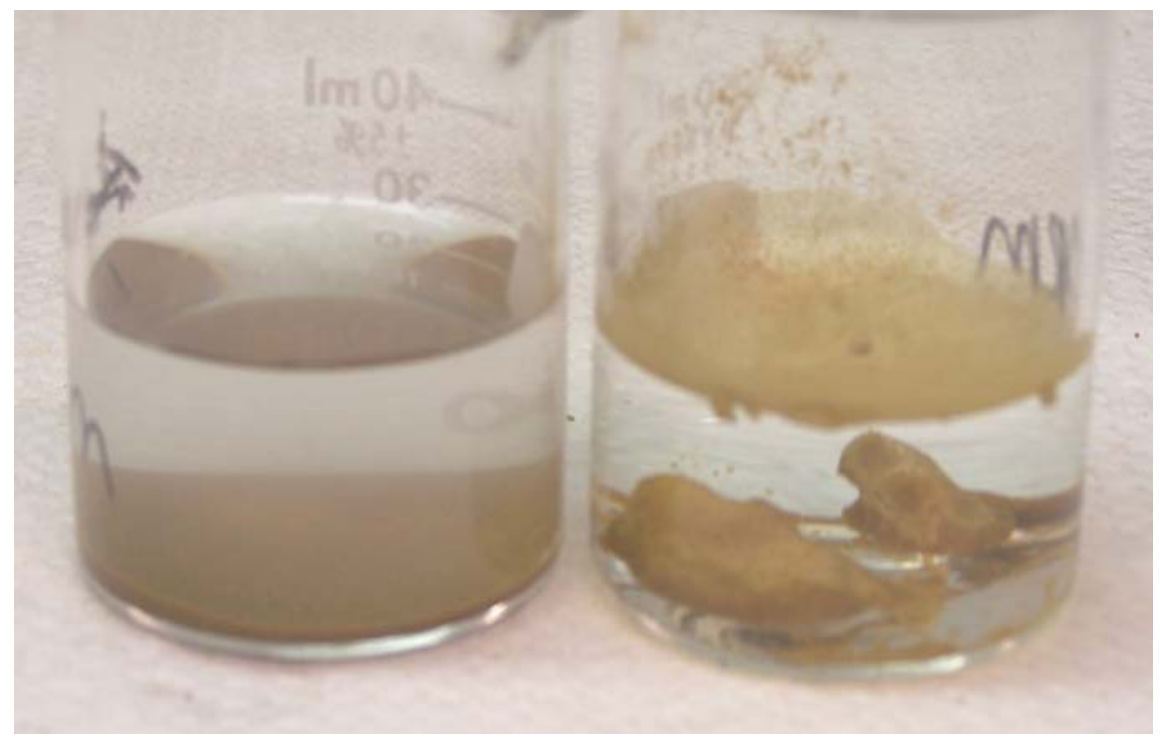

Figure 3-41. SME 308 Glass-Only Compared to Glass plus Silicone Lubricant during Deionized Water Rinse

\subsection{Summary of Glass S02244 versus S02247}

The two DWPF pour stream glass samples S02244 and S02247, while both samples nominally represent SME batch 308, were clearly different. S02244 appears to have two factors at play. The first factor, characterized by its hydrophobic behavior in water, appears to be due to contamination by a siliconebased grease or lubricant. This is supported by the FT-IR spectrum obtained from the methylene chloride wash of the glass sample (see Figure 3-10) which shows the presence of a partially oxidized, silicone-type material and the non-radioactive glass testing.

The second factor, characterized by the dark particles in the SEM QBS detector images (see Figure 3-14 and Figure 3-21), appears to be due to the presence of a carbon-based compound distinct from the glass. This is supported by the TGA-MS data (see Figure 3-32) and the comparison of this data with that obtained from anthracite coal (see Figure 3-35). Further support is provided by the density difference between the two glass samples (see Table 3-3), though analytical uncertainties must be considered when comparing small differences in density. The lower density obtained for glass sample S02244, as compared to S02247, supports the presence of a lighter component within the first glass matrix. Furthermore, simulant glass studies with coal added to the glass mixture, even in a relatively large amount, does not result in the hydrophobic behavior noted for the first glass sample (see Figure 3-37). So the secondary particles and the silicone-based contamination appear, at least with the current data available, to be distinct and separate issues. It is believed that no grease or lubricant could survive to $900+{ }^{\circ} \mathrm{C}$ in the TGA-MS analysis and produce $\mathrm{NO}_{2}$ and $\mathrm{SO}_{2}$ combustion products at these elevated temperatures. Similarly, the electron beam used in EDS to generate the $\mathrm{x}$-ray fluorescence spectrum is believed to have penetrated a film coating on the surface of the glass. While the amount of the carbonbased material (potentially coal) appears to be very small, it was not possible to quantify it due to limitations of sample size.

The source of the grease or lubricant contamination is still unclear. We were unable to determine any point source or step in the glass handling procedures in the SRNL Shielded Cells which could have introduced a silicone-based contaminant. Similarly, the presence of a carbon-based material within the 
glass is difficult to explain considering the 60-hour residence time of SME material within the DWPF melter. There is some evidence from closed crucible studies that coal can survive in an oxygen deficient system at melter temperatures ${ }^{9}$, but extrapolation of this scenario to the DWPF melter system has not been carried out. 


\subsection{CONCLUSIONS}

DWPF pour stream glass samples S02244 and S02247 have been examined through a series of experiments with both the radioactive glasses and a non-radioactive simulant to explain the anomalous behavior observed with glass sample S02244 when the ground glass was exposed to water. The following conclusions can be drawn from these studies:

1. Glass S02244 was contaminated with a silicone-based lubricant or grease which resulted in the following observations and data:

a. The glass had a hydrophobic behavior in water.

b. The contaminant is not removed in water, ethanol or $n$-hexane.

c. Methylene chloride partially dissolves the contaminant.

d. The FT-IR spectrum of the contaminant corresponds to a silicone (-Si-O-Si-) containing material.

2. No source for the contamination could be found in the SRNL Shielded Cells glass handling operations.

3. Glass S02244 contains a very high-temperature burning, carbon-based material which resulted in the following observations and data:

a. The ground glass has secondary particles in the SEM images which give XRF spectra that are largely carbon-based and which are distinctly different from the glass particles.

b. The TGA-MS data for the glass show the loss of $\mathrm{CO}_{2}, \mathrm{NO}_{2}$, and $\mathrm{SO}_{2}$ at temperatures similar to that observed for anthracite coal.

c. The glass density is slightly lower than observed for the second glass sample S02247.

4. SME 308 simulant glass studies with a silicone stopcock grease and coal support the following observations:

a. The presence of grease on the glass significantly alters the behavior of ground glass in water giving it a hydrophobic nature.

b. The presence of coal does not change the wetting properties of ground glass in water.

5. Glass S02247 displayed neither the hydrophobic behavior in water, the secondary particles in SEM images, nor TGA-MS off-gas data for $\mathrm{CO}_{2}, \mathrm{NO}_{2}$, and $\mathrm{SO}_{2}$ at approximately $900{ }^{\circ} \mathrm{C}$. 
WSRC-TR-2005-00240

Revision 0

This page intentionally left blank. 


\subsection{RECOMMENDATIONS/PATH FORWARD}

SRNL will wash and dry DWPF pour stream glass samples in methylene chloride prior to milling the samples for PCT, elemental and radiochemical analyses to help ensure the removal of any grease contamination. The methylene chloride should be a more effective solvent for grease prior to milling and distribution of the grease onto a large number of small particles. This is permitted by the PCT procedure ${ }^{1}$ which calls for washing of the bulk sample prior to grinding but does not specifically call out the solvent to be utilized for this washing. Additionally, the ground, washed, PCT glass fraction will be submitted for SEM imaging and XRF spectra to ensure the homogeneity of the sample used in the PCT. Other glass handling controls, documented elsewhere ${ }^{10}$, will continue to be implemented. 
WSRC-TR-2005-00240

Revision 0

This page intentionally left blank. 


\subsection{REFERENCES}

${ }^{1}$ Standard Test Methods for Determining Chemical Durability of Nuclear, Hazardous, and Mixed Waste Glasses and Multiphase Glass Ceramics: The Product Consistency Test (PCT), ASTM C 1285-02, ASTM International, West Conshohocken, PA (2002).

${ }^{2}$ Hodoh, O. B., Fellinger, T. L., and Bibler, N. E., DWPF Glass Results For the Analysis of a Pour Stream Sample Taken During Pouring of the 50th Canister (Canister S00471), WSRC-RP-98-00053 (1998).

${ }^{3}$ Hodoh, O. B., Fellinger, T. L., and Bibler, N. E., DWPF Glass Results For the Analysis of a Pour Stream Sample Taken During Pouring of the 61st Canister (Canister S00482), WSRC-RP-98-00054 (1998).

${ }^{4}$ Fellinger, T. L. and. Bibler, N. E, DWPF Glass Results for the Analysis of a Pour Stream Sample Taken During the Pouring of the 409th Canister (Canister S00834) in Macrobatch 1, WSRC-RP-98-01400, Savannah River Site, Aiken, SC (1999).

${ }^{5}$ Fellinger, T. L. and. Bibler, N. E, Results of the Chemical Composition and the Product Consistency Test for the DWPF Macro Batch 2 Glass Pour Stream Sample Taken During the Pouring of Canister S01142, WSRC-RP-299-00281, Savannah River Site, Aiken, SC (2000).

${ }^{6}$ Cozzi, A. D. and Bibler, N. E., Analytical Results of DWPF Glass Sample Taken During Filling of Canister S01913, WSRC-TR-2004-00316, Rev. 1, Savannah River Site, Aiken, SC (2004).

${ }^{7}$ Fowler, J. R., Estimate of Maximum Amount of Reducing Agents and Sand in SRP Waste for DWPF TDS, “Don’t Say It - Write It”, September 9, 1980, Savannah River Site, Aiken SC 29808.

${ }^{8}$ Hessley, R. K., Reasoner, J. W., and Riley, J. T., Coal Science: An Introduction to Chemistry, Technology, and Utilization, Wiley-Interscience, New York (1986).

${ }^{9}$ Jantzen, C. M., Zamecnik, J. R., Koopman, D. C., Herman, C. C., and Pickett, J. B., Electron Equivalents Model for Controlling REDuction/OXidation (REDOX) Equilibrium During High Level Waste (HLW) Vitrification, WSRC-TR-2003-00126, Savannah River Site, Aiken, SC (2003).

${ }^{10}$ Bibler, N. E. and Bannochie, C. J., Current and New Controls in the Shielded Cells for Handling DWPF Pour Stream Glasses and Comments Concerning S02244 and S02247 Glasses, SRNL-ITS-200500127, Savannah River Site, Aiken, SC (2005). 
WSRC-TR-2005-00240

Revision 0

This page intentionally left blank. 


\subsection{ACKNOWLEDGEMENTS}

The authors would like to acknowledge the support of the SRNL Shielded Cells technicians and supervision as well as that of the ITS technicians involved in the simulant glass studies. Additionally, we would like to thank ADS personnel Dr. Mike Summer, Dr. Art Jurgensen, and Dr. Damon Click for helpful discussions and exceptional service in examining a number of non-routine samples. We would also like to thank Dr. Carol Jantzen for useful discussions and for examining PCCS spreadsheet data during the investigation of the glass behavior. 
WSRC-TR-2005-00240

Revision 0

This page intentionally left blank. 
WSRC-TR-2005-00240

Revision 0

This page intentionally left blank. 


\section{Distribution:}

E. W. Holtzscheiter, SRNL

D. A. Crowley, ACTL

S. L. Marra, ACTL

T. B. Calloway, ACTL

D. K. Peeler, ACTL

M. E. Stone, ACTL

N. E. Bibler, SRNL

C.M. Jantzen, SRNL

J. R. Harbour, SRNL

G. C. Wicks, SRNL

C. C. Herman, SRNL

T. L. Fellinger, SRNL

M. E. Smith, SRNL

C. J. Bannochie, SRNL

D. R. Best, SRNL

M. S. Miller, DWPF

J. E. Occhipinti, DWPF

R. M. Hoeppel, DWPF

J. F. Iaukea, DWPF

J. W. Ray, DWPF

W. B. Van-Pelt, DWPF

F. A. Washburn, DWPF

A. V. Staub, DWPF

B. H. Culbertson, DWPF

O. G. Lien, DWPF

H. H. Elder, Tank Farm 